Transport of silver nanoparticles in the soil-water nexus

Karrar Najah Mahdi 


\section{Thesis committee}

\section{Promotors}

Prof. Dr V. Geissen

Personal chair at the Soil Physics and Land Management

Wageningen University \& Research

Prof. Dr C.J. Ritsema

Professor of Soil Physics and Land Management

Wageningen University \& Research

\section{Co-promotors}

Dr R.J.B Peters

Researcher, RIKILT

Wageningen University \& Research

Dr J.E.M. Baartman

Assistant professor, Soil Physics and Land Management

Wageningen University \& Research

\section{Other members}

Prof. Dr A.A. Koelmans, Wageningen University \& Research

Dr I.C. Regelink, Wageningen University \& Research

Dr C. Dias-Ferreira, CERNAS, Coimbra, Portugal

Dr C. Cascio, EFSA, Parma, Italy

This research was conducted under the auspices of the Research School for SocioEconomic and Natural Sciences of the Environment (SENSE) 


\title{
Transport of silver nanoparticles in the soil-water nexus
}

\author{
Karrar Najah Mahdi
}

\section{Thesis}

submitted in fulfilment of the requirements for the degree of doctor at Wageningen University

by the authority of the Rector Magnificus,

Prof. Dr A.P.J. Mol,

in the presence of the

Thesis Committee appointed by the Academic Board

to be defended in public

on Thursday 05 July 2018

at 11 a.m. in the Aula. 
Karrar Najah Mahdi

Transport of silver nanoparticles in the soil-water nexus,

123 pages.

PhD thesis, Wageningen University, Wageningen, the Netherlands (2018)

With references, with summaries in English and Dutch

ISBN: 978-94- 6343-276-4

DOI https://doi.org/10.18174/445531 


\section{Table of contents}

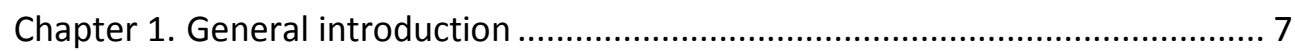

Chapter 2. Silver nanoparticles in soil: Aqueous extraction combined with single-particle ICP-MS for detection and characterization

Chapter 3. Tracking the transport of silver nanoparticles in soil: a saturated column experiment

Chapter 4. Transport of silver nanoparticles by runoff and erosion - A flume experiment

Chapter 5. Modelling silver nanoparticle transport with runoff water and erosion using the LISEM and PestPost models.

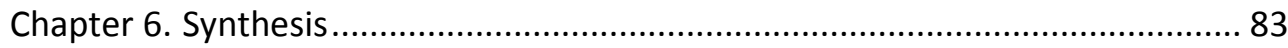

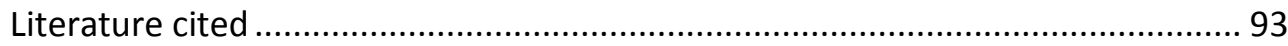

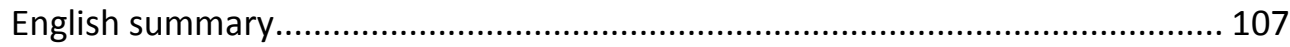

Nederlandse samenvatting............................................................................. 111

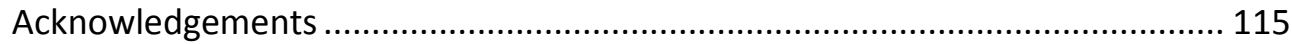

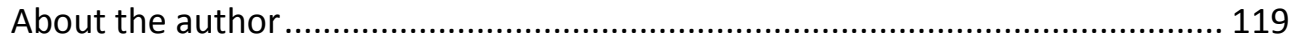





\section{General introduction}




\subsection{Background information}

\subsubsection{Development and use of nanoparticles}

In 1959, Nobel Prize winning physicist Professor Richard Feynman put forth the idea of changing a particle's size (Feynman, 1960). In 1974, professor Norio Taniguchi coined the term "Nanotechnology" and from the 1980's on, interest in nano-sized materials, or 'nanoparticles', grew (Benelmekki, 2015; Klaine et al., 2012). Nanoparticles (NPs) are defined as materials with at least one dimension equal to or less than $100 \mathrm{~nm}$ (SCENIHR, 2007a). NPs are produced so that they have different properties than their bulk counterparts with the aim of improving the quality of the final products/applications. This is due to the fact that the percentage of the surface of a nanoparticle in relation to the percentage of its volume becomes significant (Reidy et al., 2013). This can be seen with gold, for example. Although bulk gold is not active, but gold nanoparticles are very reactive (Auffan et al., 2009).

In general, nanoparticle can form naturally in the environment. Soot, which is formed due to the incomplete combustion of fuels and vegetation, is a naturally formed nanoparticle (Batley et al., 2012; Nowack and Bucheli, 2007). Nanoparticles can also be manufactured from their bulk counterparts and are then called engineered nanoparticles (ENPs) (Batley et al., 2012).

ENPs have received a lot of attention since they offer new solutions for a variety of problems, which could make huge improvements to our lives (Englert, 2007; Lowry et al., 2010). Nowadays, ENPs are incorporated in a wide range of products and applications such as construction material, paints, lubricating oils, medical equipment, electronics, pharmaceutical products, cosmetics, energy production, environmental treatments, textiles, agricultural treatments and food packaging (Dai et al., 2016; Kaiser et al. 2013; López-Serrano et al., 2014; Nazari et al., 2010; Nowack and Bucheli, 2007). The production and use of ENPs have risen dramatically in recent years and it's use is expected to continue to grow (Lowry et al., 2010; Musee, 2011). ENPs, such as fullerenes, carbon nanotubes (CNT), titanium dioxide $\left(\mathrm{TiO}_{2}\right)$ and silver nanoparticles (AgNPs) are the focus of the current research on ENPs in the environment since these are the most widely used ENPs (Kaegi et al., 2010; Nowack and Bucheli, 2007; Peters et al., 2016).

The increasing production of ENPs will, without a doubt, lead to the emission of these materials to the environment. However, our current knowledge concerning the presence and behaviour of these particles and their impact on the environment and human health are limited (Lowry et al., 2010). For example, only recently information about the actual presence of nanomaterials in surface waters has become available (Peters et al., 2018). In 
order to assess the impact of ENPs on the environment and human health, powerful detection techniques and extensive knowledge about their release, transport and fate is needed (Yu et al., 2015a).

\subsubsection{Properties and use of silver nanoparticles}

Silver is an expensive metal that was first mined round 3000 B.C. (SNWG 2017). Silver has been used in currency, jewellery and food storage for thousands of years. More recently, silver has been used in antibiotics and drug delivery systems (Dakal et al., 2016; Liu and Jiang, 2015). However, the use of silver as an antibacterial agent has declined because of the uncertainty surrounding its toxicity and because of the appearance of silver nanoparticles (AgNPs) which have shown to have stronger antibiotic properties than silver itself (Tolaymat et al., 2010). AgNPs are not a recently invented material. As early as 1897, the first AgNP measuring $10 \mathrm{~nm}$ in diameter named "Collargol" was manufactured and used for medical application (Nowack et al., 2011). More recently, AgNP production has increased as they are incorporated into an increasing number of applications (Lombi et al., 2014; Nanodatabase 2017). In 2010, the worldwide production of AgNP was around 320 tons and it has been increasing each year (Musee, 2011; Nowack et al., 2011).

AgNPs are used in many different applications. In agriculture, there are more than 100 silver-based antibacterial pesticides (Bergeson, 2010). In the petroleum industry, AgNPs are used as an additive to enhance the lubrication mechanisms in engines (Dai et al., 2016). In hygiene and medicine applications, AgNPs are regarded as powerful antimicrobial agents since they can kill some of the antibiotic-resistant bacteria (Rai et al., 2009). In addition to that, AgNPs are used in many day-to-day items such as water purifiers, washing machines, clothing, fabrics, shoes, toothpaste, shampoo, detergents, deodorants, kitchenware, refrigerators, children's toys and feeding bottles, humidifiers, etc. (Gaillet and Rouanet, 2015; Vance et al., 2015).

The presence of AgNPs in so many consumer products and applications makes it likely that humans and other living beings are being exposed to AgNPs (Ahamed et al., 2010; Gliga et al., 2014). Although many studies have looked at the toxicological effects of AgNPs, the current knowledge about the potential hazards of AgNPs is still too limited and many urgent questions remain to be answered before AgNPs can be safely applied on a large scale (Whiteley et al., 2013). 


\subsubsection{Environmental pathways of silver nanoparticles}

The rapid increase of the AgNP production has led to direct and indirect emission of AgNPs into the environment. AgNPs have already been detected in natural waters (Peters et al., 2018) and in sludge-treated soil and sediments (Brar et al., 2010; Gottschalk et al., 2009; Wang et al., 2016). AgNPs can reach soil through many different pathways such as unintended spills (Reidy et al., 2013), released from building facades coated with AgNPs (Kaegi et al., 2010) and sludge application of waste water treatment plants (WWTPs) (Schlich et al., 2017). AgNPs could be naturally formed in environment as a results of the biological and chemical reduction processes (Yin et al., 2015b). However, WWTP sludges that are applied to soil as soil fertilizer are considered to be the most significant pathway for AgNPs to enter the environment and it is estimated that more than $90 \%$ of AgNPs are released from various products originating from WWTP biomass (Mueller and Nowack, 2008).

Once released to the soil, a AgNP may be affected by the physical and chemical characteristics of the soil which could lead to changes in the AgNP's initial properties and composition (Brunetti et al., 2015). However, the AgNPs applied to soil via WWTP sludge can stay in the soil for years and can be transported through and by surface runoff to surface water bodies (Schlich et al., 2017). AgNP concentrations in soils are expected to increase in the future because more AgNP-based applications are being developed which leads to additional pathways for AgNPs to reach the soil. Therefore, the public and scientific concerns about the (potential) effects of AgNP concentrations in soil should be addressed (Gliga et al., 2014).

\subsubsection{Impact of AgNPs on soil organisms and plants}

AgNPs applied to soil can be sulfurized (transformed) to $\mathrm{Ag}_{2} \mathrm{~S}$ in the presence of sulphur (i.e. sludges) or they can dissolve by releasing $\mathrm{Ag}^{+}$ions. Sulfurized forms of AgNPs can also become bioavailable to soil microorganisms and can cause potential long term damage (Kraas et al., 2017). Once AgNPs are applied to soil, they can adversely alter the reproduction of earthworms by affecting cocoon production, hatching rates and apoptosis (Lapied et al., 2010; Schlich et al., 2013a). Pallavi et al. (2016) showed that AgNPs in soil could change the soil bacterial diversity and that the extent of this change differed with differing concentrations of AgNPs. Kwak and An (2015) found that the application of AgNPs to soil could cause severe problems for the juvenile growth of earthworms. Hänsch and Emmerling (2010) reported a significant effect of AgNPs on soil microbial biomass. AgNPs can also have severe effects on plant life. AgNPs can affect peanut yield and quality due to 
the fact that AgNPs can alter the fatty acid content in peanut grains after exposure (Rui et al., 2017). Dimkpa et al. (2013) found that exposure of plant roots to AgNPs caused a decrease in the length of wheat shoots and roots which, in turn, affected their growth. Stegemeier et al. (2015) found that in alfalfa, AgNPs accumulation in the root apoplast was due to up-taking the partially dissolved AgNPs.

\subsubsection{Detection and quantification of AgNPs in soil}

To assess the behaviour, impact and potential risk of AgNPs it is necessary to detect and quantify AgNPs in the different soil matrices (Yu et al., 2015b). As many other analytical techniques, the detection procedure for AgNPs consists of two main steps: first, the separation of the AgNP particles from soil samples and secondly, the characterization and quantification of the AgNPs (Mattarozzi et al., 2017; Peters et al., 2015). Therefore, the detection procedure of nanomaterials is often time-consuming and needs careful efforts. Detection of AgNPs in soil is particularly difficult since the AgNPs may undergo transformation processes after their release into the environment which can significantly reduce their recovery from soil (Brunetti et al., 2015). Mueller and Nowack (2008) showed that the predicted environmental concentrations of AgNPs in soil and sediments are expected to be low, somewhere in the range of $1-10 \mu \mathrm{g} \mathrm{kg}^{-1}$, which adds to the difficulty of AgNP detection at very low concentrations .

It is essential for AgNP characterization to assess both the concentration and the particle size distribution of the AgNPs since the particle sizes are inversely correlated with the potential toxicity of AgNPs (Pal et al., 2007). The analytical procedure for the detection of AgNPs should also avoid the use of chemicals and physical methods that may disturb the state of the AgNPs in the sample (Mahdi et al., 2017). Currently, there are a few useful detection techniques for AgNPs in different mediums such as water, food, animals, plants and consumer products (Peters et al., 2015). However, information concerning nanomaterial concentration in soils is rare due to the lack of techniques that are able to detect nanomaterials in soils effectively (Gottschalk and Nowack, 2011; Peijnenburg et al., 2016). Depending on the matrix, the separation methods that are available for AgNPs are centrifugation, membrane filtration, dialysis, centrifugal ultrafiltration, hydrodynamic chromatography (HDC), and field flow fractionation (FFF) (Peters et al., 2015; Yu et al., 2015b). However, only a few separation techniques, with low recovery rates, are available for soil samples which has resulted in a limited number of studies that study the toxicity of exposure to AgNPs in natural soils (Schwertfeger et al., 2017). 
AgNP characterization and quantification often requires the use of high-resolution techniques (Franze and Engelhard, 2014). Electron microscopy has been used to determine the particle size distribution in solid samples such as soil. Nanoparticle tracking analysis (NTA) has been used to determine the particle size in liquids and differential mobility analysers (DMA) have been used to detect the particle size in aerosols. Specifically, $\mathrm{Ag}$ concentrations in soil have been determined using acidic digestion of the soil samples (EPA, 1996). However, since AgNPs dissolve during this procedure, any information about the presence of AgNPs in soil is lost and nothing can be concluded about the stability, transportation and transformation of AgNPs in the soil. A method called the single particle inductively coupled plasma mass spectrometry method (spICP-MS) can be used to determine the particle size distribution as well as the particle mass concentration. The spICP-MS method was considered as the only method that could detect the AgNP concentration and particle size in soil at low concentrations and within a reasonable time (Laborda et al., 2013; Peters et al., 2014).

\subsubsection{Transport of AgNPs in the environment}

AgNPs can be released into the environment during production, leaching from products during use, or during disposal of the products containing AgNPs (Reidy et al., 2013). After being released into the soil environment, AgNPs may seep into deeper soil layers or even leach into the groundwater (Hou et al., 2017), or they may undergo surface transport caused by overland flow (Mahdi et al., 2017). Transport of AgNPs in soil is affected by two main factors: soil properties and the AgNP's characteristics. The most important soil properties are the soil type (soil particle size distribution), soil slope and soil chemical characteristics (like $\mathrm{pH}$, ionic strength and cation exchange capacity). AgNP characteristics affecting their transport in soil are particle size, initial applied concentration and particle coating.

\subsection{Objective and research question}

The objective of this research is to contribute to our understanding of the detection and transport of AgNPs in soil. The following research objectives were addressed.

- Develop a method to extract and measure (low) concentrations and particle size distributions of AgNPs in different soil types.

- Assess transport of AgNP through soil columns and determine changes in AgNP size. 
- Determine AgNP transport by soil surface runoff and erosion, and investigate the effect of soil slope.

- Simulate AgNP transport by runoff and erosion using a hydrological and particle displacement model.

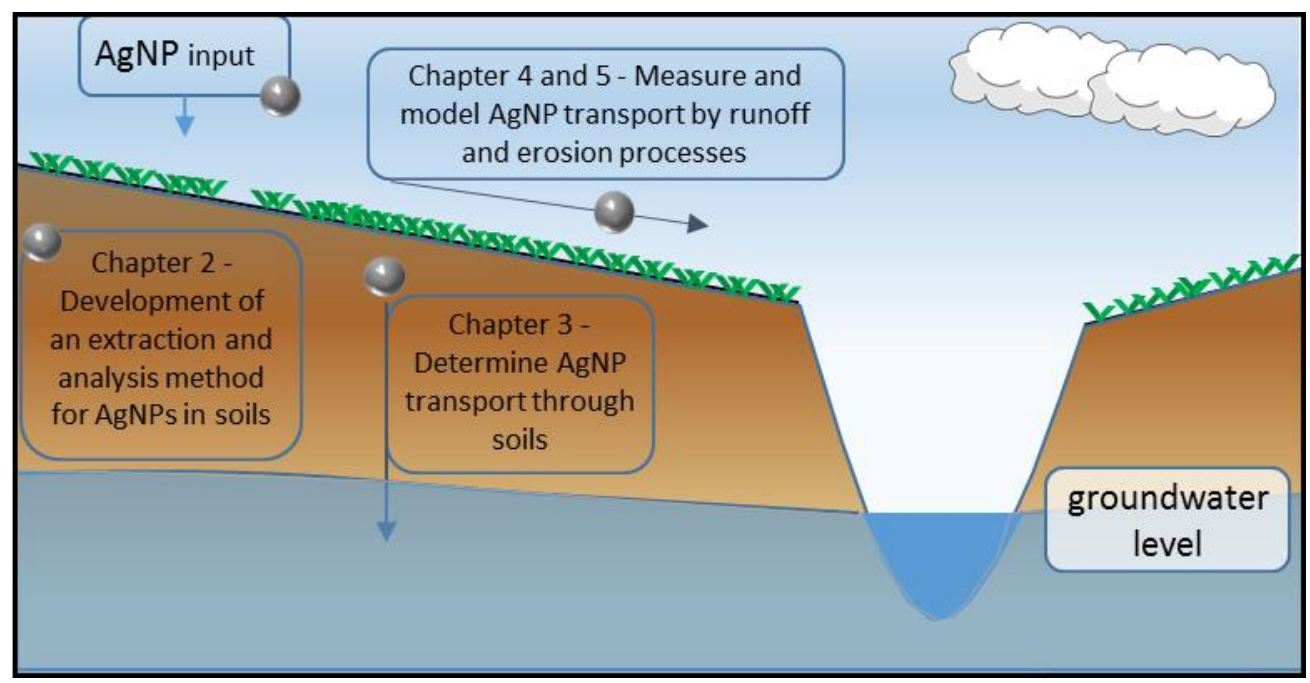

Figure 1.1 conceptual approach of the thesis and related research chapters.

\subsection{The outline of this thesis}

The research objectives are addressed in Chapters 2 to 5 (Figure 1.1).

In Chapter 2, a new extraction method for AgNPs from soil samples is discussed. The method was developed and validated for the quantification of AgNP concentrations and particle size distributions in soils. AgNPs extraction rates were tested for their repeatability and reproducibility. The development of an extraction method for the detection of low AgNPs concentrations was required for the experiments described in chapters 3 and 4 .

In Chapter 3, the transport of AgNPs in their "particle form" through the water saturated soil columns was assessed. The effect of soil properties were also considered in order to determine the effect of these properties on AgNP concentration distribution and the possible changes in AgNP size. Distribution of AgNPs of the saturated flow in the soil columns and in the leachate were analysed. 
In Chapter 4, transport of AgNPs by runoff and erosion was investigated using a flume experiment and rainfall simulator. A low concentration of AgNPs was applied to two soilflumes with different slopes. Rainfall was applied on the flumes in 4 equal period events with same intensity. AgNPs was measured in the on the flume surface and with eroded sediment and runoff water at the outlet of each flume.

In Chapter 5, was simulated the transport of AgNPs by overland flow and soil erosion based on the results gained in Chapter 4. For this purpose, 2 models were combined. The first model called LISEM, is an event-based model to simulate runoff and erosion during a rainfall event. The second model named PestPost is a newly developed model for simulation of chemical transport based on the output results of LISEM. The combined models offer the possibility to simulate AgNPs transport by runoff and erosion during rain events.

Chapter 6 is the synthesis of this thesis and presents the major findings and conclusions of the previous four chapters. Furthermore, the implications of this study for environment and society are also discussed. Lastly, the limitations of this study and recommendations for future work are highlighted as well. 


\title{
2. Silver nanoparticles in soil: Aqueous extraction combined with single-particle ICP-MS for detection and characterization
}

\begin{abstract}
Silver nanoparticles (AgNPs) are used in a growing number of applications and products. Previous studies showed AgNPs can leach from these products to the environment. As a result of AgNPs leaching, sediment, soil and sludge-treated soils may be contaminated with AgNPs. Methods to detect, quantify and characterize AgNPs in soil are urgently needed. This study describes the development and validation of a method for the extraction, quantification and particle size determination of AgNPs in soils. The final method consists of pre-wetting the sample followed by an aqueous extraction, using sonication to re-suspend adsorbed AgNPs, and analysis of the aqueous extract with single particle ICP-MS. Validation of the method showed that the recovery of AgNPs spiked to soil was $44 \%$ for sandy soil and $42 \%$ for clayey soil. Although this recovery is relatively low, the repeatability and reproducibility values of the particle concentration were within the limits of Horwitz ratio, which makes the method suitable for its purpose. Further, the method concentration detection limit, LODc., is $5 \mu \mathrm{g} \mathrm{kg}^{-1}$ soil. The developed method can be applied in eco-toxicological and risk-assessments studies for AgNP in the soil environment.
\end{abstract}

\section{Based on:}

K.N.M. Mahdi, R.J. Peters, E. Klumpp, S. Bohme, M.J. van der Ploeg, C.J. Ritsema, V. Geissen. 2016. Silver nanoparticles in soil: Aqueous extraction combined with single-particle ICPMS for detection and characterization. Environmental Nanotechnology, Monitoring \& Management 7: 24-33. 


\subsection{Introduction}

Nanomaterials are materials with particle sizes ranging from 1 to $100 \mathrm{~nm}$ in at least one dimension and have properties that are different from their bulk material (SCENIHR 2007, Auffan et al. 2009). Engineered nanomaterials (ENMs) are a promising field of study for science and engineering since it offers many prospects for new products. Hence, nanotechnology has been described as "the second industrial revolution" (Englert 2007). While titanium and silicon-dioxide are probably the most used nanomaterials, silver nanoparticles (AgNPs) have the widest range of applications due to their antimicrobial, catalytic, optical, electronic and magnetic properties (Durán et al. 2005). Therefore, AgNPs can be found in electrical and chemical equipment, medical products, textiles, agricultural fields and food as well as in the food packaging industry (López-Serrano et al. 2014). As a sequence the production of AgNPs has risen dramatically in the last decade and is expected to continue to increase (Musee 2011). In 2010, AgNPs were used in more than $23 \%$ of all nanotechnology-based commercial products (Zhang and Oyanedel-Craver 2011). According to the "Project on Emerging Nanotechnologies" inventory, AgNPs are applied in more than 400 commercial products, including plastics, textiles, health care and medical products, kitchen appliances, and toothpastes (The project of Emerging Nanotechnologies 2015). As a result of all these applications it is expected that AgNPs will end up in the environment (Blaser et al. 2008).

While AgNPs can be produced by natural processes (Yin et al. 2015b), the majority of AgNPs found in the environment probably originate from anthropogenic sources (Yu et al. 2013). Plastics and textiles containing AgNP-based biocides are expected to be responsible for up to $15 \%$ of the total-silver emissions to the aquatic environment in the European Union in 2010 (Kaegi et al. 2010). Ultimately, AgNPs released from products can reach wastewater treatment plants (WTP) and can be transformed quickly to another forms (Brunetti et al. 2015). Mueller and Nowack 2008 stated that around 90\% of the AgNPs reached to WTP is removed from the effluent water and adsorbed to the WTP sewage sludge (Mueller and Nowack 2008). Sewage sludge is used in many countries as a source of biomass energy and is applied as agricultural fertilizer, disposed of in landfills or incinerated in thermal wastetreatment plants (Blaser et al. 2008). As a result, it is expected that AgNPs will most likely end up in sediments and sludge-treated soils (Gottschalk and Nowack 2011, Yu et al. 2013). Model calculations have predicted AgNPs concentration of $2 \mu \mathrm{g} \mathrm{kg}-1$ in sediments and $8 \mu \mathrm{g}$ $\mathrm{kg}^{-1}$ in sludge treated soils (Gottschalk et al. 2009).

AgNPs can enter the soil through many pathways (Anjum et al. 2013). These include natural processes where ionic silver is transformed into AgNPs by biological and chemical reduction (Yin et al. 2015a). However, leaching from anthropogenic sources and applications of 
AgNPs-containing products are the two most common sources (Mueller and Nowack 2008). AgNPs in the environment can be toxic to aquatic and terrestrial organisms (Schlich et al. 2013a) and have been shown to affect earthworm reproduction (Tsyusko et al. 2012), soil microbial communities (Simonin and Richaume 2015) and wheat growth (Dimkpa et al. 2013). The toxicity of the AgNPs in soil is governed mainly by five factors: particle size, stability and shape, as well as the soil chemistry and texture (Kim et al. 2012, Sagee et al. 2012, Anjum et al. 2013). Previous studies have indicated that AgNPs are not only toxic in their pristine state (Allen et al. 2010, Farkas et al. 2010, Griffitt et al. 2012, Tsyusko et al. 2012) but also after having been adsorbed to sludge or aged in soil (Schlich et al. 2013b).

The transport of AgNPs through soil profiles depends on the particle properties and the physicochemical characteristics of the soil (Sagee et al. 2012). As a result, AgNPs concentrations and particle sizes will differ throughout the soil profile resulting in different toxic intensities along the profile (Cornelis et al. 2012, Liang et al. 2013a). Yang et al. (2014) reported that $\mathrm{Ag}, \mathrm{CeO}_{2}$, and $\mathrm{TiO}_{2}$ nanomaterials can leach into groundwater by colloidal flow. However, our knowledge of the transport, distribution and effects of AgNPs in soils is limited due to the complexity of the soil system, the (unknown) adsorption of AgNPs onto organic matter in soil, and, especially, the analytical difficulties of the detection and characterization of AgNPs in soil (Klitzke et al. 2015, Yu et al. 2015). Therefore, monitoring the transport and fate of AgNPs in soil needs to be investigated in more detail.

Information concerning nanomaterial concentration in the soil is rare due to the lack of techniques that are able to detect nanomaterials effectively (Gottschalk and Nowack 2011). During sample processing, AgNPs need to be separated from the matrix, quantified and characterized using appropriate detection techniques (Yu et al. 2015b). Sample processing often consists of an extraction method followed by some physical separation technique such as filtration, centrifugation or dialysis. During such processes, the physicochemical properties of AgNPs may change due to aggregation and dis-aggregation processes and can even be due to the dissolution of the particles. As a result, sample processing may lead to partial or even significant changes of the properties of the AgNPs. In soil, AgNPs may also interact with the soil physicochemical structures leading to difficulties in tracking low AgNPs concentration during transport and in determining the final fate of the AgNPs in the soil ( $\mathrm{Yu}$ et al. 2015b). Finally, the anticipated low environmental AgNPs concentrations in soils and sediment (range 1-10 $\mathrm{g} \mathrm{kg}^{-1}$ ) are another problem because they require highly sensitive techniques for detection (Mueller and Nowack 2008, OCED 2014). Only a few papers in the scientific literature described the analytical techniques for separation, detection, quantification and characterization of AgNPs in soil. Table 2.1 summarizes the most used techniques. 
Table 2.1 Methods used to detect and quantify engineered nanoparticles in soil.

\begin{tabular}{|c|c|c|c|c|c|c|}
\hline Method & Methodology & Benefits & $\operatorname{LOD}_{c}{ }^{a}$ & $\begin{array}{l}\mathrm{LOD}_{\mathrm{s}}^{\mathrm{b}} \\
\mathrm{nm}\end{array}$ & Drawbacks & Reference \\
\hline $\begin{array}{l}\text { Field-flow } \\
\text { fractionation } \\
\text { combined with ICP- } \\
\text { MS. }\end{array}$ & $\begin{array}{l}\text { Separation based on } \\
\text { particle size }\end{array}$ & $\begin{array}{l}\text { Good size separation of } \\
\text { particle sizes. }\end{array}$ & $\mathrm{mg} \mathrm{L}^{-1}$ & 10 & $\begin{array}{l}\text { Poor recovery at low } \\
\text { concentrations due to } \\
\text { sorption on membrane } \\
\text { surfaces. }\end{array}$ & $\begin{array}{l}\text { (Bolea et al. } \\
\text { 2011, Weinberg } \\
\text { et al. 2011) }\end{array}$ \\
\hline $\begin{array}{l}\text { Hydrodynamic } \\
\text { chromatography } \\
\text { combined with ICP- } \\
\text { MS. }\end{array}$ & $\begin{array}{l}\text { Separation depends } \\
\text { on flow dynamics in } \\
\text { the column }\end{array}$ & $\begin{array}{l}\text { Compatible with regular } \\
\text { lab instruments (like } \\
\text { HPLC). Relatively fast }\end{array}$ & $\begin{array}{l}\mu \mathrm{g} \mathrm{L}^{-1} \text { to } \\
\mathrm{mg} \mathrm{L}^{-1} \\
\text { range }\end{array}$ & 20 & $\begin{array}{l}\text { Poor size-separation of } \\
\text { particles. Separation may } \\
\text { be influenced by sample } \\
\text { composition. }\end{array}$ & $\begin{array}{l}\text { (Domingos et al. } \\
\text { 2009, Handy et } \\
\text { al. 2012, Von der } \\
\text { Kammer et al. } \\
\text { 2012) }\end{array}$ \\
\hline $\begin{array}{l}\text { Single particle } \\
\text { ICP-MS. }\end{array}$ & $\begin{array}{l}\text { Detection of individual } \\
\text { particles due to high } \\
\text { time resolution }\end{array}$ & $\begin{array}{l}\text { Determination of low } \\
\text { particle concentrations, } \\
\text { minimizing the need for } \\
\text { sample processing. }\end{array}$ & $\mathrm{ng} \mathrm{L}^{-1}$ & 10 & $\begin{array}{l}\text { Particle size is not } \\
\text { measured but calculated } \\
\text { from the detected mass } \\
\text { of analyte in individual } \\
\text { particles }\end{array}$ & $\begin{array}{l}\text { (Laborda et al. } \\
\text { 2013, Liu and } \\
\text { Jiang 2015, } \\
\text { Peters et al. } \\
2015 \text { ) }\end{array}$ \\
\hline
\end{tabular}

a limit of detection for particle concentration

b limit of detection for particle size 
A better understanding of the fate and potential effects of AgNPs in soil requires reliable methods for the detecting and quantifying AgNPs in soil (SCENIHR 2006). While a number of techniques are available for the detection and characterization of AgNPs in suspensions, analyte extraction, clean-up and concentration are also required for a full analysis. In studies covering the determination of AgNPs in soils, the soil is typically digested with strong acids to extract any $\mathrm{Ag}$ present in the soil as ionic Ag. As a result, any information regarding the particulate nature of $\mathrm{Ag}$ in the soil is lost. Detection of AgNPs in soil, often difficult as the AgNPs may undergo transformation once it release to the environment which can significantly reduce the recovery (Brunetti et al. 2015). However, several studies considered detecting AgNPs in soil e.g., Koopmans et al. (2015) described a methodology consisting of asymmetric flow field-flow fractionation (AF4) in combination with on-line detection by UVVIS spectroscopy and off-line high resolution inductively coupled mass spectrometry (HRICP-MS) to determine size and concentration of AgNPs in aqueous spiked soil extracts. Coutris et al. (2012) reported a recovery of $21 \%$ two hours after spiking the soil and only $0.3 \%$ was recovered after two days. Whiteley et al (2013) also reported low recoveries, however, since these were measured as total-Ag after sample digestion, the nature of the extracted $\mathrm{Ag}$ is uncertain.

The aim of this study is to develop an extraction and analysis method for AgNPs in soil with better recoveries rates with as little disturbance as possible to the nature of the AgNPs. The method should allow the tracking of AgNPs concentrations and the determination of particle-size distributions in soil in future experiments to determine transport of AgNPs in soil. The method should also be efficient, produce repeatable results and show minimal changes in the chemical (e.g. dissolution) and physical properties (e.g. size) of the extracted AgNPs. Single-particle inductively coupled plasma mass spectrometry (spICP-MS) was chosen as the analytical technique because of its ability to determine particle concentration and size and doing so at very low (ppt range) analyte concentrations (Linsinger et al. 2014). This would possibly exclude the need for cumbersome analyte concentration techniques.

\subsection{Materials and Methods}

\subsubsection{Chemicals}

Aqueous suspensions of spherical silver nanoparticles with diameters of 60 and $100 \mathrm{~nm}$ (AgNPs 60 and AgNPs 100, respectively) were purchased from NanoComposix (Prague, Czech Republic). The particle suspensions with a mass concentration of $1.0 \mathrm{~g} \mathrm{~L}^{-1}$ are stabilized with citrate. A citrate-stabilized aqueous suspension of $60 \mathrm{~nm}$ spherical gold nanoparticles (RM 8013) with a mass concentration of $50 \mathrm{mg} \mathrm{L}^{-1}$ was purchased from the 
National Institute of Standards and Technology (NIST, Gaithersburg, US). An ionic silver standard with a concentration of $100 \mathrm{mg} \mathrm{L}^{-1}$ was purchased from Merck (Darmstadt, Germany). The gold nanoparticles and silver ion standard are required for quantification and sizing of AgNPs with spICP-MS. Purified water (MQW) for the preparation/dilution of samples and standards was prepared using a Millipore system (Amsterdam, The Netherlands).

\subsubsection{Soil samples}

The soil types used in this study were clay, loam, and sand from The Netherlands. The clay and loam samples were supplied by the Unifarm facility at Wageningen University and Research (WUR). The sand sample was collected at a coastal location (Zandmotor) near The Hague. All soil types were used in the initial development of the extraction method, but only the clay and sand samples were used in subsequent experiments. All soils were dried for a week in room temperature and then sieved by sieve number $5(4.00 \mathrm{~mm})$ to keep the soil properties close to the initial soil. The physical characteristics of all soil types were determined in the soil physics and land management (SLM) laboratories of (Wageningen University and Research). The soil texture were analysed by using particle size analysis (PSA) (McKenzie et al. 2002). $\mathrm{pH}$ and electrical conductivity (EC) were measured by using a portable probe (WTW pH 340) obtained from WTW company (Weilheim, Germany). Ionic strength (IS) were derived directly from EC using the formula of linear approach method [IS $\left(\mathrm{mol} \mathrm{L}^{-1}\right)=1.610^{-5} \times \mathrm{EC}\left(\mu \mathrm{S} \mathrm{cm}{ }^{-1}\right)$ ] (Aqion 2016). Organic matter was measured according to the standard method (ASTM 2000). CEC was measured by NIRs (near infra-red spectroscopy) based on 0,0166 M cobalthexamine trichloride (ISO 1994). The soil characteristics are presented in Table 2.2. 
Table 2.2 Physicochemical properties of the soil samples.

\begin{tabular}{|c|c|c|c|}
\hline Soil type & Sand & Loam & Clay \\
\hline \multirow{2}{*}{ Soil origin } & The Hague- & Wageningen-WUR & Wageningen-WUR \\
\hline & Zandmotor & Unifarm & Unifarm \\
\hline \multicolumn{4}{|l|}{ Soil properties } \\
\hline Clay (\%) & 1.02 & 14.43 & 19.57 \\
\hline Silt (\%) & 4.08 & 51.55 & 42.39 \\
\hline Sand (\%) & 94.90 & 34.02 & 38.04 \\
\hline $\mathrm{IS}^{\mathrm{a}}(\mathrm{mM})$ & $3.07 \pm 0.05$ & $4.90 \pm 0.15$ & $5.20 \pm 0.04$ \\
\hline $\mathrm{pH}(\mathrm{KCl})$ & $7.8 \pm 0.2$ & $5.3 \pm 0.7$ & $7.1 \pm 0.3$ \\
\hline $\mathrm{OM}^{\mathrm{b}}$ (w. \%) & 0.34 & 2.62 & 2.74 \\
\hline $\mathrm{CEC}_{\text {eff }}{ }^{\mathrm{C}}\left(\mathrm{mmolc} \mathrm{kg}^{-1}\right)$ & 4 & 93 & 147 \\
\hline
\end{tabular}

a lonic strength

b Organic matter

${ }^{c}$ Cation exchange capacity

\subsubsection{Methods}

Four extraction methods ( $A, B, C$ and BW) were tested for the recovery of $60 \mathrm{~nm}$ AgNPs from spiked sand, loam and clay. AgNPs recoveries were calculated by comparing the AgNPs concentration measured in the soil to the amounts of AgNPs spiked to the soil. Two AgNPsspiking suspensions were prepared with concentrations of 0.5 and $5 \mathrm{mg} \mathrm{L}^{-1}$ were prepared from the commercially obtained AgNPs $60 \mathrm{~nm}$ and AgNPs $100 \mathrm{~nm}$ suspensions (1000 mg L' $\left.{ }^{1}\right)$. The AgNPs stock suspensions were sonicated for $10 \mathrm{~min}$ prior to use. The soil samples, typically 1 gram, were spiked by the addition of $100 \mu$ of the AgNPs-spike suspensions, mixed by shaking, and allowed to equilibrate for $24 \mathrm{~h}$ in the dark at room temperature. The AgNPs concentration in the soil is thus $50 \mu \mathrm{g} \mathrm{kg}^{-1}$ (low concentration) and $500 \mu \mathrm{g} \mathrm{kg}^{-1}$ (high concentration). All soil samples and soil extracts were stored in the dark at room temperature.

The four methods, A, B, BW and C were performed in triplicate on each soil matrix. A description of each method is given below.

\subsubsection{Method A}

This method was comparable with the method used by Whitley et al. (2013) and involved bringing the AgNPs spiked soil sample in a $20 \mathrm{ml}$ syringe that contained a plug of borosilicate glass wool pre-wetted with MQW in the tip of the syringe. $10 \mathrm{ml}$ of MQW was added and the syringe was placed tip-down in a $50 \mathrm{ml}$ polyethylene (PE) tube and centrifuged at 1000 
rpm for $8 \mathrm{~min}$. The sample extract was collected from the $50 \mathrm{ml} \mathrm{PE}$ tube and diluted 100 times before analyses with spICP-MS.

\subsubsection{Method B}

The AgNPs-spiked soil sample was put into a $12 \mathrm{ml} \mathrm{PE}$ tube and $10 \mathrm{ml}$ of MQW was added. The mixture was sonicated for $15 \mathrm{~min}$. and vortexed for $10 \mathrm{~min}$. at $1500 \mathrm{rpm}$ before and after sonication. The mixture was allowed to settle for 3 hours and $2.0 \mathrm{ml}$ of the supernatant was collected through a $5 \mu \mathrm{m}$ Acrodisc syringe filter (Pall Corporation, USA) using a PE syringe. The extract was diluted 100 times and analysed with spICP-MS.

\subsubsection{Method C}

Similar to the procedure described in method B with one exception: MQW was replaced by $10 \mathrm{ml}$ of a $10 \mathrm{mM}$ sodium dodecyl sulphate (SDS) solution in MQW. Extracts were diluted 100 times and analysed with spICP-MS.

\subsubsection{Method BW}

As an alternative to method $B$, samples were pre-wetted with MQW prior to extraction. This method was applied only for clay and soil samples since the composition of the loam sample was in between clay and soil. AgNPs-spiked samples were extracted using method B after pre-wetting of the sample with $900 \mu \mathrm{MQW}$ for 24 hours. Samples were extracted twice, once directly at the end of the pre-wetting period (BW1), and a second time 6 hours after the end of the pre-wetting period (BW2).

\subsubsection{Multiple extractions}

To determine the adsorption of AgNPs to soil particles, spiked samples were extracted with method BW at time intervals of $6,12,24$, and 36 hours after the spiked sample equilibration period. Pre-wetting was used only for the first extraction. The settling time for soil particles was set to be $15 \mathrm{~min}$.

\subsubsection{Instrumental analysis}

spICP-MS was used in all methods to determine the concentration and particle size of AgNPs in soil extracts. The spICP-MS technique has been validated for the determination of AgNPs in food (Peters et al. 2014) and tested in an inter-laboratory study (Linsinger et al. 2014) for the determination of AgNPs in aqueous suspensions. Calculation of mass concentration, particle size and size distribution from the spICP-MS data was performed using a standard spreadsheet, freely available on the website of RIKILT, Wageningen University and Research (http://www.wageningenur.nl/en/Expertise-Services/Research-Institutes/rikilt/show/Singl e-Particle-Calculation-tool.htm). Thermo Scientific X series 2 (Massachusetts, USA) ICP-MS was used, equipped with a standard (conical glass concentric) nebulizer and a quartz impact 
bead spray chamber. The settings of ICP-MS were as described by Peters et al (Peters et al. 2015). The forward power was $1400 \mathrm{~W}$ and the argon gas flows were set at $13 \mathrm{~L} \mathrm{~min}^{-1}$ for the plasma, $1.1 \mathrm{~L} \mathrm{~min}^{-1}$ for the nebulizer, and $0.7 \mathrm{~L} \mathrm{~min}^{-1}$ auxiliary flow. The sample flow rate to the nebulizer was determined before the start of each series of measurements. The dwell time was set at 3 milliseconds (ms) and the total analysis time was set at $60 \mathrm{~s}$. At the start of each analysis series, a $60 \mathrm{~nm}$ gold NP suspension with a mass concentration of $50 \mathrm{ng} \mathrm{L}^{-1}$ was used to verify the performance of the ICP-MS and to determine the transport efficiency. Ionic silver standards with concentrations in the range of $0.25-5 \mu \mathrm{g} \mathrm{L}^{-1}$ were used for analyte calibration. The time scan data of the ICP-MS were exported as csv files and copied into a single particle calculation tool spreadsheet to calculate the AgNPs mass concentration, and particle number and the particle size and size distribution. The spreadsheet also allows the determination of ionic silver that may be present in the sample, for instance due to partial dissolution of AgNPs. The presence of ionic silver can be observed in the spICP-MS time scan as an increase in the background signal (Peters et al. 2015).

\subsubsection{Method validation}

The final analysis method was validated to determine the repeatability $\left(R S D_{r}\right)$, reproducibility $\left(R S D_{R}\right)$ and trueness/recovery of the method. The limit of detection (LOD) for AgNPs was estimated from method blank analysis. The performance characteristics were calculated from the results of the analysis of 7 replicates of spiked clay and sand samples analysed on 3 different days each separated by at least one week. The soil samples were spiked at a validation level (VL) of $50 \mu \mathrm{g} \mathrm{kg}^{-1}$, standards, and blank samples (e.g. nonspiked samples) were included on each validation day. The measured data for RSDr and $\mathrm{RSD}_{R}$ of AgNPs mass concentration and particle diameter were evaluated using ANOVA. The predicted RSDr and RSDR were calculated using Horwitz equations, $R S D r=C^{-0.15}$ and $R S D_{R}=$ $2 \mathrm{C}^{-0.15}$ where $\mathrm{C}$, is the concentration expressed as a mass fraction. The method can be accepted if the ratio of the value of the measured (founded) repeatability and reproducibility to the calculated values are between 0.5 and 2 times, this ratio is called Horwitz rate (HORRATr) (Horwitz 2002).

\subsection{Results and Discussion}

Four methods A, B, C and BW were tested for recovery and the results including standard deviations $(n=3)$ are shown in Figure 2.1. For method $A$, the recovery of $60 \mathrm{~nm}$ AgNPs was found to be $<10 \%$ for all three soil types, comparable to the results of Whitley et al. (2013). This indicates that simple leaching of the soil, even with a 10:1 ratio for water and soil, only recovers the AgNPs present in the pore water of the soil sample. On the other hand, these 
results indicate that the spiking procedure is realistic and that AgNPs really interact with and are adsorbed by the soil matrix.

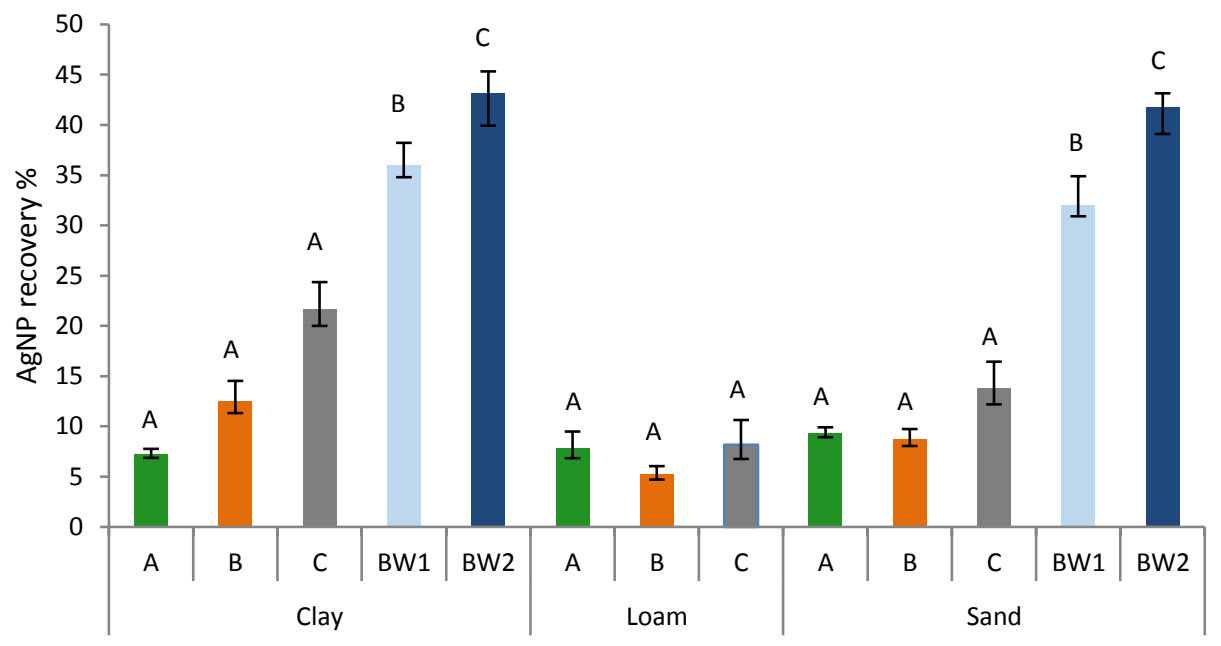

Extraction methods (A, B,C, BW1,BW2) and soil types

Figure 2.1 Recovery of $60 \mathrm{~nm}$ AgNPs from the three AgNPs spiked soil types using methods $A, B, C$ and BW1 (single extraction) and BW2 (double extraction). The letters on the bars refer to significance differences $(p<0.05)$.

In method B, sonication was used in order to release adsorbed AgNPs from the soil matrix after the addition of $10 \mathrm{ml}$ of MQW. While the recovery of AgNPs was better for clay, the results for loam and sand were comparable with the results using of method $A$ (see Figure 2.1). In method $C$, the extraction was performed with $10 \mathrm{mM}$ of SDS in MQW to stabilize AgNPs in the pore water thus avoiding re-adsorption by the soil matrix. Method $\mathrm{C}$ resulted in the highest recoveries for all sample types with a maximum recovery of $21 \%$ for clay.

Pre-wetting the samples improved recoveries for all AgNPs-spiked matrices, ranging from $32 \%$ for AgNPs in sand to $36 \%$ for AgNPs in clay (loam was not tested). When a soil sample was extracted for a second time after 6 hours (pre-wetting only prior to the first extraction), the total recoveries increased to $41 \%$ in sand and $43 \%$ in clay.

Based on the results, method BW1 and BW2 were the most effective methods and will be used in the further analyses in our study. Methods A and B were rejected because of their low recovery rates while method $C$ was rejected because the use of SDS resulted in problems due to excessive foaming during sample preparation. 


\subsubsection{Recovery rates with time using BW}

Multiple extractions of the same sample increase the total (cumulative) recovery of AgNPs from the soil samples. However, the recovery in each further extraction is lower and the cumulative recovery levels do not exceed 50\% (Figures 2.2 and 2.3). The incomplete recovery of the spiked AgNPs can be attributed to several factors including coating by dissolved organic matter, dissolution/transforming in the soil (Brunetti et al. 2015), and sorption onto/by soil particles and plastic tubes (Peters et al. 2014, Malysheva et al. 2016).

The recovery for loam, sand and clay soils in Method A is low and more or less the same for all soil types. The lowest recoveries of AgNPs using the three methods were those for loamy soil (figure 2.1). This low recovery can be attributed to many factors. For example, the low $\mathrm{pH}$, which can promote dissolution, in the loamy soil was the lowest in all of the samples (see Table 2.2) (Peters et al. 2015). In Method B, the recovery of AgNPs was the lowest for the loamy soil which could be attributed to the use of $5 \mu \mathrm{m}$ membranes as the sorption of AgNPs on membrane surface is likely to happened (Bolea et al. 2011). The use of the SDS in method $C$ was expected to increase the recovery since SDS is supposed to stabilize AgNPs in the suspension and thus release more of the AgNPs adsorbed on the soil. As expected, this was observed, most noticeably with clay.

Sample pre-wetting prior to method B, and described as method BW1 increased the AgNPs recovery to $30-35 \%$, possibly by decreasing the ionic strength of the pore water in the sample which increases the mobility of the AgNPs (Peters et al. 2015). While the wet method is far better than the dry method, the recovery is still low. To investigate further, the number of subsequent extractions for one sample was increased which should have increased the total recovery the spiked AgNPs. A second extraction at 6 hours was about $10 \%$ and $<5 \%$ for method BW and B respectively. The higher recovery in the second extraction may again be attributed to a decrease in the ionic strength of the AgNPs-soil extraction (Sagee et al. 2012). The recovery of AgNPs in the subsequent extractions, after 12,24 and 36 hrs, was lower than in each previous extraction, this can be attributed to the transformation mechanisms which reduce the recovery by time (Brunetti et al. 2015). After four subsequent extractions the total recovery of 60 and $100 \mathrm{~nm}$ AgNPs from sand and clay samples was never higher than $50 \%$ as shown in Figure 2.2 and 2.3. 


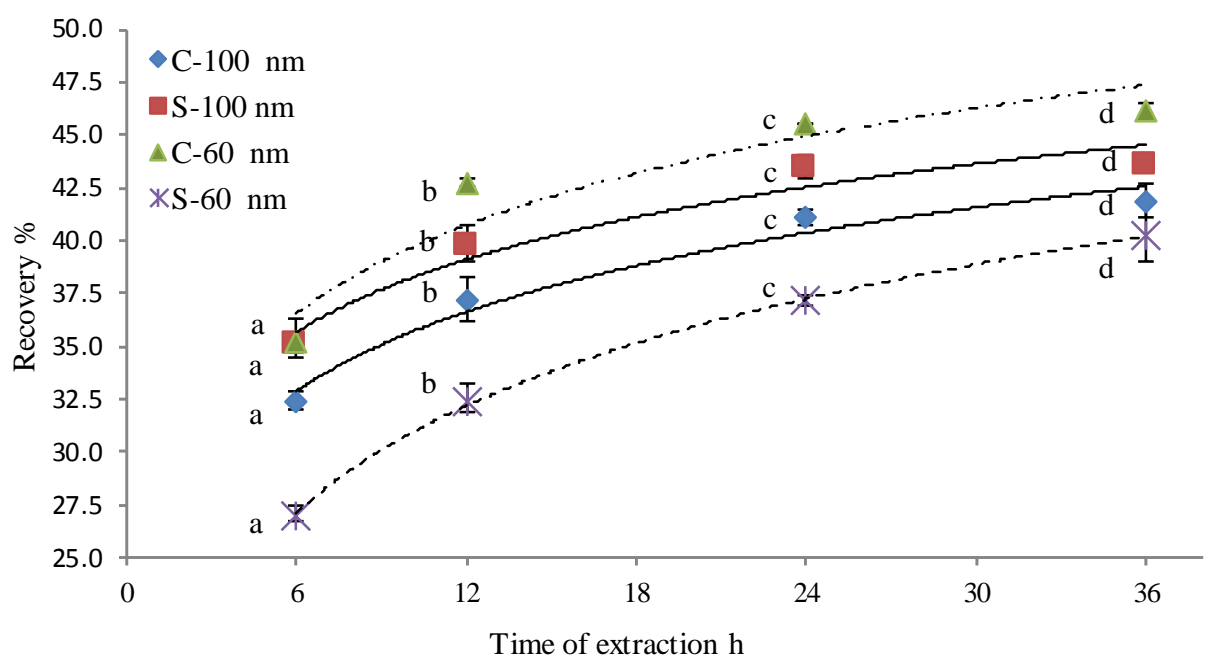

Figure 2.2 Cumulative recovery of 60 and $100 \mathrm{~nm}$ AgNPs from clay and sand soil samples, spiked at a concentration of $500 \mu \mathrm{g} \mathrm{kg}^{-1}$ soil after pre-wetting at $T=0$ and extractions after $6,12,24$, and $36 \mathrm{hrs}$ using method BW1. $C$ is clay, $S$ is sand. Different lower case letters refer to significance differences $(p<0.05)$.

Soils are complex systems and contain various concentrations of organic and inorganic ligands. Major parameters involved in metal adsorption are soil organic matter (Table 2.1), but also oxide surfaces ( $\mathrm{Fe}, \mathrm{Al}, \mathrm{Mn}$ and others), clay minerals and sulphur containing materials. The shape of the curves in Figure 2.2 and 2.3 indicates that adsorption processes play a role and that an equilibrium exists between AgNPs suspended in the pore water and AgNPs adsorbed to soil particles. The cumulative AgNPs recovery was higher in high-spiked soils than in low-spiked soils as expected in the case of adsorption processes. In addition, the results for the low-spiked soils show a clear differentiation between clay and sand with the latter showing a lower cumulative recovery. This difference may be attributed to the higher $\mathrm{pH}$ of the sandy soil which enhances silver adsorption to the soil due to higher negatively charged sites and an increase of the aggregation of AgNPs (Yin et al. 2015a). 


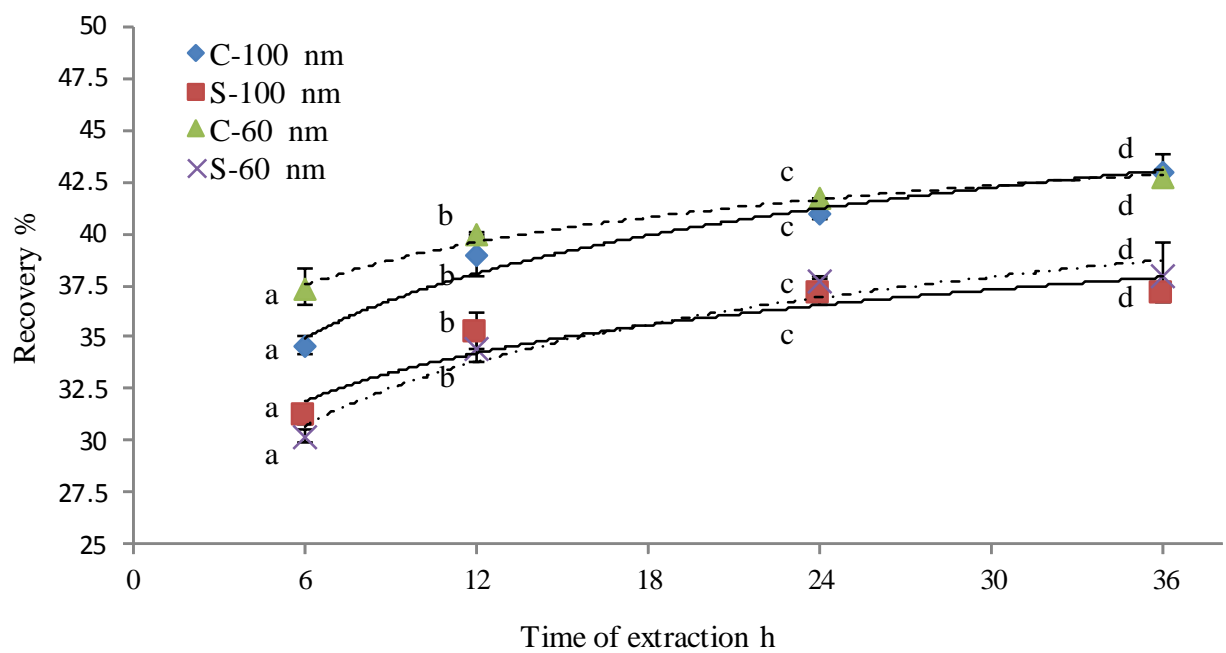

Figure 2.3 Cumulative recovery of 60 and $100 \mathrm{~nm}$ AgNPs from clay and sand soil samples, spiked at a concentration of $50 \mathrm{\mu g} \mathrm{kg}^{-1}$ soil, pre-wetted at $T=0$ and after extractions at $6,12,24$, and $36 \mathrm{hrs}$ using method $B W 1 . C$ is clay, $S$ is sand. Different lowercase letters refer to significance differences $(p<0.05)$.

\subsubsection{Recovery of the particle size distribution}

The physio-chemical stability of AgNPs in soil is unknown (Sagee et al. 2012). Depending on the ionic strengths, AgNPs may agglomerate to form larger particles which may (partly) dissolve forming ionic $\mathrm{Ag}$ and resulting in smaller sized AgNPs or which may react with sulphur species in the soil forming silver sulphide (Yin et al. 2015a). In this study, AgNPs particle sizes were found to be stable during equilibration and extraction. A comparison between the particle size distributions in the spike solutions with that of the AgNPs in soil extracts showed no significant differences. No AgNPs agglomerates were observed in the particle size distribution calculated from the spICP-MS measurements (Figure 2.4 and 2.5). The particle size distribution of the 6 hour extracts showed that spiked AgNPs can be extracted from soil with little or no changes in the particle size distribution. A subsequent extraction of the same sample after $36 \mathrm{hr}$. shows that the particle size distribution of the AgNPs extracted in the fourth extraction of the spiked soil sample is still unchanged (although this is sometimes hard to observe because of the low AgNPs concentrations in these extracts). In short, the results show that AgNPs can be extracted from soil samples with minimum disturbance of the AgNPs properties and at concentrations which are in the range of what may be present in sludge treated soils. 

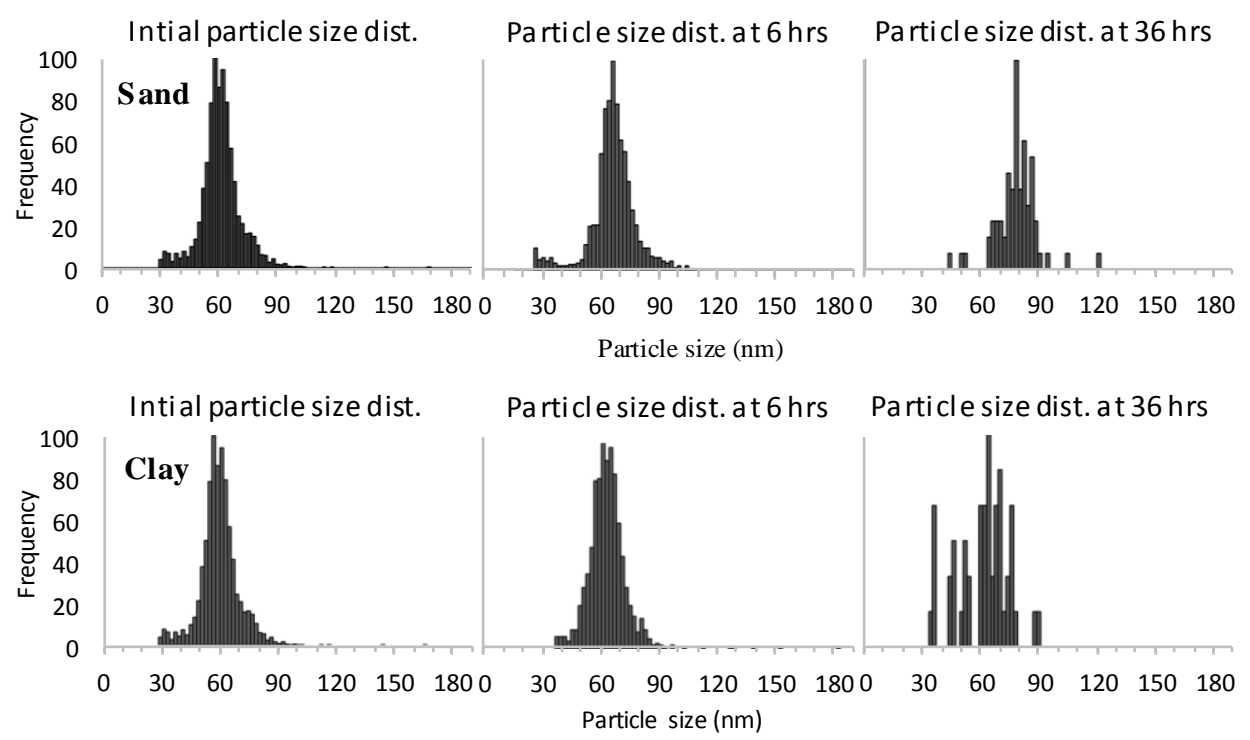

Figure 2.4 Particle size distributions of extracted $60 \mathrm{~nm}$ AgNPs in the AgNPs spiked suspension (left) and in the 6 (middle) and 36 (right) hrs extracts from soil spiked at a concentration $50 \mu \mathrm{g} \mathrm{kg}^{-1}$ at 0, 6 and $36 \mathrm{hrs}$.
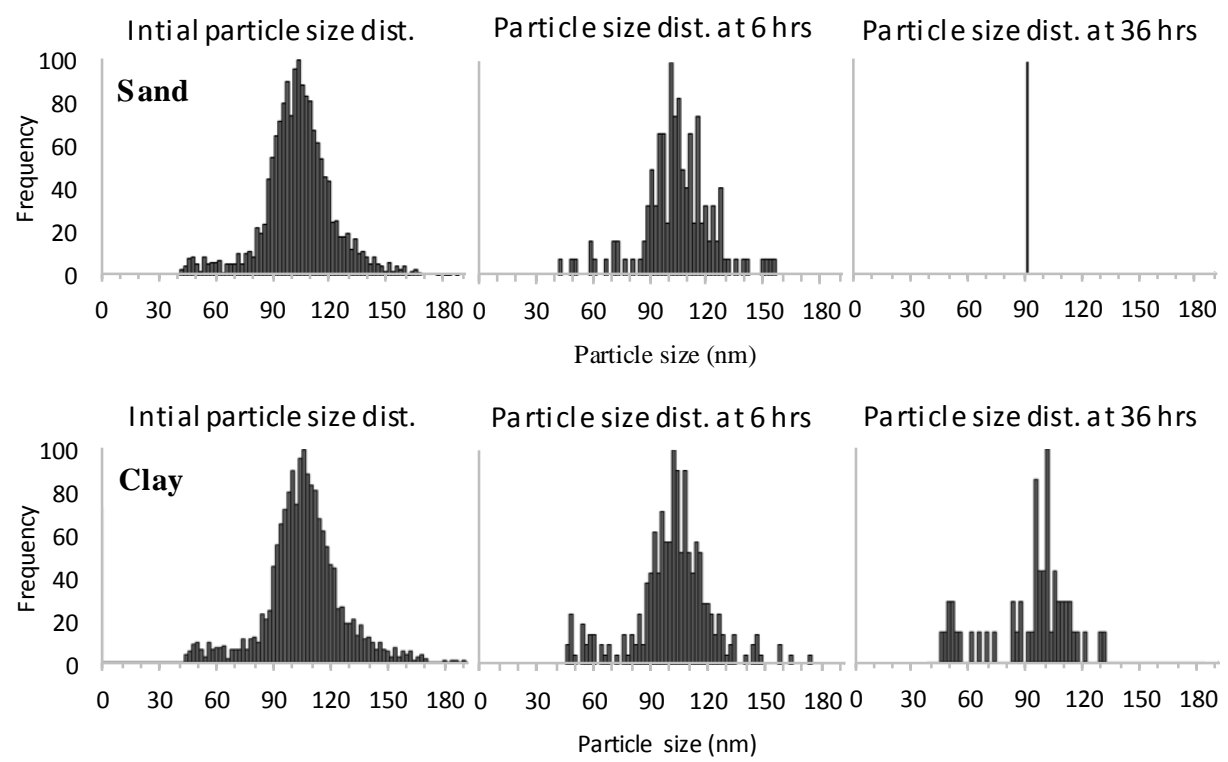

Figure 2.5 Particle size distributions of $100 \mathrm{~nm}$ AgNPs in the AgNPs spiked suspension (left) and in the 6 (middle) and 36 (right) hrs extracts from soil spiked at a concentration $50 \mu \mathrm{g} \mathrm{kg}$.

Particles can (partly) dissolve in the soil matrix resulting in ionic Ag and smaller AgNPs particle sizes. spICP-MS, allows for the differentiation of AgNPs and the ionic Ag. Since 
AgNPs appear as peaks in the time scan while ionic Ag appears as a continuous background signal (Peters et al. 2015). AgNPs and ionic Ag concentration can both be calculated using the spICP-MS calculation spreadsheet. There are limitations: AgNPs with sizes $<20 \mathrm{~nm}$ are below the size detection limit ( $\left.\mathrm{LOD}_{\text {size }}\right)$ of a quadrupole ICP-MS and will not be detected as particles but do appear in the background signal. Due to the background noise in blank samples (electronic and chemical noise), ionic Ag concentrations $<50 \mathrm{ng} \mathrm{L}^{-1}$ can usually not be detected. Close inspection of the time scans of MQW blanks and soil extracts of spiked soil samples, as shown in Figure 2.6, shows that a typical background signal for MQW blanks is 333 counts per second (cps) with excursions to $666 \mathrm{cps}$ (figure 2.6A). Background signals in the extracts from spiked soil samples were all higher than $333 \mathrm{cps}$ and mostly closer to $1332 \mathrm{cps}$ as illustrated by the time scans in Figure 2.6B. Based on the cleanliness of the ICP$\mathrm{MS}$, for example the background noise, ionic $\mathrm{Ag}$ concentrations as low as $50 \mathrm{ng} \mathrm{L}^{-1}$ can be measured in the diluted extract.
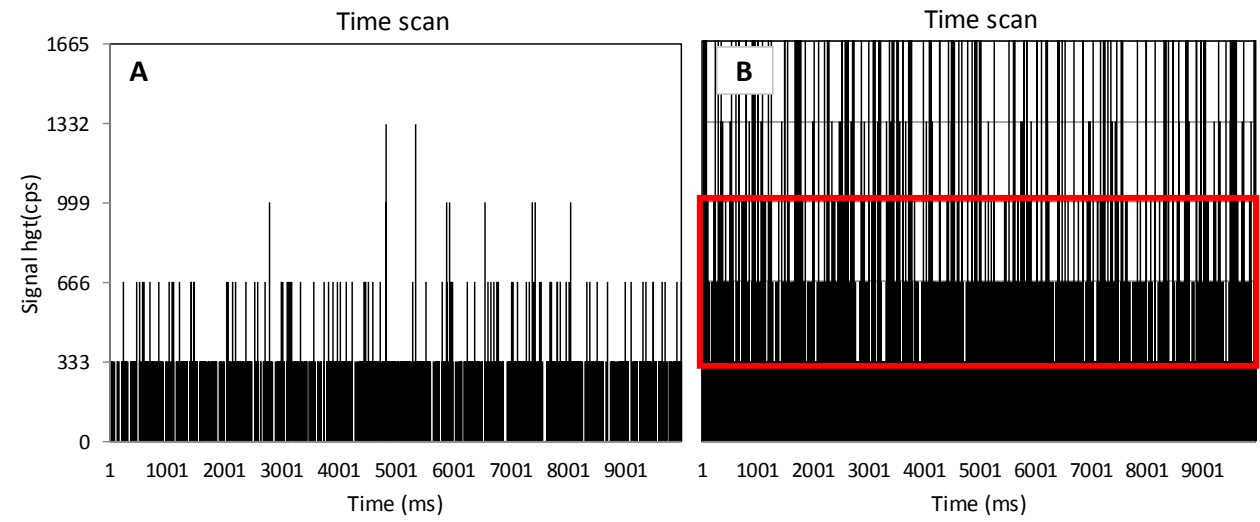

Figure 2.6 Background signals in the time scans of MQW $(A)$ and aqueous extracts from spiked soil samples (B).

Ionic Ag concentrations in the extracts of AgNPs spiked soils were calculated from the raw spICP-MS data using the spICP-MS calculation spreadsheet (Peters et al. 2015). The results for recovered AgNPs and ionic Ag are presented in Table 2.3 and show three clear trends. First, the Ag ionic release in clay was always higher than in sand for each type of spike. This may be explained as the AgNPs retention in clayey soil is higher than in the sandy soil (Sagee et al. 2012) which resulted in more AgNPs being available for dissolution. Secondly, the relative ionic Ag release was always higher in the case of the low concentration spikes. The ratio of ionic Ag released to AgNPs concentration recovered was higher for low AgNPs spikes than in high spikes of about 2 times; this reasonable since the low spike was subjected to higher dilution. Thirdly, the relative ionic Ag release was always higher when considering the $60 \mathrm{~nm}$ AgNPs compared to $100 \mathrm{~nm}$ AgNPs. This was also reported by others and is easily 
explained by the size of the AgNPs (Liu et al. 2010, Ho et al. 2011, Zhang et al. 2011). Since the 60 and $100 \mathrm{~nm}$ AgNPs were spiked to the soils in the same mass concentrations, there were about 5 times more $60 \mathrm{~nm}$ AgNPs particles with a total surface that was about 2.8 times that of the $100 \mathrm{~nm}$ AgNPs. Since ionic Ag release takes place at the surface of the particles, this higher total surface area for $60 \mathrm{~nm}$ AgNPs explains the higher ionic Ag release. In fact, the surface ratio value of 2.8 is more or less reflected in the ratios of the ionic $\mathrm{Ag}$ release by the 60 and $100 \mathrm{~nm}$ AgNPs in sand which is about 2.5.

Table 2.3 Total recoveries of Ag nanoparticles and ionic Ag detected using BW2 extraction method.

\begin{tabular}{lllll}
\hline Soil & $\begin{array}{l}\text { Particle } \\
\text { size-soil- } \\
\text { conc. }\end{array}$ & $\begin{array}{l}\text { AgNPs } \\
\text { recovered } \\
(\%)\end{array}$ & $\begin{array}{l}\text { lonic Ag } \\
\text { recovered } \\
(\%)\end{array}$ & $\begin{array}{l}\text { Total Ag } \\
\text { recovered } \\
(\%)\end{array}$ \\
\hline Clay & $100-$ C-H & $42 \pm 1$ & $4 \pm 1$ & 46 \\
& $100-$ C-L & $42 \pm 1$ & $9 \pm 2$ & 51 \\
& $60-$ C-H & $46 \pm 2$ & $5 \pm 1$ & 51 \\
& $60-$ C-L & $43 \pm 1$ & $11 \pm 2$ & 54 \\
& & & & \\
Sand & $100-$ S-H & $44 \pm 2$ & $1 \pm 2$ & 45 \\
& $100-S-L$ & $37 \pm 1$ & $4+2$ & 41 \\
& $60-S-H$ & $40 \pm 4$ & $5 \pm 2$ & 45 \\
& $60-S-L$ & $38 \pm 1$ & $11 \pm 2$ & 49 \\
\hline
\end{tabular}

*100=100nm AgNPs; 60=60 nm AgNPs; C=clayey soil; S=sandy soil; $\mathrm{H}=$ high concentration $\left(500 \mu \mathrm{g} \mathrm{kg}^{-1}\right)$; L=low concentration $\left(50 \mu \mathrm{g} \mathrm{kg}^{-1}\right)$.

\subsubsection{Method validation}

To determine whether the method is fit for the intended purpose, it was validated for the matrices sand and clay at with $60 \mathrm{~nm}$ AgNPs at a validation level of $50 \mu \mathrm{g} \mathrm{kg}^{-1}$ soil. Validation included the complete analyses from the extraction procedure up to and including the spICP-MS analysis of the sample extract. The performance characteristics determined for the parameters particle mass concentration and particle size were: trueness (expressed as the recovery of the AgNPs in the spiked sample), the repeatability (expressed as the relative standard deviation in the results of samples processed on the same day, RSDr), and the reproducibility (expressed as the relative standard deviation in the results of samples processed on different days, $\mathrm{RSD}_{\mathrm{R}}$ ). The results are summarized in Table 2.4. The particle mass concentration measured repeatability was $15 \%$ and the predicted repeatability was $12.4 \%$ for clay and sand. The particle mass concentration measured reproducibility was 25 for clay and $29 \%$ for sand while the predicted reproducibility was $24.9 \%$. 
For an analytical method we usually strive for a recovery in the range of $70-120 \%$. However, to avoid changes in the physicochemical properties of the AgNPs, no strong chemicals like acids or strong mechanical forces had been used. In this case the trueness (recovery) was $32 \%$ and $46 \%$ for sand and clay, respectively. The method still can be useful since the repeatability $(R S D r)$ and reproducibility $\left(R S D_{R}\right)$ are acceptable for a validation level of $50 \mu \mathrm{g}$ $\mathrm{kg}^{-1}$ as the calculated Horwitz ratios are within the acceptance range 0.5-2 (Horwitz 2002).

The concentration detection limit $\left(\mathrm{LOD}_{c}\right)$ is estimated from the number of peaks detected in method blanks and is $5 \mu \mathrm{gg}^{-1}$ for $60 \mathrm{~nm}$ AgNPs. Taking into account the fact that the aqueous extracts were diluted 100 times prior to spICP-MS analyses, we expect that the $\mathrm{LOD}_{\mathrm{c}}$ could even be lowered to $0.5 \mu \mathrm{g} \mathrm{kg}$ by diluting less. The size detection limit $\left(\mathrm{LOD}_{s}\right)$ depends on the ICP-MS used. In case of a standard quadrupole LOD $_{\mathrm{s}}$ is at best $20 \mathrm{~nm}$ (Linsinger et al. 2014).

Table 2.4 Validation results for trueness, repeatability (RSDr), and reproducibility (RSDR).

\begin{tabular}{llllll}
\hline Parameter & $\begin{array}{l}\text { Trueness } \\
(\%)\end{array}$ & $\begin{array}{l}\text { Repeatability } \\
\text { RSDr } \\
(\%)\end{array}$ & $\begin{array}{l}\text { HORRATr } \\
\text { RSD/PRSD } \\
(\%)\end{array}$ & $\begin{array}{l}\text { Reproducibility }_{\text {RSD }} \\
(\%)\end{array}$ & $\begin{array}{l}\text { HORRATr } \\
\text { RSD/PRSD } \\
(\%)\end{array}$ \\
\hline $\begin{array}{l}\text { Sand } \\
\begin{array}{l}\text { Particle diameter } \\
(n=21)\end{array}\end{array}$ & 106 & 1 & n.d. & 4 & n.d \\
$\begin{array}{l}\text { Particle mass } \\
\text { concentration (n=21) }\end{array}$ & 32 & 15 & 1.2 & 29 & 1.1 \\
$\begin{array}{l}\text { Clay } \\
\begin{array}{l}\text { Particle diameter } \\
\text { (n=21) }\end{array}\end{array}$ & 93 & 2 & & & \\
$\begin{array}{l}\text { Particle mass } \\
\text { concentration (n=21) }\end{array}$ & 46 & 15 & n.d. & 8 & n.d. \\
\hline
\end{tabular}

${ }^{a}$ Horwitz ratio for calculated/predicted repeatability.

${ }^{b}$ Horwitz ratio for calculated/predicted reproducibility.

PRSD; predicted repeatability (reproducibility).

n.d.; not determined. 


\subsection{Conclusion}

The aim of this study was to develop an analytical method for the detection and characterization of AgNPs in soil without changing the physio-chemical properties of the extracted AgNPs. The final method consisted of pre-wetting the analytical sample followed by an aqueous extraction, using sonication to suspend adsorbed AgNPs in the aqueous phase, and analysing the aqueous extract with single particle ICP-MS. Using this method, the particle mass and number concentration and the particle size and size distribution of the AgNPs spiked to natural soil samples could be determined. Validation of the method showed that the recovery of $60 \mathrm{~nm}$ AgNPs at a spiked concentration of $50 \mu \mathrm{g} \mathrm{kg}^{-1}$ ranged from $32 \%$ for sandy soil to $46 \%$ for clayey soil. Although the recovery is low, the repeatability of $15 \%$ and the reproducibility of $25-29 \%$ for the particle mass concentration are acceptable and make the method suitable for its purpose. The trueness, repeatability and reproducibility for the determination of the particle size of a $60 \mathrm{~nm}$ AgNP in sandy soil was $106 \%, 1 \%$ and $4 \%$, respectively. For clayey soil, this was $93 \%, 2 \%$ and $8 \%$, respectively. The concentration detection limit (LODc) for $60 \mathrm{~nm}$ AgNPs is $5 \mu \mathrm{g} \mathrm{kg}^{-1}$. The developed method can be applied to eco-toxicological and risk-assessments studies in the soil environment. 


\title{
3. Tracking the transport of silver nanoparticles in soil: a saturated column experiment
}

\begin{abstract}
Silver nanoparticles (AgNPs) can enter the environment when released from products containing them. As AgNPs enter soil, they may be retained in the soil profile and/or may leach to the groundwater. This research assessed the transport of AgNPs in their "particle form" through the soil profile using a series of columns. Three soil types, LSH (loam with high organic matter (OM)), LSL (loam with low OM) and Sand (no OM), were put into soil columns. The results showed that in the LSH columns, 6.7\% of the AgNPs applied to the 0$4 \mathrm{~cm}$ soil layer (layer 1) was transported deeper into the soil column, and 3.4\% leached as effluent from the columns. In LSL columns, 8.9\% of the AgNPs applied to the top layer was transported deeper into soil and $4.3 \%$ leached away as effluent water. However, in the sandy soil columns, $24.6 \%$ of the amount applied to the top soil layer was transported downwards and 13.9\% of AgNPs applied was detected in the effluent. Furthermore, the AgNPs particle size left in the columns packed with LSL and LSH decreased more substantially than in the columns packed with sand. The decrease in AgNP sizes in the effluent water was less than the decrease in particle size of AgNPs transported through but retained in the soil. This work highlights the ability to track AgNPs in low concentration and particle size as they leach through soil, which increases our knowledge about AgNPs transport mechanisms in porous media.
\end{abstract}

K.N.M. Mahdi, R.J. Peters, M.J. van der Ploeg, C.J. Ritsema and V. Geissen. 2018. Tracking the transport of silver nanoparticles in soil: a saturated column experiment. Submitted to Water, Air, and Soil Pollution. 


\subsection{Introduction}

Silver nanoparticles (AgNPs) is a metallic nanomaterial consisting of spherically shaped particles ranging in size from 1-100 nm (Helmlinger et al., 2016). AgNPs production is regarded as the fastest growing among nanomaterials and implies a growing number of products and applications that incorporate AgNPs (López-Serrano et al., 2014). Previous studies have indicated potential toxicity of AgNPs to humans and the environment (EC 2017). The increase in the production and number of applications that use AgNPs has raised concerns about the release of these materials to the environment during production, usage and after disposal (Gottschalk and Nowack, 2011; Yu et al., 2013).

AgNPs enter the soil environment through different pathways including natural processes, like biological and chemical reduction of ionic silver, or anthropogenic sources which seem to be the most significant (Yin et al., 2015b). Former studies showed that AgNPs can also reach the soil through plant strengthening agents (Lorenz et al., 2011; Prasad et al., 2014; Thuesombat et al., 2014), slag from incinerators (Holder et al., 2013) and attached to sludge from sewage treatment plants (Lombi et al., 2013). In Germany, around 30\% of the annual sewage sludge solids produced ( 2 million tons per year) from municipal wastewater treatment plants, are used for farmland application (Schlich et al., 2013a). Similar amounts are used in Spain, Portugal, France and the UK (Wiechmann et al., 2012). It has been found that, once introduced to the soil environment, AgNPs can be transported to deeper layers in the soil and to the groundwater (Sagee et al., 2012; Cornelis et al., 2013; Liang et al., 2013a) and can also be transported with surface water runoff (Kaegi et al., 2010; Tian, 2010; Mahdi et al., 2017).

AgNPs that are released to the soil environment may encounter changes in physicalchemical properties as they interact with the soil (Yin et al., 2015a). Therefore, soil characteristics can affect AgNPs behaviour in soil. For example, the presence of organic matter (OM) is believed to prevent AgNPs from dissolution as they coat AgNPs which inhibits Ag+ release (Klitzke et al., 2014) and can make AgNPs less mobile in the soil (Coutris et al., 2012). Other studies have shown that the retention of nanomaterials generally increases and the bioavailability decreases in soils with a finer grain size distribution (Shoults-Wilson et al., 2011a; Cornelis et al., 2012). The cation exchange capacity (CEC), ionic strength (IS), $\mathrm{pH}$ and soil particle size distribution also have an impact on the fate and transport pattern of AgNPs in soil (Lowry et al., 2010; Liang et al., 2013a). Therefore, the complexity of the soil system makes it difficult to understand the transport and distribution of AgNPs in soils (Pan and Xing, 2012). 
In relation to toxicity, many studies showed that smaller particle sizes of AgNPs result in higher toxicity effects to applied environments (Pal et al., 2007; Kim et al., 2012; Silva et al., 2014). Further, AgNPs applied in pristine form or in transformed form (due to the interaction with other soil chemicals) have both proven to be toxic to soil species (Zhang et al., 2012; Schlich et al., 2013b). Schlich et al. (2013b) also showed that AgNPs applied to soil at low concentrations can cause toxic effects for soil microorganisms.

Detection of AgNPs in soil is complicated and requires very sensitive instruments and methods (Yu et al., 2015). Generally, Ag concentration in soil has been determined using acidic digestion of the soil samples (EPA 1996). However, since AgNPs dissolve in this procedure, any information about the presence of AgNPs in soil is lost and nothing can be concluded about the stability, transportation and transformation of AgNPs in soil.

This study focuses on tracking transport of AgNPs and changes in their particle size in $16 \mathrm{~cm}$ long columns filled with different soils, and in effluent leached from these columns. We used the saturated soil column method modified to mimic real-world application of sludgecontaining AgNPs and leaching scenarios. AgNPs transport in soil is expected to increase with increased application of rainwater (RW), therefore, RW was applied in periods of 24, 48 and 72 hrs to be able to observe the transport pattern of AgNPs in the soil and effluent water (EW) that sampled after each RW application. The detection and characterization of AgNPs in soil was achieved by a combination of aqueous extraction and single particle inductively coupled plasma mass spectrometry method (spICP-MS). This combination has the capability of detecting very low AgNPs concentrations in the soil (Peters et al., 2015; Mahdi et al., 2016). The results obtained from this work contribute to filling the knowledge gap regarding AgNPs transport and leaching through soil and increases the awareness of AgNP distribution patterns in soil. These findings can be used for better understanding and management of products and waste containing AgNPs.

\subsection{Materials and Methods}

\subsubsection{Materials}

\subsubsection{Soils and Rainwater}

Three types of soil were used in this study and were provided by Unifarm (Wageningen, the Netherlands). The soils used had the following characteristics: loam with high organic matter (LSH), loam with low organic matter (LSL) and sand with no OM content (Sand). The initial characteristics of the soil are given in Table 3.1. 
The simulate rain was applied via a sprinkler on the top of the soil column. The rainwater setup is described in detail in the experimental design section (3.2.2.1). The $\mathrm{pH}$ and IS of the water were measured and were: 7.63 and $3.8 \mathrm{mM}$ respectively.

Table 3.1 Soil initial properties.

\begin{tabular}{|c|c|c|c|c|}
\hline \multicolumn{2}{|c|}{ Characteristic: } & LSH & LSL & Sand \\
\hline \multicolumn{2}{|c|}{ Clay (\%) } & 10.75 & 9.22 & 0.00 \\
\hline \multicolumn{2}{|c|}{ Silt (\%) } & 41.81 & 43.15 & 1.31 \\
\hline \multicolumn{2}{|c|}{ Sand (\%) } & 47.45 & 47.64 & 98.69 \\
\hline \multicolumn{2}{|c|}{$\mathrm{pH}(\mathrm{KCl})$} & $7.5 \pm 0.02$ & $6.8 \pm 0.03$ & $7.9 \pm 0.21$ \\
\hline \multirow{2}{*}{ CEC } & $\mathrm{Ca}^{+2}\left(\right.$ meq $\left.100 \mathrm{~g}^{-1}\right)$ & $3.8 \pm 0.22$ & $1.5 \pm 0.11$ & $0.4 \pm 0.03$ \\
\hline & $\mathrm{K}^{+}\left(\right.$meq $\left.100 \mathrm{~g}^{-1}\right)$ & $0.24 \pm 0.12$ & $0.1 \pm 0.12$ & $0.02 \pm 0.02$ \\
\hline \multicolumn{2}{|c|}{ OM (\%) } & $3.4 \pm 0.46$ & $1.8 \pm 0.11$ & $0.2 \pm 0.05$ \\
\hline \multicolumn{2}{|c|}{ IS (mM) } & $9.5 \pm 0.60$ & $11.9 \pm 0.90$ & $6.2 \pm 0.50$ \\
\hline
\end{tabular}

LSH, loamy soil with high organic matter content; LSL, loamy soil with low organic matter content; $\mathrm{OM}$, organic matter; IS, ionic strength and CEC, cation exchange capacity.

\subsubsection{Chemicals}

AgNPs: The AgNPs used consisted of an aqueous suspension of citrate-stabilized spherical AgNPs from NanoComposix (Prague, Czech Republic). The particle diameter was $60 \mathrm{~nm}$ and the particle mass concentration in the aqueous suspension was $1000 \mathrm{mg} \mathrm{L}^{-1}$.

Potassium bromide $(\mathrm{KBr})$ : a $\mathrm{KBr}$ solution with a concentration of $0.0167 \mathrm{M}$ was purchased from Fisher Scientific (Landsmeer, The Netherlands). $\mathrm{KBr}$ was used as an inert tracer in the experiments.

\subsubsection{Experimental method}

This column experiment was conducted in the soil physics laboratory of Wageningen University, the Netherlands. There were 3 replicates for each soil type and time period (24, 48 and 72 hours), resulting in a total of 27 columns. Analyses of samples collected from the soil columns and leachate (effluent water) was performed at RIKILT Wageningen University and Research, the Netherlands. Figure 3.1, shows a schematic overview of the experimental design, and a flow chart of the steps taken during the experiment. 


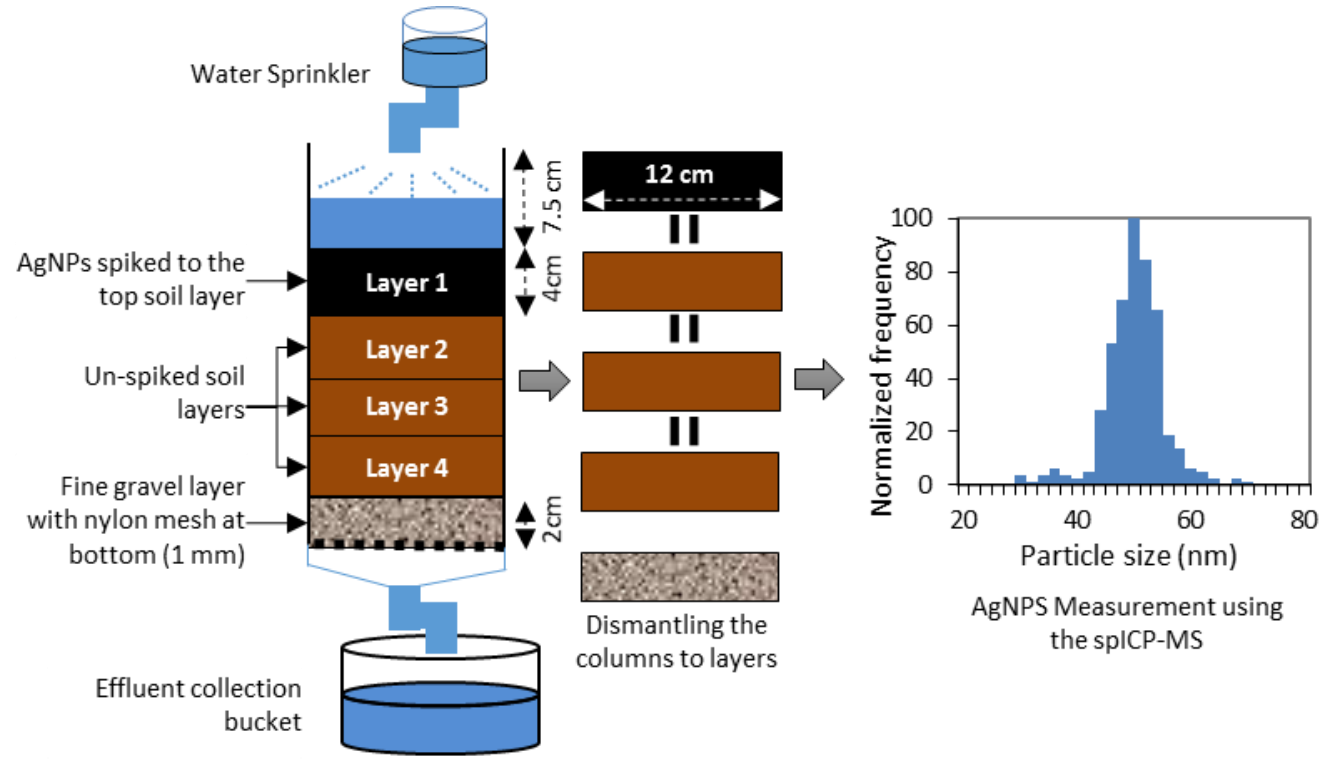

Figure 3.1 The experimental design of the column experiments.

\subsubsection{Set-up of soil columns}

Soil column preparation: The experiment was conducted using a series of polyethylene (PE) hydraulic soil columns with a diameter of $12 \mathrm{~cm}$ and depth of $25.5 \mathrm{~cm}$. The bottom of each column was covered with a thin nylon mesh with apertures $(<1 \mathrm{~mm})$. Prior to the experiment, all soil types used (LSH, LSH and Sand) were air dried at room temperature (for 7 days) and sieved using sieve \#5 (apertures size is $4 \mathrm{~mm}$ ) to keep the soil properties close to the initial soil.

Before filling the columns with soil, a $2 \mathrm{~cm}$ layer of fine gravel $(2-4 \mathrm{~mm})$ was added to the bottom (to work as a filter for soil particles from the column). Then, each column was filled up to $12 \mathrm{~cm}$ of soil representing 3 layers (each layer $\pm 4 \mathrm{~cm}$ ). During adding the soil, the column wall was gently tapped to minimize air entrapment and to achieve homogenous soil packing. With the 3 lower soil layers in place, the columns were saturated by 3 pulses of RW. Finally (after $24 \mathrm{hrs}$ ), a top layer spiked with AgNPs was added as layer 1 ensuring that it had the same moisture content as the other soil layers in the soil column.

Rainwater pulses: RW was applied to the top of the columns in pulses. Each pulse equalled 1 pore volume (PV) of the soil in the particular column. PV was determined from the total porosity of the soil samples which was considered to be equal to volumetric soil water content at saturation. Therefore, to bring the soil in a column to the saturation level, a volume of water equal to the difference between dry moisture and the saturation level 
would be necessary. The calculated porosities of LSH and LSL soil columns, were not signifacantly different .So a fixed, $42.2 \%$, PV value was used equal to the average pore volume of these soils. To avoid problems related to inconsistent calculation of the AgNPs concentration collected from different columns, this PV amount was also applied to the sand columns.

RW was applied using an inverted volumetric flask fixed above the column and connected to a sprinkler. RW application rate was such that a stable amount of water on the top layer was maintained. Following addition of the AgNPs spiked soil to the columns, 1 RW pulse was applied per day during the experiment.

Bromide tracer breakthrough check: To confirm that the column setup was functioning well, bromide ( $\mathrm{Br}$ ) was used as a soluble conservative tracer to test breakthrough volumes. Breakthrough data is an indicator of the hydrodynamic properties of the soil column.

Three columns for each soil type were tested before the experiment. The columns, were prepared in the same manner as described above with the exception that the top layer (layer 1 ) was not spiked with AgNPs. Each column was first saturated by applying 3 RW pulses. Then 3 pulses containing $20 \mathrm{mg} \mathrm{L}^{-1} \mathrm{Br}$ were applied followed by another 3 pulses $\mathrm{RW}$ to remove all $\mathrm{Br}$ from the column. Bromide concentrations were detected using an inductively coupled plasma mass spectrometer (ICP-MS) in standard mode (Creed et al., 1996). A schematic flow chart depicting the steps during the experiment is shown in Figure 3.2 .

\subsubsection{AgNPs application}

The AgNPs-spiked soil that was added to the columns (as layer 1 ) was prepared by diluting AgNPs stock solution to get a net concentration of $50 \mu \mathrm{g} \mathrm{kg}^{-1}$ with avgerage particle size equal to $\pm 60 \mathrm{~nm}$. MilliQ water (MQW) produced by an Ultrapure Water system from Millipore (Amsterdam, The Netherlands) was used for diluting AgNPs spikes, the collected AgNPs samples and to prepare all other additional chemicals. AgNPs spike solutions (in volumes equal to $1 \mathrm{PV}$ ) were mixed with the dry-sieved soil ( $\pm 400 \mathrm{~g}$ ) for soil layer 1 which was then saturated to match the saturation of the other soil layers in the column. As previously noted, the soil spiked with AgNPs was added as the top soil layer (layer 1) for each column. After addition of this layer, the columns were left in the dark to equilibrate for $24 \mathrm{hrs}$.

\subsubsection{Sample collection and characterisation}

Sample collection: During the experiment collection of the effluent water (EW) containing leached AgNPs was started after adding each RW pulse to a column and continued for 24 
hrs. For column series 1 (C24) only 1 volume of EW was collected, for column series 2 (C48) $2 \mathrm{EW}$ volumes were collected and for column series 3 (C72) 3 were collected. EW samples were collected using dark-glass flasks and stored at room temperature.

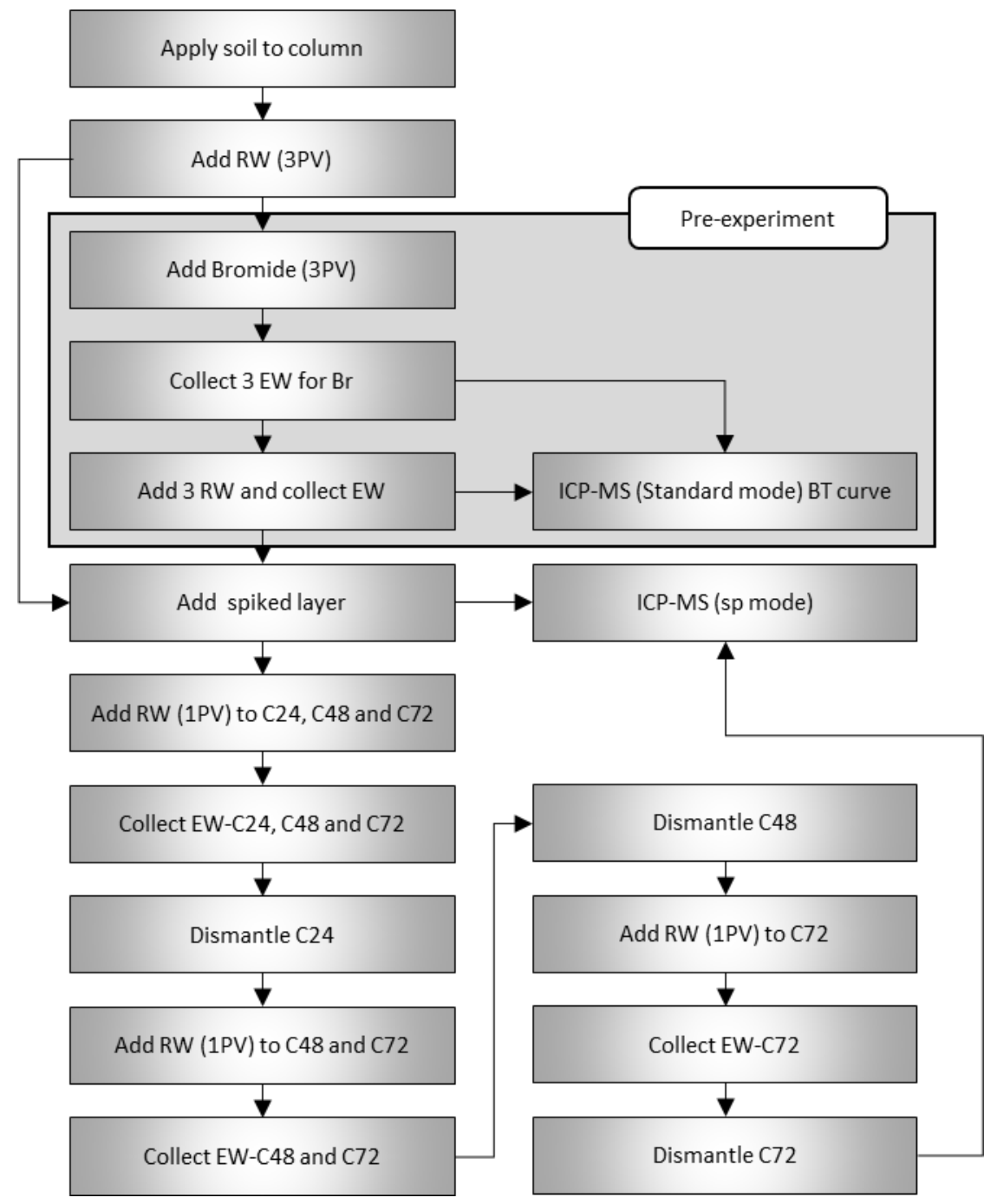

Figure. 3.2 Schematic flow chart of the steps in the experiment. RW is rainwater, PV is pore volume, EW is effluent water, $C$ is column series, the numbers 24,48 and 72 depict the residence time in the column. The flow chart represents one replicate for one soil type.

Soil samples were collected from the dismantled columns. Column series 1 (C24) was dismantled after $1 \mathrm{RW}$ pulse ( $24 \mathrm{hrs}$ ), column series 2 (C48) was dismantled after $2 \mathrm{RW}$ 
pulses (48 hrs) and column series 3 (C72) was dismantled after applying 3 RW pulses (72 hrs).

Columns were carefully dismantled and sliced into the four layers 1 to 4 , each $4 \mathrm{~cm}$ thick. Each individual soil slice was homogenized and 3 sub-samples $<10 \mathrm{~g}$ were collected for the determination of AgNPs, resulting in 36 samples per soil type. For soil property determination, 3 samples per soil layer (weight of the sample $<50 \mathrm{~g}$ ) were taken, totalling 12 samples per soil type.

Other samples like RW, initial soil, and AgNPs concentration control samples were measured simultaneously with the samples (soil and EW) containing AgNPs from the columns to get a clear image for AgNPs concentration and particle size calculations. In total, more than 100 soil and liquid (EW or RW) samples were collected for each soil type for AgNPs detection and soil characterisation.

Soil property characterization: Soil characteristics were determined both before the experiments (Table 3.1) and after dismantling the columns. Soil texture for the three soil types was analysed using laser diffraction technique at the University of Leuven (Leuven, Belgium). Soil pH was measured by using a portable probe (WTW pH 340) obtained from WTW company (Weilheim, Germany). CEC $\left(\mathrm{Ca}^{+2}\right.$ and $\left.\mathrm{K}^{+}\right)$were analysed by NIRs (near infrared spectroscopy) based on 0,0166 M cobalthexamine trichloride (ISO 1994) in the Coimbra College of Agriculture (Coimbra, Portugal). IS was derived directly from the electrical conductivity (EC) using the formula of the linear approach method (aqion, 2016). EC itself was measured using a portable probe WTW pH 340i (WTW, Weilheim, Germany). Organic matter (OM) content was measured according to the standard ASTM method (ASTM, 2000).

AgNPs quantification: AgNPs were quantified for concentration and characterised for particle size in soil samples and EW. AgNPs in soil samples were first extracted using the aqueous extraction method as described by (Mahdi et al., 2016). In EW, AgNPs were extracted by settling and dilution to remove the leached-out soil particles and OM.

After extraction, AgNPs samples were measured for concentration and particle size using the single particle inductively coupled plasma mass spectrometry method (spICP-MS). The inductively coupled plasma mass spectrometer (ICP-MS) used to perform the spICP-MS was a Thermo Scientific Xseries-2 from (Massachusetts, USA). The instrument and technical settings for spICP-MS have been described previously by Peters et al. (2015). All measurements were performed at RIKILT Wageningen University \& Research (Wageningen, the Netherlands). 


\subsubsection{AgNPs mass balance calculations}

The mass balance for the AgNPs transported in the soil columns was calculated based on the initial amount applied to layer 1 of each column, and the final AgNPs content found in the soil layers (1, 2,3 and 4), and the effluent water after each rainwater application. The total mass balance was calculted for AgNPs content at the end of the 3 times of rain application for all soil layers and EW samples were expressed in $\mu \mathrm{g}$ and comaperd with intial AgNPs contents applied.

\subsection{Results}

\subsubsection{Soil layer characterization}

After the experiment, each soil layer was used to assess the selected soil properties. The results shown in Table 3.2 indicate that the soil properties in all soil layers were more or less identical. So, no significant differences were found between the soil layers for $\mathrm{pH}, \mathrm{OM}, \mathrm{CEC}$ and IS.

Table 3.2 Average soil characteristics in the soil column layers $(n=5)^{*} \pm$ st.dev.

\begin{tabular}{llllll}
\hline Soil & $\mathrm{pH}(\mathrm{KCl})$ & $\mathrm{OM}(\mathrm{W} . \%)$ & \multicolumn{2}{l}{$\mathrm{CEC}\left(\mathrm{meq} 100 \mathrm{~g}^{-1}\right)$} & IS (mM) \\
\cline { 4 - 5 } & & & $\mathrm{Ca}{ }^{+2}$ & $\mathrm{~K}^{+}$ & \\
\hline LSH-1 & $7.3 \pm 0.3$ & $3.2 \pm 0.11$ & $4.1 \pm 0.14$ & $0.128 \pm 0.13$ & $0.9 \pm 0.06$ \\
LSH-2 & $7.4 \pm 0.2$ & $3.1 \pm 0.10$ & $3.4 \pm 0.12$ & $0.190 \pm 0.09$ & $1.2 \pm 0.5$ \\
LSH-3 & $7.4 \pm 0.1$ & $3.2 \pm 0.14$ & $3.4 \pm 0.02$ & $0.185 \pm 0.11$ & $1.0 \pm 0.14$ \\
LSH-4 & $7.3 \pm 0.1$ & $4.0 \pm 0.05$ & $3.3 \pm 0.04$ & $0.220 \pm 0.11$ & $1.3 \pm 0.44$ \\
\hline LSL-1 & $6.3 \pm 0.1$ & $1.3 \pm 0.15$ & $1.8 \pm 0.09$ & $0.054 \pm 0.02$ & $1.2 \pm 0.10$ \\
LSL-2 & $6.4 \pm 0.3$ & $1.7 \pm 0.17$ & $1.5 \pm 0.03$ & $0.069 \pm 0.07$ & $1.1 \pm 0.11$ \\
LSL-3 & $6.1 \pm 0.1$ & $1.7 \pm 0.41$ & $1.4 \pm 0.01$ & $0.071 \pm 0.12$ & $1.3 \pm 0.08$ \\
LSL-4 & $6.2 \pm 0.1$ & $1.6 \pm 0.36$ & $1.4 \pm 0.03$ & $0.081 \pm 0.18$ & $1.4 \pm 0.22$ \\
\hline Sand-1 & $7.7 \pm 0.3$ & $0.6 \pm 0.17$ & $0.4 \pm 0.11$ & $0.014 \pm 0.10$ & $0.6 \pm 0.06$ \\
Sand-2 & $7.2 \pm 0.2$ & $0.1 \pm 0.15$ & $0.6 \pm 0.13$ & $0.009 \pm 0.14$ & $0.5 \pm 0.04$ \\
Sand-3 & $7.1 \pm 0.1$ & $0.2 \pm 0.09$ & $0.4 \pm 0.05$ & $0.008 \pm 0.01$ & $0.5 \pm 0.05$ \\
Sand-4 & $7.5 \pm 0.2$ & $0.1 \pm 0.15$ & $0.3 \pm 0.05$ & $0.008 \pm 0.03$ & $0.4 \pm 0.05$ \\
\hline
\end{tabular}

$\mathrm{LSH}$, loam soil with high organic matter; LSL, Loam soil with low organic matter; Sand, sandy soil with no organic matter, OM, soil organic matter; CEC, cation exchange capacity; IS, Ionic strength; numbers (1-4), soil column layer (1=top layer and 4=bottom). Different lowercase letters indicate the significant differences $(p<0.05)$ between soil layers for the same soil column. 


\subsubsection{Performance of soil columns}

The bromide tracer experiment revealed different breakthrough curves (see Figure 3.3). Columns packed with sand showed the fastest and highest breakthrough, and columns packed with LSL the slowest and lowest. Breakthrough curves of LSH showed an intermediate pattern.

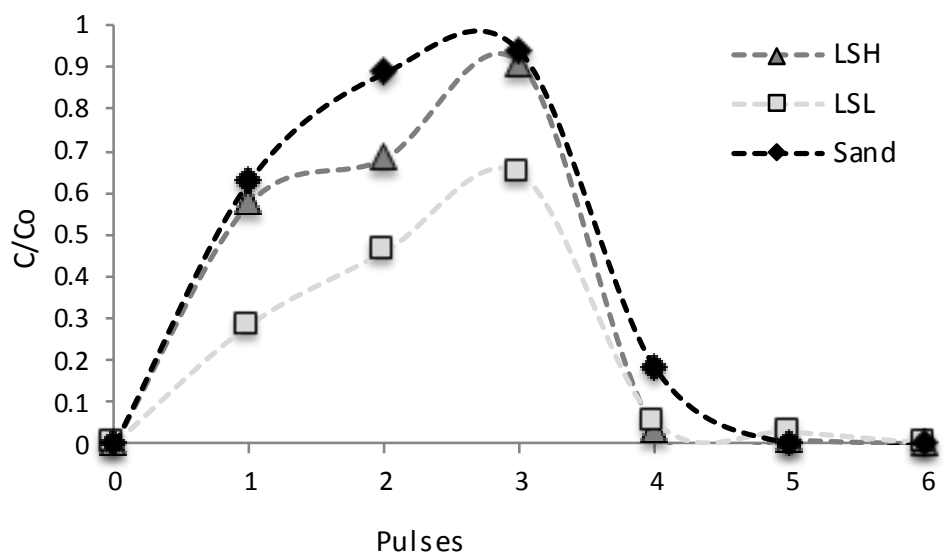

Figure 3.3 Breakthrough curves for bromide in the soil columns. LSH, column packed with loam soil with high organic matter; LSL, column packed with loam soil with low organic matter; Sand, column packed with sand. $\mathrm{C} / \mathrm{Co}$ is ratio of the detected concentration of $\mathrm{Br}$ to the initially applied concentration. The first 3 pulses contained $\mathrm{Br}\left(20 \mathrm{mg} \mathrm{L}^{-1}\right)$ and the others (4, 5 and 6) only rain water.

\subsubsection{AgNPs transport in the soil columns}

\subsubsection{AgNPs concentration in the soil layers}

The levels of AgNPs detected in the soil layers are shown in Figure 3.4. In the columns packed with LSH, there was very limited AgNPs transport after 24 hrs as less than $1 \mu \mathrm{g}$ AgNPs was detected in each of soil layers 2 and 3, almost none in layer 4, while $20 \mu \mathrm{g}$ of the initially applied AgNPs remained in layer 1 . After $48 \mathrm{hrs}$, there was very little change in the transport of AgNPs compared with the $24 \mathrm{hr}$ results. However, after $72 \mathrm{hrs}$, AgNPs content increased in layers (2, 3 and 4); the detected amount in layer 2 increased to $2 \mu \mathrm{g}$, in layer 3 to $0.7 \mu \mathrm{g}$ and in layer 4 to more than $1.5 \mu \mathrm{g}$ while AgNPs in layer 1 was reduced to $15 \mu \mathrm{g}$.

In the columns packed with LSL, the highest AgNPs content was also found in layer 1 . However, AgNPs detected in the soil layers 2, 3 and 4 were substantially higher than in the columns packed with LSH for all 3 times (24, 48 and 72). The transported AgNPs to the layers 2, 3 and 4 was the highest after 24 hrs and, then decreased with time. Further, AgNPs 
content in layer 2 after 24 hrs was $6.2 \mu \mathrm{g}$ which was higher than the AgNPs content in layers 3 and 4. However, after 72 hrs AgNPs content in layer 2 decreased to just $1.6 \mu \mathrm{g}$ which was lower than the AgNPs detected in layer 4.

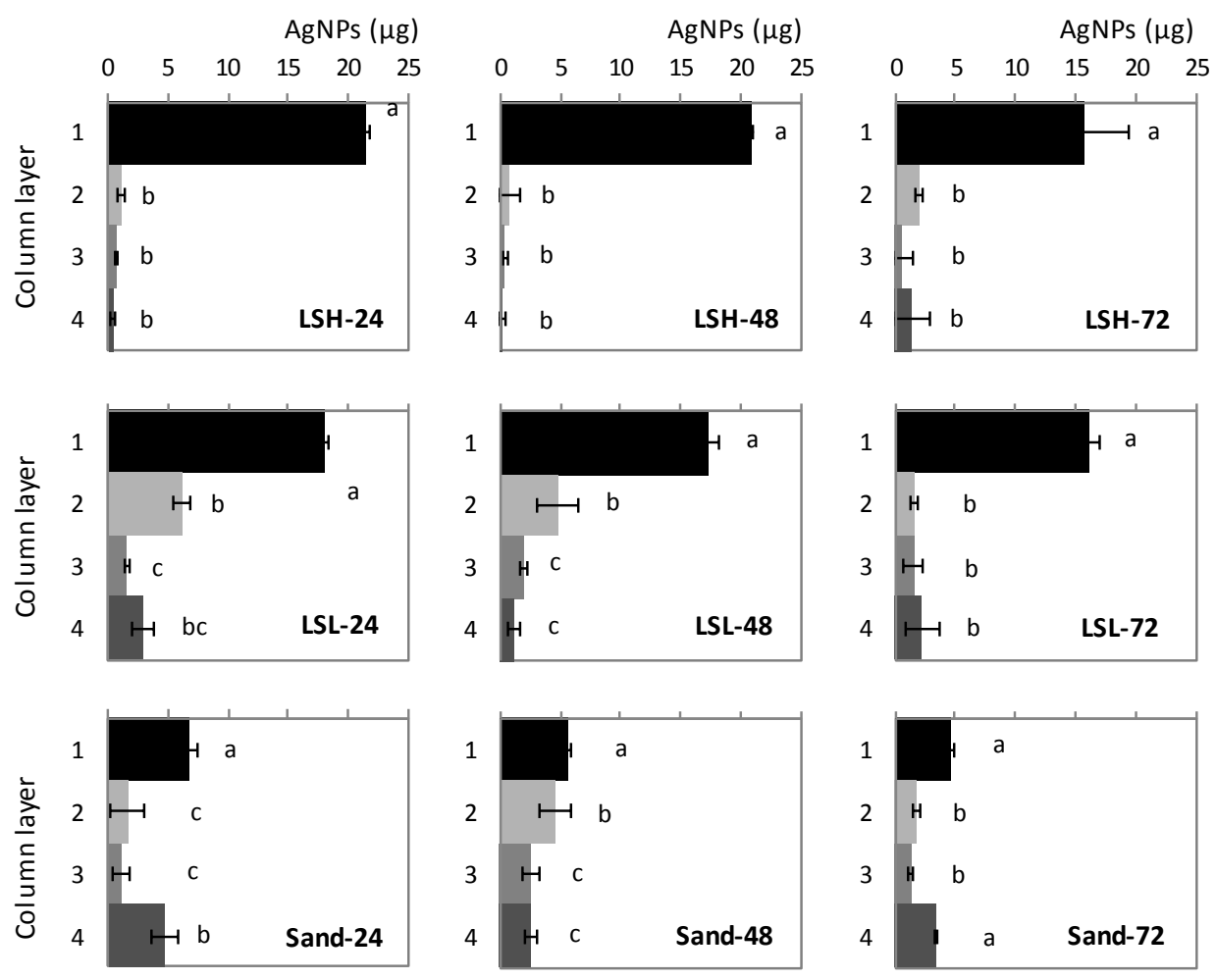

Figure. 3.4 AgNP content in soil columns after conclusion of the experiment. LSH, columns packed with loam soil with high organic matter; LSL, columns packed with loam soil with low organic matter, and Sand, columns packed with sandy soil; the numbers (24, 48 and 72 ) refer to the residence time of the AgNPs in the soil columns, and the time when they were dismantled to layers. Different lowercase letters indicate the significant differences $(p<0.05)$ of AgNPs content between soil layers for the same soil column.

In columns packed with sand, the AgNPs transport pattern was different than that found in the columns of soils LSH and LSL columns. In the sand columns, layer 1 retained less AgNPs indicating that more AgNPs was transported to the deeper layers. After $24 \mathrm{hrs}$, AgNPs content in layer 1 was $6.8 \mu \mathrm{g}$ and in layer 4 it was $4.8 \mu \mathrm{g}$ while in layers 2 and 3 the content was $1.6 \mu \mathrm{g}$ and $1.1 \mu \mathrm{g}$ respectively. After $48 \mathrm{hrs}$, AgNPs content in layers 2 and 3 increased to $4.5 \mu \mathrm{g}$ in layer 2 and $2.6 \mu \mathrm{g}$ in layer 3 while it dropped to 5.5 in layer 1 and 2.5 in layer 4 . After $72 \mathrm{hrs}$, AgNPs content in all layers decreased except in layer 4 as in layer 1 it was $<5$ $\mu \mathrm{g}$, in layers 2 and 3 was $<2 \mu \mathrm{g}$ while in layer 4 it was $3.4 \mu \mathrm{g}$. Further, in several soil columns, we noticed a significant difference between AgNPs content in layer 4 and layers 2 and/or 3, 
this due to AgNPs filtration problems from soil to gravel layers which also the case in real scenarios (Kumahor et al., 2016).

\subsubsection{AgNPs content in the effluents (EW)}

The results for the levels of AgNPs detected in effluent water (EW) are shown in Figure 3.5. In the EW from columns packed with LSH, less than $1 \mu \mathrm{g}$ AgNPs was detected for each of the 3 collection times (24, 48 and 72 hrs). The total AgNPs content in EW from these columns $(2.2 \mu \mathrm{g})$ was the lowest of the totals from all three soil types.

For columns packed with LSL, AgNPs content detected in EW collected was highest after 24 hrs $( \pm 1.8 \mu \mathrm{g})$ and then decreased significantly in the EW collected at 48 and $72 \mathrm{hrs}$, with only $\pm 0.3 \mu \mathrm{g}$ detected at $72 \mathrm{hrs}$.

Similar to the results for the EW from the LSL columns, the AgNPs content in EW from the sand columns was highest after the 24 hrs collection and then decreased in the EW collected after 48 and 72 hrs. However, the amount detected after 24 hrs was greater than that detected in the LSL EW, making the total AgNPs content collected from the sand EW the highest among all soil types.

Overall the AgNPs content in the EW increased from fine textured to coarse textured soil. As expected there was an inverse relationship between OM and the AgNPs detected in the EW. A similar relationship existed for CEC.

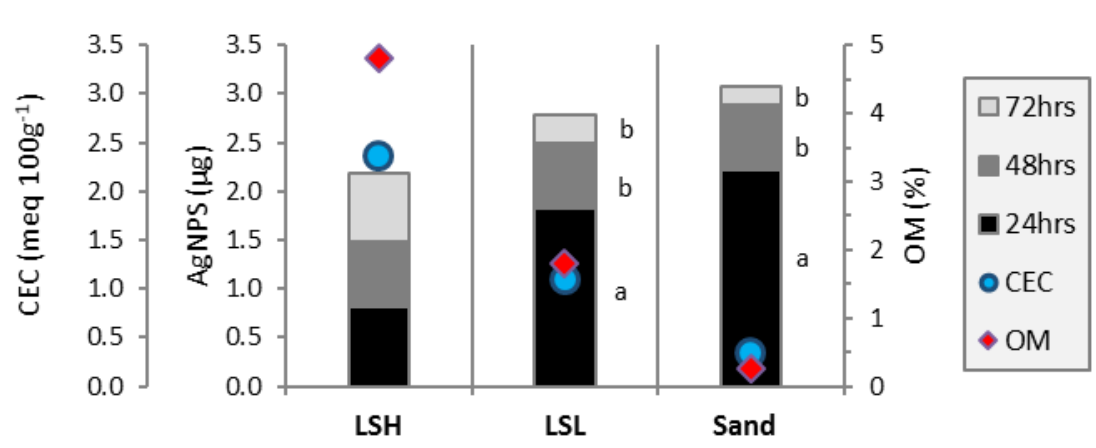

Figure 3.5 AgNPs content detected in effluent water. LSH, columns packed with loam soil with high organic matter; LSL, columns packed with loam soil with low organic matter; Sand, columns packed with sandy soil; $O M$, organic matter (represented by the secondary $Y$-axis); and CEC, cation exchange capacity calculated for $\mathrm{Ca}^{+2}$ and $\mathrm{K}^{+}$. Different lowercase letters indicate the significant differences $(p<0.05)$ of AgNPs content in the 3 collection times of $E W$. 


\subsubsection{Particle size tracking in the columns and effluent}

The particle size of the AgNPs decreased continuously in the soil column layers as particles moved from the top to the bottom layers as shown in Figure 3.6. This was true for all soil types, although the amount of change differed between soils. In the LSH and LSL columns, AgNPs particle size in layers 3 and 4 was reduced by $60-70 \%$ after $72 \mathrm{hrs}$ of AgNPs residence time in the columns. In sand columns, the particle size reduction was $40-50 \%$ after $72 \mathrm{hrs}$.

In the EW, AgNPs particle sizes are generally larger than the ones found in soil layers 2 to 4, indicating existence of flood paths facilitating rapid transport of particles from layer 1 to the effluent water. In the sand columns particle size decreased the least.
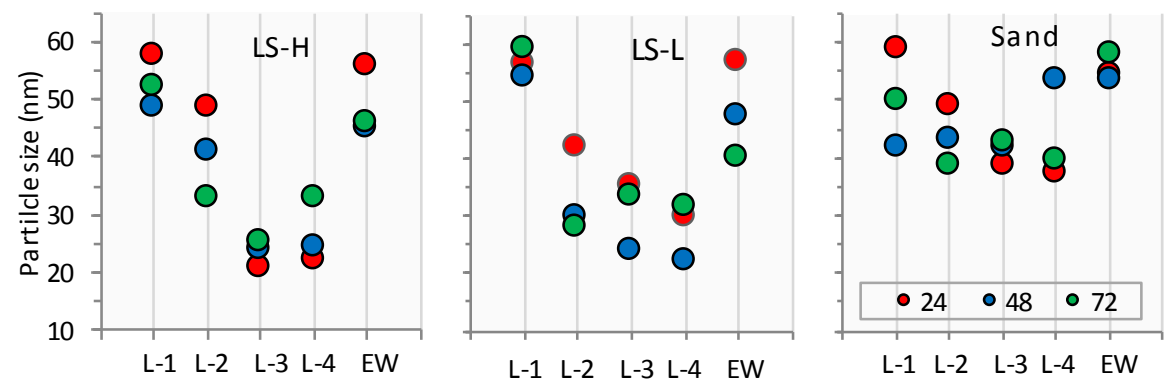

Figure 3.6 AgNPs particle size in the columns. $L S H$, columns packed with loam soil with high organic matter; $L S L$, columns packed with loam soil with low organic matter column; Sand, columns packed with sandy soil. (L-1 to L-4), soil layers; EW, column effluent; the numbers (24, 48 and 72$)$ refer to the time of soil column dismantling and the time to collect the effluent.

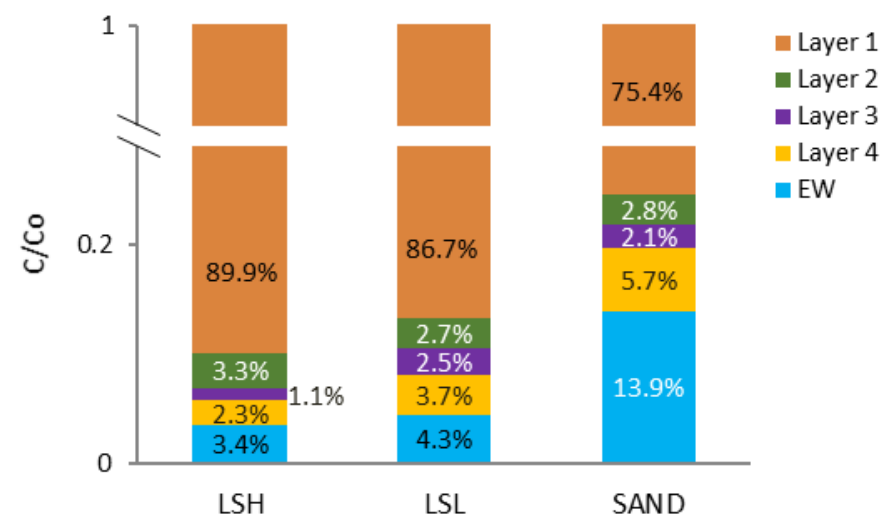

Figure 3.7 Total transported amount of AgNPs in the soil columns' layers and in the effluents. C/Co is the ratio of the initial applied AgNPs concentration to the detected concentration; LSH, columns contain loam soil with high organic matter; LSL, columns contain loam soil with low organic matter column; SAND, columns contain sandy soil. EW, the column effluents accumulated for the three times of collection. 


\subsubsection{Total AgNPs transported through the soil columns}

As shown in Figure 3.7, the total amounts of AgNPs transported from layer 1 to layers 2-4 and EW were $10.1 \%, 13.3 \%$ and $24.6 \%$ of the initial applied AgNPs in the LSH, LSL and Sand columns respectively.

\subsection{Discussion}

AgNPs transport patterns differ per soil and per layer as a result of differences in amongst others OM, CEC and soil texture.

In the columns packed with LSH, AgNPs found after 24 and $48 \mathrm{hrs}$ was $\pm 1 \mu \mathrm{g}$ in layer 2 and $<1 \mu \mathrm{g}$ in layers 3 and 4 . However, after $72 \mathrm{hrs}$, the amount of AgNPs detected had increased in all layers, especially in layers 2 and 4 where it increased to more than $1.5 \mu \mathrm{g}$ in each layer. The retardation of AgNPs transport was due to the fine texture of LSH (compared to LSL and Sand) and the related high organic matter and CEC content. Fine textured soil and high OM and CEC are known to increase AgNPs adsorption on soil particles (Sagee et al., 2012; Coutris et al., 2012; Liang et al., 2013a).

In the columns packed with LSL, AgNPs transport after applying the first RW pulse (samples collected after $24 \mathrm{hrs}$ ) was substantial, causing relatively high concentrations in deeper soil layers and effluent water. LSL is less fine textured than $\mathrm{LSH}$, reducing the adsorption potential of AgNPs on soil particles, and thus increasing AgNPs mobility (Shoults-Wilson et al., 2011b). Further, the lower OM and CEC in LSL increased AgNPs mobility as OM can retard AgNPs mobility by coating the Ag particles, and the lower CEC content can reduce cation bridging (Liang et al., 2013a). After 48 and 72 hrs only small differences in the AgNPs content of layers 2 and 3 were noticed, and they had almost the same content after 72 hrs.

In the columns packed with sand the AgNPs transport pattern was fast and unstable due to its coarse texture. Our findings confirm what has been reported by others (Sagee et al., 2012; Liang et al., 2013b). In addition, there was no retardation to AgNPs transport as OM and CEC were also low. In addition, the low IS content also enhanced AgNPs transport due to the compression of the electric double layer (Liang et al., 2013a). 


\subsubsection{AgNPs concentration in the effluents water}

As with the distribution of AgNPs in the soil layers, AgNPs content in EW was influenced by soil texture, OM and CEC. As a result coarse textured media with low OM content showed most rapid and distinct transport of AgNPs towards the bottom of the columns, and high concentrations in effluent water.

\subsubsection{Particle size distribution}

AgNPs particle sizes in the soil layers and in the EW were also monitored during the transport process. Particle size of AgNPs has been linked in many studies to the potential toxicity impact of AgNPs, with smaller particles expected to have a higher toxicity (Pal et al., 2007; Kim et al., 2012; Silva et al., 2014). In general, our results showed that AgNPs particles became smaller as they moved through the soil over time and their new size depended on the soil type and soil depth. Figure 3.6, shows some differences in the AgNP sizes inside each individual column for layers 2, 3 and 4 but they were not significant. However, particles size differences for AgNPs retained in these layers and AgNPs in layer 1 and in EW were significant.

In the columns packed with LSH and LSL soils, AgNPs particle sizes decreased with time and depth due to chemical interaction with the soil particles. In the columns packed with Sand the AgNPs particle sizes were more stable than in the LSH and LSL columns. While most of the particle size decrease occurred in the lower layers, some also occurred in layer 1 . The AgNPs concentration in layer 1 was far higher than in the other layers so the dissolution of AgNPs was less.

Yin et al. (2015a) reported that AgNPs particle size decrease is related to the AgNPs properties (initial concentration, coating, particle size, etc.) and to the receiving soil medium ( $\mathrm{pH}, \mathrm{IS}, \mathrm{CEC}, \mathrm{OM}$, soil type and soil particle distribution). In this study only one type and one particle size of AgNPs was used so differences in AgNPs particle sizes in this study are expected to have been the effect of soil characteristics. In general, AgNPs particle size decrease occurs directly after AgNPs is mixed with water due to dissolving of $\mathrm{Ag}_{2} \mathrm{O}$ which enhances the $\mathrm{Ag}^{+}$release (Sotiriou et al., 2012). Our results showed that $\mathrm{Ag}$ particle size in the soil layers were subjected to more dissolving than in the EW. The reason for that is AgNPs mobility in the columns packed with LSH and LSL soils was restricted due to the presence of $\mathrm{OM}$ and larger amounts of the fine textured particles (clay and silt) compared to sand. This caused the AgNPs to be trapped in the pore voids of soil. This trapping also led 
to increased interaction between AgNPs and soil particle reactive compounds like OM and CEC.

In EW, AgNPs were transported "mostly" directly from layer 1 (where the AgNPs was applied) to the outlet which means less effect on particle size from CEC or OM than what occurred in the soil layers. This was verified by following the time scans of $\mathrm{Ag}^{+}$signal in ICPMS. In the time scan for layers 2, 3 and 4 of all columns, where AgNPs particle size decrease was higher than in layer 1 , the higher signal of $\mathrm{Ag}^{+}$meant that a higher dissolution rate occurred. However, in layer 1 and EW, AgNP size decreased less and the $\mathrm{Ag}^{+}$signal was less. This verifies that AgNPs in EW were mostly leached directly from layer 1.

\subsection{Conclusion and recommendations}

- $\quad$ AgNPs have been confirmed to be transported with water in soil columns which can lead to retention in deeper soil layers and leaching with effluent water despite low (initial) concentration applied. This may cause pollution.

- The detection of AgNPs in soil layers and in the effluents confirms the potential risk of contamination resulting from AgNPs application to soil.

- $\quad$ AgNPs retention in soil is affected by soil OM, and AgNPs particle size was affected by the CEC of soil.

- $\quad$ The spICP-MS method allowed detecting the AgNPs particle size in soil layers and in the effluents which revealed that AgNPs in the effluent were more stable in size than in the soil layers, which at the end may impact receiving water bodies.

- $\quad$ Besides, that AgNPs can be transported through soils, it also might be redistributed by runoff and erosion processes in undulated areas due to its strong adsorption to soil particles.

- Further research is needed on the transport of AgNPs in soil considering lower concentrations of applied AgNPs, other AgNPs particle sizes and other types of soil to assess the difference in transport dynamics and potential toxicity of the transported AgNPs on different soil species and plants.

\section{Acknowledgements}

We would like to thank the Soil Physics and Land Management laboratory and RIKILT, for their contribution and for the use of their facilities and devices for executing the experiments. Many thanks to Demie Moore for suggestions regarding the English editing. We also thank the Higher Committee for Education Development in Iraq for their financial support. 


\title{
4. Transport of silver nanoparticles by runoff and erosion - A flume experiment
}

\begin{abstract}
Silver nanoparticles (AgNPS) are being used in many products as they have unique antimicrobial-biocidal properties. After disposal of these products AgNPs can reach the soil environment. This work aimed to study the transport of AgNPs by water and sediment during overland flow and soil erosion. This was done in a laboratory setting, using a flume and rainfall simulator. A low concentration of AgNPs (50 $\left.\mathrm{g} \mathrm{kg}^{-1}\right)$ was applied to two soilflumes with slope percentages of $10 \%$ and $20 \%$. The rainfall was applied in four events of 15 min each with a total amount of rainfall of $15 \mathrm{~mm}$ during each event. After applying the rainfall, samples of the non-transported background soil and the transported sediment were collected from the flume surface. Runoff sediment and water were collected from the outlet. AgNPs were detected in all samples collected. However, concentration varied according to sample type (soil or water), time of collection (for runoff water and sediment) and the slope of the soil flume. Higher concentrations of AgNPs were detected in the background soil than in the transported sediment likely due to the fact that the background soil contains more fine particles (silt and clay). The AgNPs concentration in the runoff sediments increased with subsequent applied rain events. In addition, increasing the slope of the flume from 10\% to 20\% increased the total AgNPs transported with the runoff sediment by a factor 1.5. The study confirms that AgNPs can be transported by both overland flow and sediment transport due to erosion.
\end{abstract}

Based on:

K.N.M. Mahdi, M.C. Commelin, R.J.B. Peters, J.E.M. Baartman, C.J. Ritsema, V. Geissen. 2016. Transport of silver nanoparticles by runoff and erosion - A flume experiment. Science of The Total Environment 601-602:1418-1426. 


\subsection{Introduction}

According to the Scientific Committee on Emerging and Newly Identified Health Risks (SCENIHR), nanomaterials are defined as materials that are smaller than $100 \mathrm{~nm}$ in at least one dimension (SCENIHR, 2007). For many industries, nanomaterials are very promising, hence the number of nanotechnology based applications is growing swiftly (Yu et al., 2013). A recent study expects the global nanotechnology market to grow to US\$ 75.8 billion by 2022 (Businesswire 2015). Silver nanoparticles (AgNPs) are a nanomaterial that is used in a wide range of applications (Lombi et al., 2014) and the number of products that contain AgNPs are three times higher than the number of products containing nano-titanium or nano-carbon (Kaegi et al., 2010). This is because AgNPs have unique antimicrobial, catalytic, optical, electronic and magnetic properties (Liu and Jiang, 2015). As a result, AgNPs are used in medical applications (Chen and Schluesener, 2008), textiles (Benn and Westerhoff, 2008), cosmetics (Liu and Jiang, 2015), food and agriculture (Peters et al., 2016), food packaging (Echegoyen, 2015) and drinking water purification (Lin et al., 2013).

As more AgNPs based products are being produced, used and discarded, more AgNPs will be released into the environment (Bystrzejewska-Piotrowska et al., 2009; Fabrega et al., 2011; Luoma, 2008; Yin et al., 2015b). AgNPs can reach the soil environment through various pathways; the application of fertilizers that contain AgNPs (Batley et al., 2013), the application of sewage sediments as soil amendments (Schlich et al., 2013b), the disposal of biosolids (Benn and Westerhoff, 2008), wastes (Yin et al., 2015b), unintended spills of materials containing AgNPs (Yin et al., 2015a) or through the leaching of AgNP-containing products (Kaegi et al., 2010). After being released to the soil, AgNPs may be affected by soil physical processes as they might be redistributed by surface runoff (Kaegi et al., 2010), or transported downwards to ground water systems (Sagee et al., 2012). Also chemical changes can happen as the released AgNPs might dissolve into Ag ions (Yu et al., 2013). While these materials have beneficial properties, there is also some concern about their long-term environmental impact and little is known about their exact pathways in the environment. The toxicity of AgNPs has been examined in a study with pristine AgNPs applied to soil (Allen et al., 2010), and also in long-term toxicological studies which included transformation products of AgNPs, such as $\mathrm{Ag}_{2} \mathrm{~S}$ and ionic $\mathrm{Ag}$ (Schlich et al., 2013a). AgNPs in soil were found to disturb plant growth (Dimkpa et al., 2013) and negatively affect soil organisms (Zhou et al., 2015). In view of the increasing use of AgNPs, it is expected that they will have an increasingly important impact on the environment and possibly on human health also (Anjum et al., 2013).

In order to assess the effects of AgNPs in the soil, knowledge about their transport mechanisms is needed. While numerous studies have considered AgNPs in the 
environment, very limited information is available about their fate and transport in soil (Yin et al., 2015a; Yu et al., 2013). In fact, information about the surface transport of particulate pollutants of any kind in soil is rare. However, many studies have been conducted on the transport of chemicals (i.e. pesticides or heavy metals) after soil application. These studies identified various factors and conditions that can be instrumental in the surface transport of chemicals in soils. For example, heavy rain after glyphosate application increased glyphosate surface transport (Candela et al., 2010), the transport of glyphosate due to erosion in Chinese loess soils was affected by the soil slope (Yang et al., 2015), and there was a correlation between concentrations of heavy metals in surface runoff and the concentration of heavy metals deposited in the soil (He et al., 2004). Therefore, the aim of this study is to investigate the transport of AgNPs associated with runoff and erosion using a soil-flume experimental setup.

\subsection{Materials and Method}

\subsubsection{Materials}

\subsubsection{Chemicals and solvents}

An aqueous suspension of citrate-stabilized spherical silver nanoparticles (AgNPs) with a diameter of $60 \mathrm{~nm}$ and a mass concentration of $1000 \mathrm{mg} \mathrm{L}^{-1}$ was purchased from NanoComposix (Prague, Czech Republic).

For determination of the transport efficiency in the inductively coupled plasma mass spectrometry (ICP-MS) system, a citrate-stabilized aqueous suspension of $60 \mathrm{~nm}$ spherical gold nanoparticles (RM 8013) with a mass concentration of $50 \mathrm{mg} \mathrm{L}^{-1}$ was purchased from the National Institute of Standards and Technology (NIST) (Gaithersburg, US).

For the AgNPs calibration measurements an ionic silver standard with a concentration of $100 \mathrm{mg} \mathrm{L}^{-1}$ was purchased from Merck (Darmstadt, Germany). A Milli-Q Plus Ultrapure Water system from Millipore (Amsterdam, The Netherlands) was used to produce purified Milli-Q water (MQW) for the preparation of diluted materials, calibration standards and sample dilution.

\subsubsection{Soil and 'rainwater'}

In this study a loamy soil has been used, collected from the $0-30 \mathrm{~cm}$ top layer at Unifarm Wageningen, The Netherlands. The initial characteristics are given in Table 4.1. 
Tap water was used as rainwater, and applied via a rainfall simulator. $\mathrm{pH}$ and IS of the tap water equalled 7.23 and $3.4 \mathrm{mM}$, respectively.

Table 4.1: Characteristics of the soil used in the experiment $(n=3) \pm$ st.dev.

\begin{tabular}{ll}
\hline Characteristic: & \\
\hline Clay (\%) & $10.2 \pm 0.7$ \\
Silt (\%) & $43.5 \pm 0.2$ \\
Sand (\%) & $46.4 \pm 0.9$ \\
pH (KCl) & $7.5 \pm 0.1$ \\
CEC (meq 100g-1) & $6.9 \pm 0.04$ \\
OM (g kg-1) & $3.8 \pm 0.1$ \\
IS (mM) & $8.2 \pm 0.2$ \\
\hline
\end{tabular}

Organic matter, OM, cation exchange capacity, CEC and lonic strength, IS.

\subsubsection{Experimental setup}

To quantify the transport and distribution of AgNPs resulting from runoff and erosion, a soil flume experiment was conducted in the Kraijenhoff Van der Leur Laboratory for Water and Sediment Dynamics at Wageningen University, the Netherlands. Figure 4.1 shows a schematic overview of the experimental design. After preparing the soil flume, 4 rainfall events were applied to the flume, causing runoff and erosion on the flume surface. After the $4^{\text {th }}$ rain event, samples were taken of the non-eroded background soil (BS) and transported sediment (SS). Runoff water (RW) and sediment within the runoff (RS) were collected after each rainfall event. All samples were analysed for AgNPs. In addition, the soil remaining on the flume was scanned before and after each rainfall event using a PhotoScan to record erosion and deposition dynamics. These scans were then used for determination of AgNPs presence and distribution on the soil surface. The experiment was run 3 times on each of 2 flumes with varying slopes. Details of the design and execution of the experiment are elaborated below.

\subsubsection{Flume and rainfall simulation design}

The experiment was conducted using a hydraulic soil flume with length, width and depth of 100,50 and $30 \mathrm{~cm}$ respectively. Two flume variants, in terms of slope, were used: flume 1 (S10) and flume 2 (S20) with slopes of $10 \%$ and $20 \%$ respectively (Figure 4.2 ). The flume surface was divided into five $20 \mathrm{~cm}$ segments and a bucket was installed the flume outlet for RW and RS collection (Figure 4.2C). 
Rainfall was applied to the entire flume equally using 2 pairs of nozzles placed on a stationary bar at a height of 3.85 meters above the ground surface of the simulator. The flow rate in the nozzles can be controlled independently; all nozzles were tested and calibrated before the experiment to maintain a stable rainfall intensity throughout the experiment.

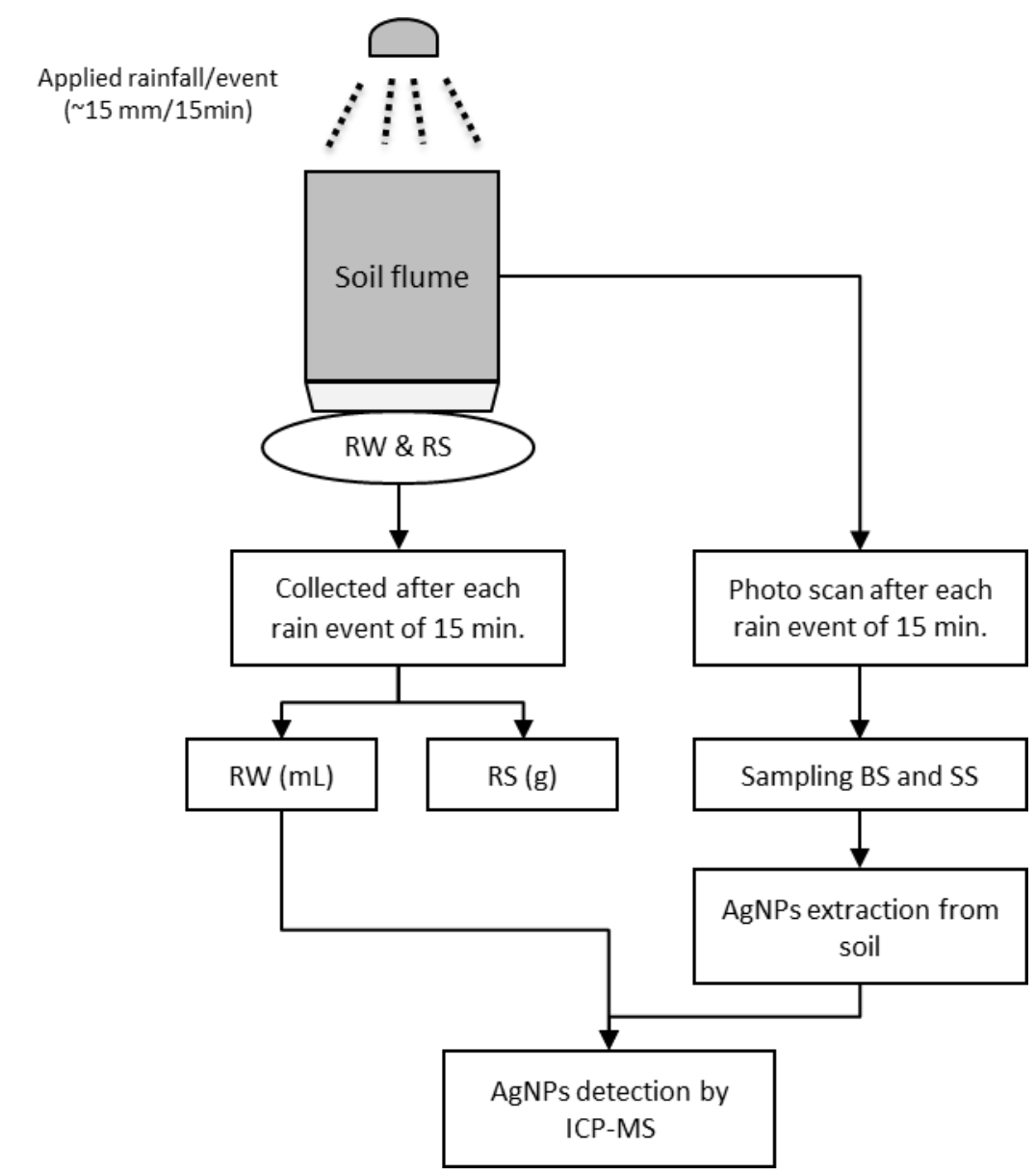

Figure 4.1. Schematic flow chart of the steps of the experiment: runoff water (RW), runoff sediment (RS), background soil (BS) and surface sediment (SS).

\subsubsection{Flume soil preparation}

For each run of the experiment, the soil collected from the field site (sieved and dried) was applied to the surface of the flume to a depth of $15 \mathrm{~cm}$. During the experiment, soil moisture content was monitored using 12 soil moisture sensors (EC-5 small, Decagon) installed when the flume was prepared. The soil moisture sensors were placed in the soil at depths of 5 
and $10 \mathrm{~cm}$. The sensors were connected to a CR1000 logger box which recorded measurements at one minute intervals during the entire experiment. The initial moisture content of the soil on the flume was of about $6 \%$ (wt./wt.). Pre-wetting was conducted one day before starting the experiment, which increased the moisture content up to $\pm 16 \%$ (vol.) at the surface.
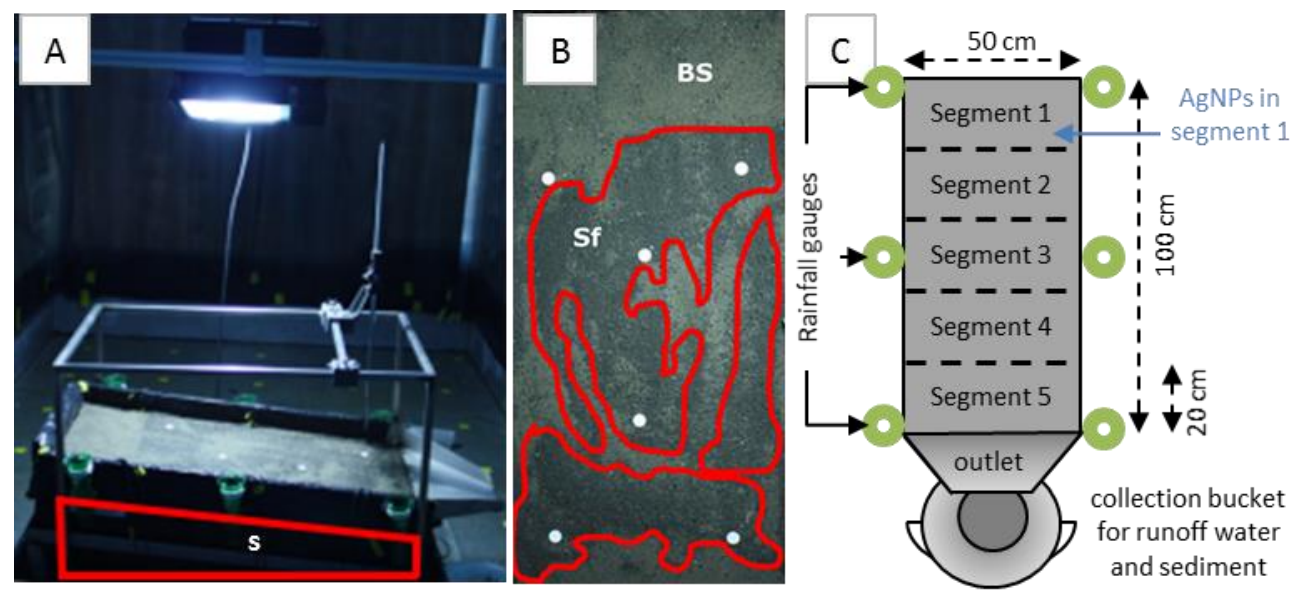

Figure 4.2 (A) flume design: slope of the flume (S); (B) the soil surface after a rainfall event showing background soil (BS) and surface sedimentation (SS) (the white dots are ground control points for coordination in photo scanning). (C) five segments of the soil flume surface and collection bucket. Segment 1 was spiked with AgNPs and from here transported by runoff and erosion to segments 2-5 and the flume outlet and collection bucket.

During the preparation of the flume, the height of the soil in segment 1 was slightly lower $(0.75 \mathrm{~cm})$ than the soil in the other segments to leave room for the soil spiked with AgNPs. The spiked soil layer in segment 1 was applied after the pre-wetting.

The AgNP-spiked soil was prepared by diluting the commercial AgNPs suspension with MQW and mixing it with $1 \mathrm{~kg}$ of the sieved-dried soil. The volume of the diluted AgNPs suspension added to the soil was adjusted to reach an initial soil moisture content of $\pm 16 \%$ (vol./vol.) which was close to the adjusted moisture content of soil in the flume. The AgNPspiked soil was then placed on top of the initial soil in the segment 1 (Figure $4.2 \mathrm{C}$ ) and gently adjusted so that the final height of the soil was equal to that in the other segments. The target concentration of AgNPs in the soil was $50 \mu \mathrm{g} \mathrm{kg}^{-1}$. This concentration is about 5 to 10 times the predicted environmental concentration of AgNPs in soil (Gottschalk et al., 2013). 
After adding the spiked soil, the flume was left for an hour to allow the water content of the newly added AgNP-spiked soil to come into equilibrium with that of the rest of the soil flume system before initiating the rain events.

\subsubsection{Rain Events}

Rainfall with an intensity of $60 \mathrm{~mm} \cdot \mathrm{h}^{-1}$ was applied during four events lasting 15 minutes each with 30 minutes of no rain between events. As mentioned above, the rain intensity was calibrated before starting the experiment. This was done by measuring the rainfall on a $0.5 \times 0.5 \mathrm{~m}$ grid as explained by (Lassu et al., 2012). In addition, before and after each rainfall event, the rainfall was measured using six gauges fixed on the sides of the flume as shown in Figure 4.2C.

\subsubsection{Flume surface analysis}

As the rainfall was applied to the soil flume, two different soil patterns developed on the flume surface as can be seen in Figure 4.2B. We refer to one as background soil (BS) which was assumed to have not been moved by erosion processes, and to the other as surface sediment (SS), the soil transported by the erosion and runoff from the rain events.

To monitor the movement of the sediments on the flume surface, high quality pictures were taken before and after each of the four 15-min rainfall events using a high quality Canon camera and strong illumination. Both the camera and the illuminating lamps were mounted on a frame to ensure stable light conditions and top view photos. In addition, photos from different angles and different flume corners were taken manually. The photo analysis was an object-based image analysis method for image segmentation and classification. Agisoft PhotoScan Professional software version 1.1.6. (2015) obtained from Agisoft LLC (www.agisoft.com) was used to construct a 3-dimensional (3D) image of the flume using all pictures taken from the different positions around the flume. Ground control points (GCP, the white dots in Figure 4.2B) were used for to construct a surface raster map. Photos were adjusted using the software program Definiens Professional software version 5 (2006) obtained from Definiens AG (www.definiens.com).

From the collected pictures and the surface raster map, the BS and SS patterns are made visible in each segment. The borders of the plot were disturbed by cables for the soil moisture sensors and thus could not be taken into account for the Definiens analysis, resulting in a loss of $2 \mathrm{~cm}$ surface area around the borders of the flume. The surface raster maps were exported to ArcGIS software to calculate the surface area of the BS and SS in each segment. Finally, these data were combined with the AgNPs concentrations measured in the collected soil samples and recalculated to determine the AgNPs mass for the BS and SS areas. 


\subsubsection{Sampling}

To ensure an accurate picture of the AgNPs transport from successive rain events, soil sampling of the flume surface was done only at the beginning and end of each experimental run; during the experiment, only photos were taken of the flume surface before and after each rainfall event. Before the initial rain event, about $50 \mathrm{~g}$ of both the initial blank soil samples and initial spiked soil samples (segment 1 only) were collected from the upper layer of the soil $(<0.5 \mathrm{~cm})$. The BS and the SS samples were collected at the end of each run of the experiment; BS samples were taken from the top $2 \mathrm{~cm}$ while SS samples were carefully taken from just the surface. About $100 \mathrm{~g}$ of BS was collected for each run, however for SS, the amount collected was $<10$ g per run.

Runoff sediments (RS) and runoff water (RW) were collected after each 15-min rainfall event. The RS was separated from the RW samples directly after collection, and weighed thereafter. Some sediment remained in the RW that was collected after initial separation; therefore, the RW samples were oven-dried for 24 hours at $105^{\circ} \mathrm{C}$ to be able to determine the total RS.

At the end of each run of the experiment, the RS, RW, BS and SS samples were split into three parts: two for the analysis of AgNPs and one for the determination of soil properties. All samples were stored in the dark at room temperature until further analysis could be conducted. A subsample of the spiked soils from the start of the experiment was stored with the samples to detect any loss of AgNPs during storage.

\subsubsection{Sample analysis}

\subsubsection{Determination of soil parameters}

Soil texture was analysed using particle size analysis (PSA) (McKenzie et al. 2002). pH and electrical conductivity (EC) were measured using a portable meter (WTW 340i) obtained from the WTW company (Weilheim, Germany). lonic strength (IS) was derived directly from the EC using the formula from the linear approach method [IS $\left(\mathrm{mol} \mathrm{L}^{-1}\right)=1.610^{-5} \times \mathrm{EC}(\mu \mathrm{S}$ $\mathrm{cm}^{-1}$ )] (Aqion, 2016). Organic matter (OM) was measured by oven drying at $550^{\circ} \mathrm{C}$ according to the standard test methods of ASTM (2000). CEC was measured by NIRS (near infrared spectroscopy) based on $0.0166 \mathrm{M}$ cobalt hexamine trichloride (ISO 2010).

\subsubsection{Determination of AgNPs content}

Samples of the flume soil (BS and SS), sediments (RS) and runoff water (RW) were analysed for AgNPs at RIKILT Wageningen University \& Research using the inductively coupled plasma mass spectrometry (ICP-MS) instrument. The ICP-MS used was a Thermo Scientific X series 
2 (Massachusetts, USA) equipped with a standard, conical glass concentric nebulizer and a quartz impact bead spray chamber. The settings of the ICP-MS were in accordance with Peters et al. (2015). The forward power was $1400 \mathrm{~W}$ and the argon gas flows were set at 13 $\mathrm{L} \mathrm{min}{ }^{-1}$ for the plasma, $1.1 \mathrm{~L} \mathrm{~min}^{-1}$ for the nebulizer, and $0.7 \mathrm{~L} \mathrm{~min}-1$ for the auxiliary flow. The sample flow rate to the nebulizer was set at approximately $0.5 \mathrm{~mL} \mathrm{~min}^{-1}$ and was determined before the start of each series of measurements. The dwell time was set at 3 ms.

At the start of each analysis series, a $60 \mathrm{~nm}$ gold NP suspension with a mass concentration of $50 \mathrm{ng} \mathrm{L}^{-1}$ was used to verify the performance of the ICP-MS and to determine the transport efficiency. Ionic silver standards with a concentration range of $0.25-5 \mu \mathrm{g} \mathrm{L}^{-1}$ were used for Ag mass calibration. The time scan data of the ICP-MS were exported as csv files and copied into a dedicated spICP-MS spreadsheet to calculate the AgNPs mass concentration, particle size and size distribution (Peters et al., 2014). This spreadsheet can be downloaded from the RIKILT internet site: (http://www.wageningenur.nl/en/ExpertiseServices/Research-Institutes/rikilt/Software-and-downloads.htm).

AgNPs in sediment and soil samples were analysed by the spICP-MS method as described by (Mahdi et al., 2016). In short, subsamples of approximately 0.5 g were collected in $12 \mathrm{~mL}$ polyethylene (PE) tubes and $4 \mathrm{~mL} M Q W$ was added. The tube was vortexed for $3 \mathrm{~min}$, sonicated for $10 \mathrm{~min}$ and stored overnight in the dark at room temperature to allow the soil/sediment to settle. Lastly, a subsample of the supernatant was collected then diluted with MQW prior to add it to the ICP-MS. The RW samples were also analysed by the spICPMS method, but the samples were only diluted 2 times and added to the ICP-MS.

The recovery of AgNPs extracted from the spiked soil in segment 1 before the first rain event occurred was in the range of $40-45 \%$ of the applied concentration which is comparable with the recovery found in the analytical method validation (Mahdi et al., 2016). The AgNPs concentrations in the soil samples collected from the flume surface, BS and SS, are expressed in $\mu \mathrm{g} \mathrm{m}^{-2}$ since the AgNPs transported over the surface was calculated according to the surface area of the BS and SS distribution patterns in all segments of the flume. In the runoff sediment (RS) and runoff water (RW) samples, AgNPs concentrations were expressed in $\mu \mathrm{g} \mathrm{kg}^{-1}$ and $\mu \mathrm{g} \mathrm{L}^{-1}$, respectively. The total mass balance for AgNPs in all samples was expressed in $\mu \mathrm{g}$. 


\subsubsection{Statistical analysis of the results}

The results of the experiment were all statistically analysed to identify the significant differences. The analysis of variance (ANOVA) was used to find effects and differences between measured variables of AgNPs concentrations on the flume surface and in the runoff water and sediment. In addition, the differences in RW and RS quantities for the different slopes, S10 and S20, were analysed. All statistical analyses were done with the IBM SPSS Statistics 22 software.

\subsection{Results}

\subsubsection{Sample characteristics}

\subsubsection{BS and SS characteristics}

The physical and chemical characteristics of the BS and SS determined after the experiments and are shown in Table 4.2. The properties for BS were only slightly different than those for the initial soil shown in Table 4.1. The differences between the SS samples and the initial soil were greater, and there were some significant differences between the BS and SS soils. The BS samples showed a higher amount of silt while the SS samples had higher sand content. Organic matter (OM) and cation exchange capacity (CEC) in BS samples were about three times higher than those measured in SS samples, while the $\mathrm{pH}$ was found to be similar for both.

Table 4.2: Characteristics of BS and SS collected from the soil flume $(n=3) \pm$ st.dev.

\begin{tabular}{|c|c|c|}
\hline Characteristic & BS & SS \\
\hline Clay (\%) & $9.1 \pm 0.21$ & $9.4 \pm 0.13$ \\
\hline Silt (\%) & $44.7 \pm 0.35 \mathrm{~A}$ & $34.5 \pm 0.88 \mathrm{~B}$ \\
\hline Sand (\%) & $46.2 \pm 0.49 \mathrm{~B}$ & $56.1 \pm 2.50 \mathrm{~A}$ \\
\hline $\mathrm{pH}(\mathrm{KCl})$ & $7.4 \pm 0.28 \mathrm{~B}$ & $7.7 \pm 0.17 \mathrm{~A}$ \\
\hline $\operatorname{CEC}\left(\right.$ meq $\left.100 \mathrm{~g}^{-1}\right)$ & $6.6 \pm 0.02 \mathrm{~A}$ & $2.1 \pm 0.03 \mathrm{~B}$ \\
\hline $\mathrm{OM}\left(\mathrm{g} \mathrm{kg}^{-1}\right)$ & $4.3 \pm 0.38 \mathrm{~A}$ & $1.53 \pm 0.06 \mathrm{~B}$ \\
\hline IS (mM) & $7.3 \pm 0.40 \mathrm{~A}$ & $4.4 \pm 0.23 \mathrm{~B}$ \\
\hline
\end{tabular}

Background soil (BS), surface sediment (SS), cations exchange capacity (CEC), organic matter (OM) and ionic strength (IS). Different capital letters indicate significant differences between BS and SS sample type at $p<0.05$. 


\subsubsection{Runoff water and sediment characteristics}

The collected amounts of RW and RS after each of the 4 rain events are presented in Figure 4.3 for both slopes. The moisture content of the soil flume at $5 \mathrm{~cm}$ depth was slightly higher for the $10 \%$ slope than for the $20 \%$ slope for all rain events except for the last one as presented in Table 4.3. The amounts of RW collected were comparable for slopes of $10 \%$ and $20 \%$. However, the amounts of RS collected after each event were higher for S20 than for S10. In addition, the amount of RS collected in subsequent rainfall events at S20 increased markedly while at S10, the amounts of RS doubled from E1 to E2 but then remained more or less stable. The $\mathrm{pH}$ was similar in all of the collected RS samples and the cation exchange capability (CEC) was similar except for the third rain event. While the amount of organic matter was lower in the fourth rain event, the ionic strength (IS) was higher.

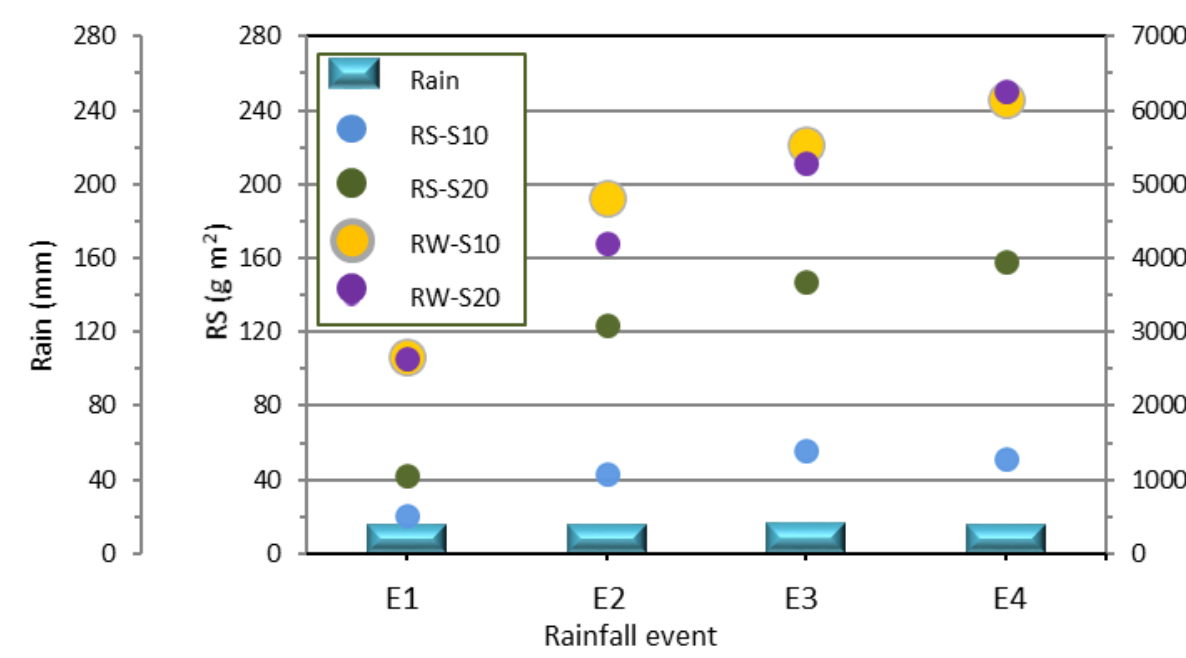

Figure 4.3 The amounts of rainfall applied, the collected amounts of RW (rain water) and RS (Runoff sediments) during the 4 rainfall events (E1,E2, E3 and E4) for the two slopes (S2O and S10). The rainfall amounts and RS are presented by the primary $Y$-axis while the $R W$ represented by the secondary $Y$-axis.

\subsubsection{Distribution of AgNPs}

\subsubsection{AgNPs distribution in the soil surface layer of the flume}

Total AgNPs content found in BS and SS per segment of the soil flume is given in Table 4.4. The results show that, overall, the BS samples had a higher AgNPs content than the SS samples and, in addition, the AgNPs content in the BS samples in the S20 experiments were 
higher than in the S10 experiments. The highest AgNPs contents were found in the BS located halfway down the soil flume, in segments 3 and 4.

Table 4.3 Characteristics of rainfall, runoff water and sediment for the different rain events $(n=3)^{*} \pm$ st.dev.

\begin{tabular}{|c|c|c|c|c|}
\hline & E1 & E2 & E3 & $\mathrm{E} 4$ \\
\hline Rainfall (mm) & $15.9 \pm 0.29$ & $15.6 \pm 0.07$ & $16.1 \pm .034$ & $15.3 \pm 0.26$ \\
\hline MC-S10 (\%) at $5 \mathrm{~cm}$ & $26.5 \%$ & $29.4 \%$ & $30.3 \%$ & $30.9 \%$ \\
\hline MC-S20 (\%) at $5 \mathrm{~cm}$ & $24.8 \%$ & $28.2 \%$ & $30.0 \%$ & $31.5 \%$ \\
\hline RW-S10 (ml) & $1151 \pm 1037 a$ & $2254 \pm 920 \mathrm{~b}$ & $2603 \pm 804$ bc & $2951 \pm 721 \mathrm{c}$ \\
\hline RW-S20 (ml) & $1320 \pm 990$ & $2105 \pm 1581$ & $2644 \pm 944$ & $3128 \pm 744$ \\
\hline RS-S10 (g) & $10.3 \pm 8.6$ & $20.7 \pm 13$ & $27.0 \pm 9.3$ & $26.5 \pm 2.4$ \\
\hline RS-S20 (g) & $16.0 \pm 9.5$ a & $46.5 \pm 10.5 \mathrm{ab}$ & $63.0 \pm 16.7 \mathrm{~b}$ & $71.8 \pm 17.8$ b \\
\hline Clay (g) & $0.78 \pm 0.18 a$ & $2.1 \pm 0.43 \mathrm{~b}$ & $2.2 \pm 0.38 \mathrm{a}$ & $1.9 \pm 0.45 \mathrm{c}$ \\
\hline Silt (g) & $3.8 \pm 0.8 \mathrm{a}$ & $10.5 \pm 2.8 \mathrm{~b}$ & $10.34 \pm 0.7 \mathrm{a}$ & $7.70 \pm 0.8 c$ \\
\hline Sand (g) & $5.7 \pm 1.5 \mathrm{ab}$ & $8.8 \pm 3.9 \mathrm{~b}$ & $14.5 \pm 1.7 \mathrm{ab}$ & $16.1 \pm 6.0 \mathrm{a}$ \\
\hline $\mathrm{pH}(\mathrm{KCl})$ & 8.1 & 8.2 & 8.2 & 8.4 \\
\hline $\operatorname{CEC}\left(\right.$ meq $\left.100 \mathrm{~g}^{-1}\right)$ & 6.7 & 6.6 & 4.9 & 6.0 \\
\hline OM (\%) & 2.5 & 3.0 & 3.1 & 1.5 \\
\hline IS (mM) & 4.2 & 3.9 & 4.1 & 4.6 \\
\hline
\end{tabular}

* st.dev was not calculated for $\mathrm{pH}, \mathrm{CEC}, \mathrm{OM}$ due to the limited number of sample quantities. Soil flume with $20 \%$ slope (S20), Soil flume with $10 \%$ slope (S10), moisture content (MC), amount of runoff water (RW), amount of runoff sediment (RS), cation exchange capacity (CEC), organic matter (OM) and ionic strength (IS). Different lowercase letters indicate significant differences at $p<0.05$ between rainfall events.

Table 4.4 Total AgNPs content $(\mu \mathrm{g})$ in the BS and SS of each flume segment $(n=3) \pm s t$.dev.

\begin{tabular}{llllll}
\hline Flume & S10 & & & S20 & \\
\cline { 2 - 3 } \cline { 5 - 6 } Segment & Ag-BS & Ag-SS & & Ag-BS & Ag-SS \\
\hline 1 & $15.8 \pm 0.33 \mathbf{a}$ & n. a. & & $14.2 \pm 1.60 \mathbf{a}$ & n. a. \\
2 & $0.14 \pm 0.41 \mathbf{b}$ & $0.05 \pm 0.019$ & & $0.16 \pm 0.06 \mathbf{b}$ & $0.19 \pm 0.10$ \\
3 & $0.26 \pm 0.25 \mathbf{b}$ & $0.27 \pm 0.09$ & & $0.51 \pm 0.42 \mathbf{b}$ & $0.10 \pm .08$ \\
4 & $0.19 \pm 0.19 \mathbf{b}$ & $0.05 \pm 0.04$ & & $0.55 \pm 0.37 \mathbf{b}$ & $0.06 \pm 0.03$ \\
5 & $0.15 \pm 0.16 \mathbf{b}$ & $0.02 \pm 0.01$ & & $0.05 \pm 0.02 \mathbf{b}$ & $0.05 \pm 0.02$ \\
\hline
\end{tabular}

Soil flume with $10 \%$ slope (S10), Soil flume with $20 \%$ slope (S20), AgNPs content ( $\mu \mathrm{g})$ in the background soil samples (Ag-BS), AgNPs content ( $\mu \mathrm{g})$ in the surface sediment samples (Ag-SS), n.a. = not applicable. Significant differences between segments for the same soil group, are indicated by different lowercase letters $(p<0.05)$. 


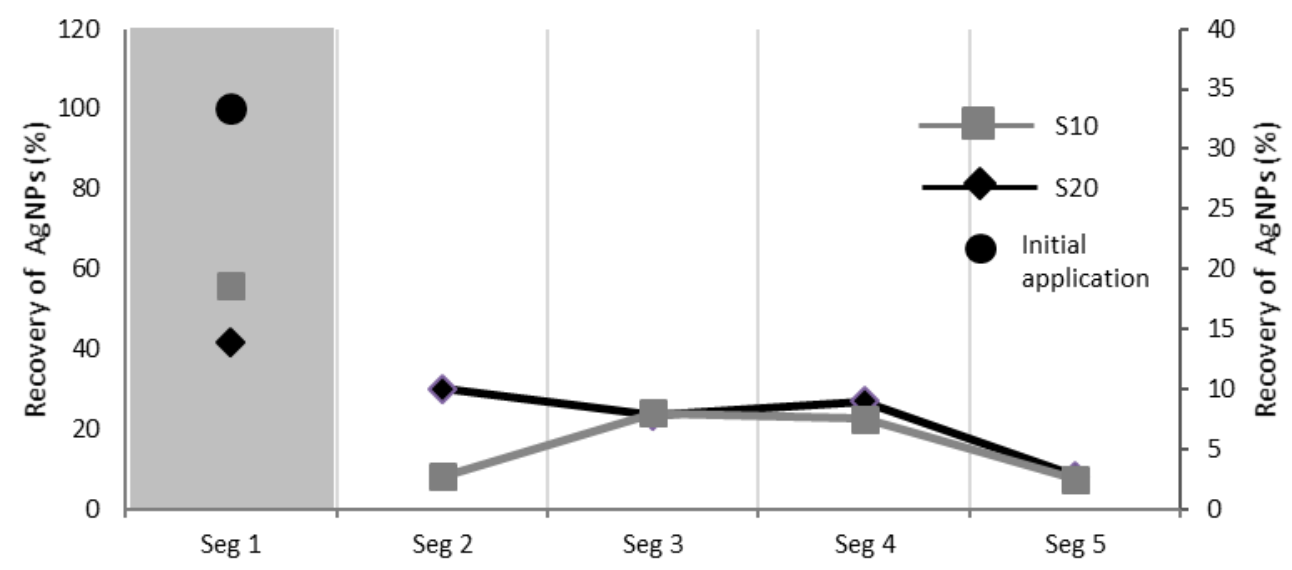

Figure 4.4 Total AgNPs recovered in soil flume segments after conclusion of the experiment. Segment 1 (in grey) represented by the primary $Y$ axis (on the left). The results of other segments (2-5) are represented by the secondary $Y$ axis (to the right). The black circle refers to the AgNPs initially applied. The square and the rhombic shapes represent the \%AgNPs detected in the S10 and S2O flumes respectively.

The AgNPs contents recovered from BS and SS samples were calculated for each rainfall event depending on the initial recovery. AgNPs concentration remaining in segment 1 in flume S10 was higher than in S20. Further, in segments 2 and 4, AgNPs concentration in the BS and SS in S20 were slightly higher than in S10 (see Figure 4.4). In segments 3 and 5, the AgNPs detected for S10 and S20 were almost equal.

Using the photos taken during the experiment, the surface areas of BS and SS are shown in Figure 4.5. Comparing the two slopes, the total surface area of (re)deposited sediment (SS) was larger for S10 than for S20. This is confirmed by the RS measured at the outlet, which is almost three times higher for S20 compared to S10 (Table 4.3).

AgNPs distribution in BS and SS was calculated by dividing the detected AgNPs content ( $\mu \mathrm{g}$ ) by the calculated area covered by the respective soil in each segment (Figure 4.5). The area of each soil cluster in each segment was calculated by using ArcGIS software depending on the photos collected during the experiment and analysed by PhotoScan. Soil samples were taken up to $0.2 \mathrm{~cm}$ depth and the soil density was calculated also, being $1.25 \pm 0.03$ for S10\% flume and $1.3 \pm 0.04$ for $\$ 20 \%$. 


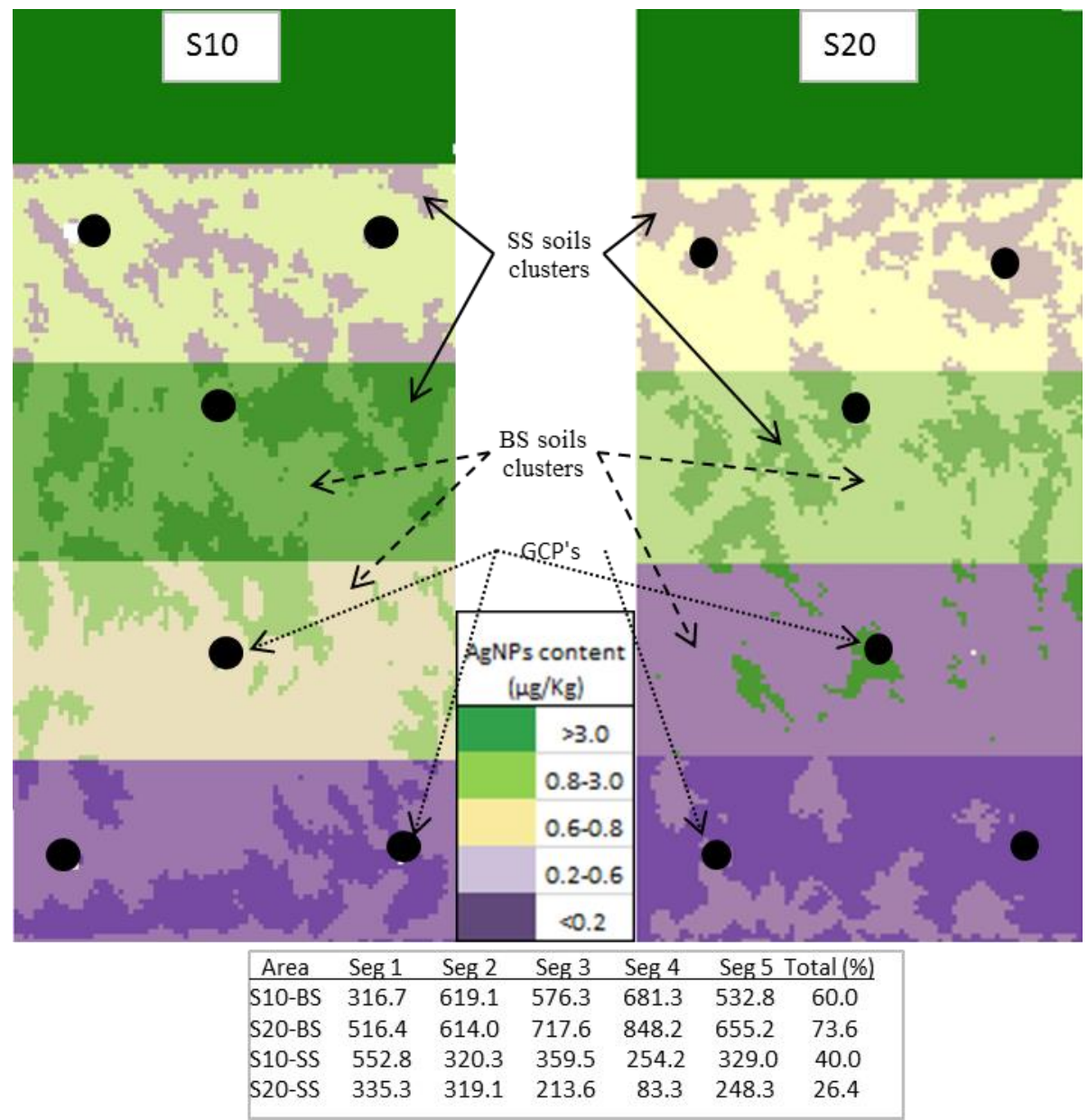

Figure 4.5 AgNPs distribution ( $\left.\mu \mathrm{g} \mathrm{cm}^{-2}\right)$ in soil flume surface areas. Ground control point (GCP), background soil (BS), and surface sediments (SS).

\subsubsection{AgNPs concentration in RS and RW}

AgNPs concentrations in RS and RW were calculated on basis of the amounts collected after each of the four rainfall events per flume (Table 4.5). Although there were some exceptions, overall, higher concentrations of AgNPs were measured for S20 than for S10. For the RS samples, the results show that the AgNPs concentration increased gradually with each subsequent rain event (except for $\mathrm{S} 10$ after the third rain event). After the last rain event, AgNPs concentration in RS was five and seven times higher than after the first for flumes S10 and S20 respectively. For the RW samples, the AgNPs concentrations from both slopes were highest after the first rain event and then decreased. 
Table 4.5 AgNPs concentration in the runoff sediment (RS) and runoff water (RW) following each rain event $(n=3) \pm$ st.dev.

\begin{tabular}{|c|c|c|c|c|}
\hline Flume & S10 & & S20 & \\
\hline Rain Event & $\begin{array}{l}\mathrm{Ag}-\mathrm{RS} \\
\left(\mu \mathrm{kg}^{-1}\right)\end{array}$ & $\begin{array}{l}\text { Ag-RW } \\
\left(\mu g L^{-1}\right)\end{array}$ & $\begin{array}{l}\mathrm{Ag}-\mathrm{RS} \\
\left(\mu \mathrm{kg}^{-1}\right)\end{array}$ & $\begin{array}{l}\text { Ag-RW } \\
\left(\mu g \mathrm{~L}^{-1}\right)\end{array}$ \\
\hline 1 & $0.54 \pm 0.31$ & $0.28 \pm 0.11$ & $0.65 \pm 0.32$ & $0.22 \pm 0.12$ \\
\hline 2 & $1.12 \pm 0.32$ & $0.12 \pm 0.06$ & $1.06 \pm 0.33$ & $0.15 \pm 0.06$ \\
\hline 3 & $0.85 \pm 0.24$ & $0.08 \pm 0.05$ & $1.68 \pm 0.10$ & $0.13 \pm 0.03$ \\
\hline 4 & $2.55 \pm 1.65$ & $0.06 \pm 0.03$ & $4.42 \pm 2.53$ & $0.12 \pm 0.05$ \\
\hline
\end{tabular}

AgNPs detected in runoff sediment (Ag-RS) and runoff water (Ag-RW). There were no significance differences.

\subsubsection{Total AgNPs transported}

AgNPs spiked in the first segment was detected in the flume surface samples (BS and SS) and in the RS and RW. These samples were collectively measured for mass balance of the transported amounts of the AgNPs in the flume. The results showed that $4.3 \%$ of the total AgNPs applied was transported in the $\mathrm{S} 10$ flume, while $7.3 \%$ of the total AgNPs applied was transported in the S20 flume as shown in Figure 4.6. The results also showed that the highest amount of transported AgNPs was in the RW.
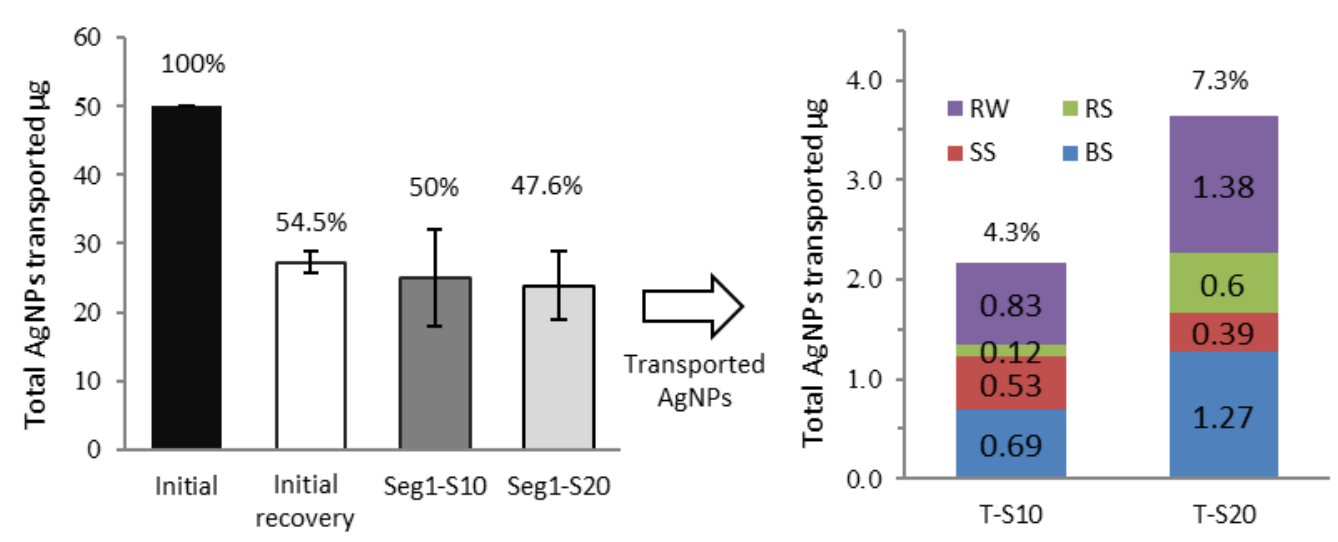

Figure 4.6 The initial AgNPs applied at segment 1 is represented by the primary Y-axis (on the left). The data for the total AgNPs transported in the flume with 10\% slope (T-S10) and 20\% slope (T-S20) is represented by the secondary Y-axis (to the right). Background soil (BS), surface sediment (SS), runoff water (RW) runoff sediment (RS). 


\subsection{Discussion}

This study aimed to assess the potential transport of AgNPs by runoff and erosion. Previous studies proved that pollutants could be transported by surface runoff causing off-site deposition of these pollutants (Candela et al., 2010; Ulén et al., 2014; Yang et al., 2015). Runoff and erosion during rainfall events occurred as infiltration excess overland flow, which is common in most rainfall experiments (Dunkerley, 2008). The findings of this study confirm that AgNPs can be redistributed by surface runoff and sediment transport, away from the point of application. AgNPs concentrations downstream varied in dependence of the rainfall sequence and slope steepness.

\subsubsection{AgNPs distribution on the flume surface soil}

AgNPs on the flume surface were determined in surface areas of BS and SS as monitored by PhotoScan and calculated by ArcGIS. The total surface area of SS was larger in the S10 soil flume than in S20, as shown in Figure 4.5. This may seem counterintuitive since more sediment dynamics are expected on steeper slopes than on gentler slopes. However, what occurred here was more (re)deposition of sediment (SS) on the gentler slope due to slower overland flow in the S10 flume compared with the flow on the steeper flume. This is confirmed by the higher amount of sediment found in the runoff water and related sediment.

Further, AgNPs concentration varied between the BS and SS in the two flumes. In both flumes AgNPs concentrations in the BS samples were higher than the ones detected in SS samples for the down flume segments (Table 4.4). This may be attributed to particle size differences between BS and SS, BS containing higher silt and clay fractions and SS sand. The BS samples had more organic matter content than the SS samples also. Higher organic matter would allow the BS soil to capture more AgNPs.

\subsubsection{AgNPs concentration in RS and RW}

For RS and RW, RS amounts increased with increasing flume slope due to more concentrated and faster flow as seen in Figure 4.3. However, the amounts of RW collected from both flumes were approximately the same (Figure 4.3). AgNPs concentrations detected in RS samples were higher than in RW for both slopes as seen in Table 4.5. AgNPs amounts in collected RW decreased after the first rainfall applied (Table 4.5). In contrast, the AgNPs concentration in the RS samples increased after the first rainfall event, which 
indicates that the AgNPs transported with RW started to attach to the sediment particles in RS.

\subsubsection{AgNPs transport mechanisms}

AgNPs were transported across the flumes towards the outlet, however during transport a substantial part was redistributed on the flume surface. This paper does not analyse the mechanisms involved, however some observations and postulations can be made. Most likely, erosion of AgNPs polluted sediment from segment 1 resulted partly in (re)deposition in downstream SS segments. The AgNPs found in the BS, which was assumed to have not moved, was most probably caused by (re)infiltration of AgNP containing runoff water originating from segment 1

Looking at the temporal patterns in the concentration of AgNPs that did reach the flume outlet (RW and RS; Table 4.5), shows an interesting trend: the concentration in the RW is highest after the first rainfall event and decreases after subsequent events, while the concentration in the RS increases over time with additional rainfall events. At the start of the experiment, applied AgNPs in segment 1 would most likely be easily available for transport by runoff water, as shown by the results of rain event 1 . However, in subsequent events more and more of the AgNP fraction in segment 1 will be adsorbed to the soil and OM particles, resulting in a decreasing trend in AgNP transport by runoff water. By contrast, the source of the RS after rain event 1 would have been mostly the down flume segments where little to no AgNPs would be present, resulting in a low initial concentration. For subsequent rain events more of the soil would contain AgNPs resulting in higher concentrations in the RS. As would be expected, the sediment in the steeper flume showed higher concentrations of AgNPs compared with the shallower slope, which was also found by e.g. Yang et al., (2015).

\subsubsection{Mass balance and total recovery for AgNPs transported}

After conclusion of the experiments $45.7 \%$ and $45.1 \%$ of the originally applied AgNPs were missing in the S10 and S20 flumes, respectively. This can be caused by several processes, like transformation/dissolution in the soil to $\mathrm{Ag}$ ions and/or $\mathrm{Ag}_{2} \mathrm{~S}$, a dissolved organic matter coating around Ag particles (Brunetti et al., 2015), or adsorption soil particles (Malysheva et al., 2016; Peters et al., 2014). These phenomena can reduce the recovery of AgNPs in soil significantly (Brunetti et al., 2015), which was also found by Mahdi et al. (2016) concluding that the reduction could be between $40-45 \%$. 
From this study, we learned that once the AgNPs are applied to the soil, they can be transported downwards by runoff and erosion. After AgNP application, transport by runoff water is prominent first, and later particulate transport of AgNP is the dominant process.

\subsubsection{Limitations of the study}

The experiment faced some limitations. For example, maintaining exactly the same conditions for each flume during the experiment was difficult since disturbed soil was used in the flumes. Also, the rainfall application in this experiment was not exactly the same in all of the rainfall events. Besides that, we faced difficulties during the AgNPs extraction procedure due to the low concentrations of applied AgNPs, and transformation and adsorption of AgNPs in soil. If this experiment would be repeated it would be preferred to include longer experimental time steps for each rainfall event, as well as using other soil type and different silver nanoparticle sizes and types. Furthermore, a controlled field experiment would be helpful to advance the state of knowledge in this domain.

\subsection{Conclusion}

- AgNPs in soils can be transported by runoff and erosion processes.

- Runoff induced AgNP transport mainly occurs during a first rainfall event and decreases after subsequent rains, while particulate transport of AgNPs increases over time and with additional rainfall events.

- The detection of AgNPs in runoff water and transported sediments confirms the potential risk of downstream pollution by AgNPs.

- More work is needed to assess AgNP transport in other soil types, considering different particle sizes and rainfall intensities as well.

- Ecotoxicological studies are also needed to understand the potential effect of the transported AgNPs on soil organisms and plants.

\section{Acknowledgements}

I would like to thank the Soil Physics and Land Management laboratory and RIKILT, both belonging to Wageningen University \& Research, for their contribution and for the use of their facilities and devices for executing the experiments. I also like to thank the HCED of Iraq for their financial support. 


\title{
5. Modelling silver nanoparticle transport with runoff water and erosion using the LISEM and PestPost models
}

\begin{abstract}
The presence and transport of nanoparticles (NPS) in soil has attracted a great deal of attention in recent years due to the growing amounts of NPs used in many products, industries and applications. Many studies have investigated NP pathways, impacts, and transport. Like many other chemicals, silver nanoparticles (AgNPs) can be transported through and over the soil surface due to rainfall events. In this study, we combined a hydrological soil erosion model (LISEM) with a particle-transport model (PestPost) to simulate the transport of AgNPs due to runoff and erosion processes. AgNPs were applied to 2 soil flumes ( $S 10$ \& S20) with different slopes (10\% and 20\% respectively). The two models were calibrated separately using measured data from a rainfall experiment. The calibration of LISEM showed high model efficiency for both sediment (MEF=0.81) and runoff (MEF=0.79). The S10 flume showed better calibration results for runoff water and sediments than the S20 flume. This was related to the effect of slope on infiltration efficiency, which decreases with increasing slope steepness. In the PestPost model, we used the Mean Distance of Points to Line $\left(\Delta_{p l}\right)$ criterion to find the parameters for which the simulated results were closest to the measured ones. The simulation of AgNPs in runoff water was much better than that in the eroded sediment for both flumes $\left(\Delta_{p l}<0.01\right.$ for runoff and $\Delta_{p l}=0.06$ and 0.02 for sediment in $S 10$ and $S 20$, respectively). This difference in results for sediment was related to the increasing AgNP content in the sediment after each single rainfall event due to the increase of AgNP adsorption on soil particles. By combining the LISEM soil erosion model and the newly developed PestPost model, risk assessment of AgNPs (and other nanomaterials) can be done adequately and easily.
\end{abstract}

K.N.M. Mahdi, M.C. Commelin., J.E.M. Baartman, R.J.B. Peters, V. Jetten, V. Geissen, C.J. Ritsema, J.G. Wesseling 2018. Modelling silver nanoparticle transport with runoff water and erosion using the LISEM and PestPost models. Submitted to Environmental Nanotechnology, Monitoring \& Management. 


\subsection{Introduction}

Engineered nanoparticles (ENPs) are considered to be any material with at least $50 \%$ of the particles having one or more dimension of size in the range of 1-100 nm (EC, 2011). In recent years, the ENP market has grown rapidly because they have unique properties that yield large benefits. They can increase the quality of many products and industry practices. For example, gold is considered to be inert in its bulk form, but gold nanoparticles are very reactive (Auffan et al., 2009; Yu et al., 2015; Velicogna et al., 2016). The global nanotechnology market is expected to grow to up to $78.5 \$$ billion by the year 2020 (Markets, 2015). The increase in nanotechnology investments means that there will be an inevitably increasing release of these particles into the environment (Yin et al., 2015). Compared to other nanoparticle types, the production of silver nanoparticles (AgNPs) is very high. This is due to their anti-microbial activity and thus they have been incorporated into a large amount of products (Cascio et al., 2015). For example, AgNPs have been used in textiles, foods, cosmetics, wastewater treatment and medical devices (Kumar et al., 2014).

Most of the AgNPs released are believed to reach the soil environment through different pathways: dumping waste containing AgNPs, application of wastewater treatment biosolids to land, accidental spills or intentional applications such as the use of nano-pesticides (Gottschalk et al., 2013; Kah and Hofmann, 2014). Besides the direct application of AgNPs to soil, AgNPs can be deposited from atmospheric pathways due to the increase in AgNPs emissions (Walser et al., 2013), or the release of AgNPs from coated building facades (Kaegi et al., 2010).

Due to the antibacterial activity of AgNPs, soil microorganisms and plants can be affected by their release and by the reactivity of AgNPs in soil (Dimkpa et al., 2013; Thuesombat et al., 2014; Zhou et al., 2015). Therefore, the concerns of AgNPs' potential biological (toxic) effects on soil species and human health are rising (Zhou et al., 2015).

Like other chemicals, AgNPs in soil can be subject to soil physical processes such as erosion and (co-)transport by surface runoff, either dissolved in water or attached to soil particles (Gottschalk et al., 2013; Yang et al., 2015; Mahdi et al., 2017). Kaegi et al. (2010) found that AgNP concentration in soil increased after a rainfall event. This means that AgNPs can be transported over the soil surface far from their initial application point and they may reach surface water in streams or lakes through the erosion transport pathway. Therefore, modelling the physical processes of erosion and runoff are key factors in understanding the transport of AgNPs over elevated soil surfaces (Werkenthin et al., 2014; Yang et al., 2016; Mahdi et al., 2017). 
Previous studies showed that AgNP concentrations in sediments are often low $\left(<10 \mu \mathrm{g} \mathrm{kg}^{-1}\right)$ (Gottschalk et al., 2009; Gottschalk et al., 2013). This makes the determination of the AgNP concentration in soil samples difficult and requires subsequent steps for sample collection and high resolution instruments for characterization and quantification (Navratilova et al., 2015). Furthermore, these concentrations can be reduced significantly once AgNPs are subjected to physical processes like soil erosion or chemical interactions with soil particles.

Models are regarded as powerful tools increasingly used in the assessment of contaminant behaviour in the environment. Thus, models are essential for scientific and regulatory purposes (Ramaswami et al., 2005). In modelling, scientific hypotheses can be easily modified to study the importance of various processes and can highlight those critical parameters that need to be studied experimentally in laboratory or field studies (Devia et al., 2015). In addition, modelling can test alternative theories about the mechanisms underlying an observed experimental result, identify significant scientific uncertainties, and evaluate possible release scenarios (Dale et al., 2015). Therefore, using models to understand the transport behaviour of silver nanoparticles over elevated soil surfaces would contribute to filling knowledge gaps and identify critical properties and parameters.

The aim of this study was to simulate the transport of AgNPs over the soil surface using two models. The first model is The Limburg Soil Erosion Model (OpenLISEM) also called LISEM, which is a model used for simulating runoff, flooding and erosion (Bout and Jetten, 2018). The second model is PestPost (Pesticide Postprocessor), which is a newly developed model to simulate the particulate transport of chemicals over the soil surface using the runoff and erosion output from LISEM.

\subsection{Methods}

Transport of AgNPs over the soil surface was modelled by combining the models LISEM and PestPost. LISEM was used to simulate the runoff and sediment losses in an experimental flume, while PestPost was used to simulate the AgNP concentration distribution and transport on the soil flume surface, and its content in the runoff water and sediment. PestPost uses the output data from LISEM to generate the final results for AgNP transport. Each model was calibrated separately using data obtained from previous rainfall laboratory experiments (Mahdi et al., 2017). An overview of the methods is shown in Figure 5.1. 


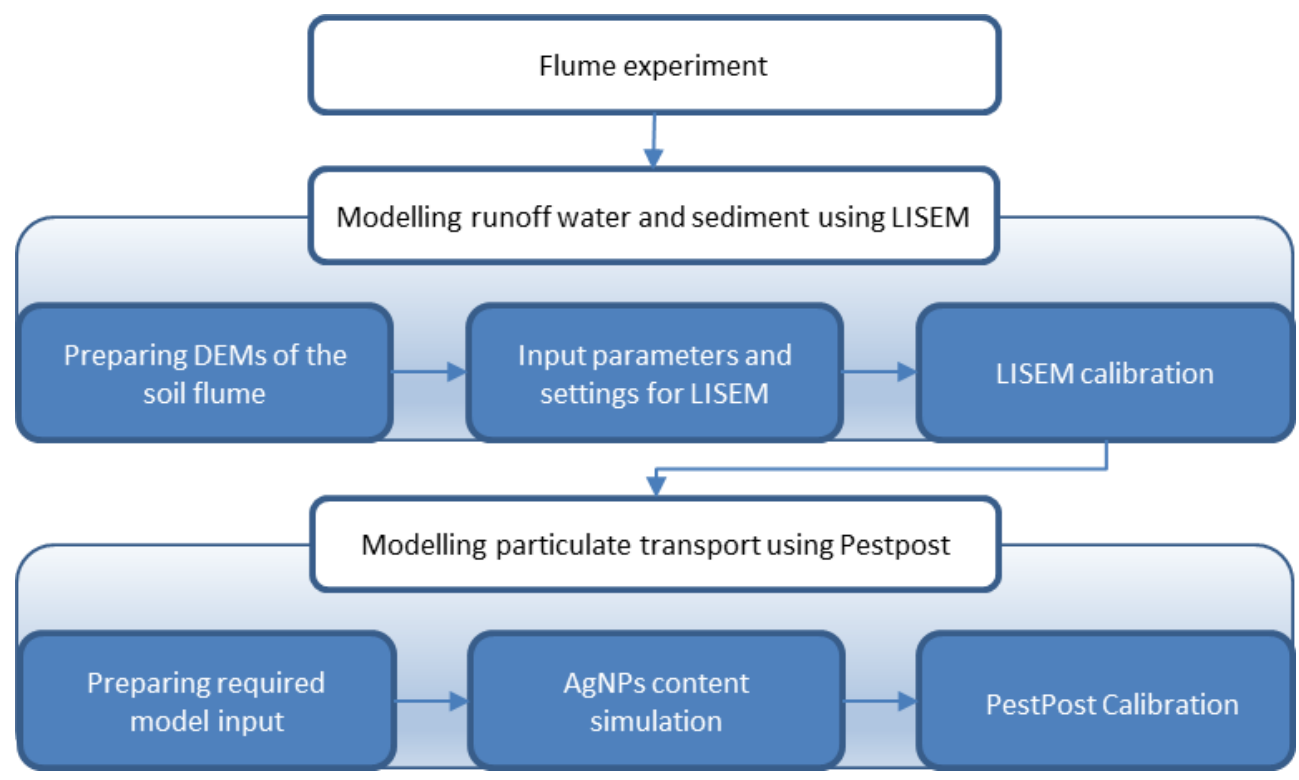

Figure 5.1: Methodological approach to simulate AgNP transport by runoff and erosion.

\subsubsection{Flume experiment}

The laboratory experiment used two flumes with different slopes: S10 (10\% slope) and S20 (20\% slope). Each flume had dimensions of $100 \times 50 \times 30 \mathrm{~cm}$ (length $\times$ width $\times$ depth) as shown in Figure 5.2. Four short rainfall events (runs), lasting 15 min each, were applied to each flume with a 30 minutes interval between them. Each flume was divided into 5 segments of $20 \mathrm{~cm}$ each. Before starting the experiment, AgNPs were applied to the upslope segment (segment 1) of the flume (Figure 5.2). Runoff water and erosion sediment were collected after each rainfall event at the outlet of the flume. Sampling of the flume surface was done once at the end of the full experiment after the 4 rainfall events applied.

The measured eroded sediment and runoff water data from the experiment were used to calibrate LISEM while the measured AgNP concentration distribution in the sediment and runoff were used to calibrate PestPost. Other input data, such as soil properties, rainfall intensity, initial moisture contents and initial AgNPs concentrations were the same for both LISEM and PestPost as derived from the experiment (Mahdi et al., 2017). 


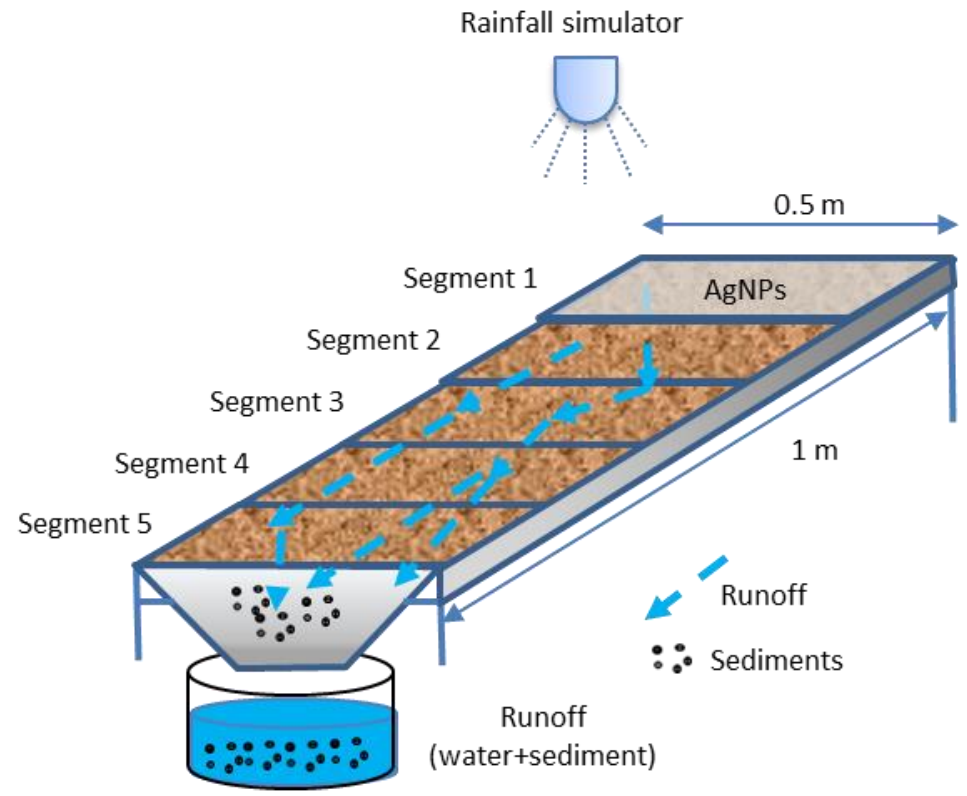

Figure 5.2 Schematic view of the flume experiment.

\subsubsection{Modelling runoff water and sediment using LISEM}

The Limburg soil erosion model (LISEM) is an event-based model that simulates the temporal and spatial sediment and water dynamics during and after a rainfall event (De Roo et al., 1994). LISEM was originally developed for the province of Limburg, the Netherlands, to test the impacts of grass strips and other small scale soil conservation measures on soil loss (De Roo and Offermans, 1995). The model has been applied mostly at the catchment scale with a size ranging from 1 ha up to tens of $\mathrm{km}^{2}$ (Baartman et al., 2012). In the LISEM version (3.96) used, the amount of decimals was increased to enable simulating low water and sediment flows that result from erosion and runoff processes on a smaller experimental scale (soil flume). Hence, LISEM was used to simulate runoff and erosion during and after rainfall events as assessed in the flume experiment (section 5.2.1).

Processes incorporated into the model include plant interception, surface water storage in micro depressions, infiltration, vertical movement of water in the soil, overland flow, channel flow (in manmade ditches), detachment by rainfall and through fall, transport capacity and detachment by overland flow (De Roo et al., 1996; Baartman et al., 2013). 
To run LISEM, spatially explicit digital input maps for the soil, vegetation (absent in this case) and hydrological parameters and topography are required. An overview of the input data required to run LISEM and calibrate its results are listed in the following 3 sections.

\subsubsection{DEM of the soil flume}

The main input for LISEM is the digital elevation model (DEM), which defines the catchment topography (size and slope). In our case, this means the flume surfaces. DEMs were obtained from image data collected during the experiment. These images were then processed using Agisoft PhotoScan Professional software version 1.1.6. (2015) obtained from Agisoft LLC (www.agisoft.com) to construct a three-dimensional image of the flume using six white coins as ground control points (GCPs) with known $\mathrm{x}$, y and $\mathrm{z}$ coordinates. The procedure to build DEMs of this small size was described and tested for accuracy by Blokker (2014). The final DEM has a cell size of $1 \mathrm{~cm}^{2}$.

LISEM normally simulates runoff and erosion in (natural) catchments with defined catchment boundaries. In the present experiments, the boundaries were the sides of the soil flumes and consisted of vertical wooden boards at the top and sides. In the DEM, these boards were represented by virtual walls (without width), so-called "flow barriers", along the upper and side borders of the flume. These flow barriers enabled water to leave the flume only in the downstream direction while not affecting erosion and deposition calculations.

\subsubsection{Input parameters and settings for LISEM}

The required input parameters for LISEM are listed in Table 5.1. For the soil and hydrological parameters, it was assumed that the flume was homogeneous so that the same value was used for the entire flume (i.e. no spatial variation). The surface area of the soil flume was bare, so the vegetation related parameters were set to zero.

To calculate infiltration, the 2-layer "Green and Ampt" method was used because the flume had a permeable lower boundary that prevented saturation. Therefore, the first layer was the soil layer in the flume and the second layer was (virtually) placed underneath, representing the permeable bottom of the flume. Input parameters for the Green and Ampt infiltration method include $\mathrm{K}_{\text {sat }}$ (saturated hydraulic conductivity), porosity, initial moisture content, suction $(\psi)$ at the wetting front and soil depth $(\mathrm{cm}) . K_{\text {sat, }}$ porosity, soil depth and initial soil moisture content were measured during the experiment. $K_{\text {sat }}$ was measured with a Decagon minidisc infiltrometer and the initial moisture content was calculated using the average measured soil moisture data, which was obtained from moisture sensors placed at 5 and $10 \mathrm{~cm}$ depth in each flume. Porosity was measured using $100 \mathrm{cc}$ rings and soil depth was the depth of the soil in the flume $(15 \mathrm{~cm})$. 
To calculate overland flow and erosion, several soil surface and erosion-related maps were needed. The splash delivery ratio defines the amount of sediment detached through splash erosion, which is also available for transport through overland runoff. The splash delivery ratio is left on its default value which is 0.1 . The aggregate stability value was estimated using the drop test method as shown in the study of (Cammeraat and Imeson, 1998). Cohesion was measured using a torvane. The median grain size (D50) was obtained from a texture analysis of the used soil. The Manning's' $(n)$ value taken was relatively low since the flume surface was bare (Jetten, 2017).

Random roughness $(\mathrm{rr}$ ) describes the random variation of height within a cell (Thomsen et al., 2015). Usually, $\mathrm{rr}$ is measured with a pin-board and is calculated as the standard deviation of the height of the pins (Thomsen et al., 2015). This was not possible on our small flume. We therefore calculated the $\mathrm{rr}$ as the standard deviation of the heights of 30 randomly selected rows of 20 cells taken from the high-resolution DEMs of the experimental runs. The average $\mathrm{rr}$ was $0.14 \mathrm{~cm}$, with a standard deviation of $0.01 \mathrm{~cm}$.

The kinetic energy $(\mathrm{KE})$ of the rainfall in the rainfall simulator differed from natural rain (Lassu et al., 2015). According to this study, KE for an intensity of $60 \mathrm{~mm} \mathrm{~h}^{-1}$ will be between 7 and $11 \mathrm{~J} \mathrm{~mm}^{-1}$. Based on a sensitivity analysis of LISEM, a maximum variation of $5 \%$ in final output was found between the two extreme values of KE. Therefore, a value of $10 \mathrm{~J} \mathrm{~mm}^{-1}$ was used in our simulations. Rainfall intensity in the experiment varied between 63.5 and $60.0 \mathrm{~mm} \mathrm{~h}^{-1}$. Rainfall input used in LISEM was a homogeneous rainstorm of constant intensity with a fall value within the average range of experimental rain intensity values. The input parameters for LISEM are presented in the Table 5.1.

Finally, in LISEM, both the simulation timestep and the minimum timestep need to be defined. The simulation timestep is the timestep at which infiltration is computed. As this was assumed to be a stable process, the timestep was set to $5 \mathrm{sec}$. The minimum timestep calculates the runoff water and sediment dynamics and was set to $0.1 \mathrm{sec}$. The courant factor was set to low ( 0.1) as the flux should not be a major fraction of the water content of the cell, otherwise, changes in velocity would occur between timesteps. Furthermore, larger outflow of water content can leave negative water volumes. 
Table 5.1: Input parameters for the LISEM model.

\begin{tabular}{|c|c|c|c|c|}
\hline Parameters & Unit & S10 & S20 & Source \\
\hline Rainfall & $\mathrm{Mm} \mathrm{h}^{-1}$ & 61.5 & 62.1 & Measured \\
\hline Soil depth* & $\mathrm{cm}$ & 15 & 15 & Measured \\
\hline Ksat & $\mathrm{Mm} \mathrm{h}^{-1}$ & 155 & 155 & Measured \\
\hline$\theta$ & - & 0.155 & 0.146 & Measured \\
\hline$\theta s$ & $\mathrm{~cm}^{3} \mathrm{~cm}^{-3}$ & 0.44 & 0.44 & Measured \\
\hline $\mathrm{rr}$ & $\mathrm{cm}$ & 0.15 & 0.15 & Measured/estimated \\
\hline$\Psi$ & $\mathrm{cm}$ & 7.48 & 7.48 & $\begin{array}{l}\text { (Baartman et al., 2012; Regalado et } \\
\text { al., 2005) }\end{array}$ \\
\hline D50 & $\mu \mathrm{m}$ & 40 & 40 & Measured \\
\hline $\mathrm{N}$ & - & 0.076 & 0.076 & (Hessel et al., 2003a) \\
\hline Soil Cohesion & $\mathrm{kPa}$ & 6.18 & 6.18 & Measured \\
\hline As & \# drop & 45 & 45 & $\begin{array}{l}\text { Estimated (Cammeraat and Imeson, } \\
\text { 1998) }\end{array}$ \\
\hline KE & $\mathrm{Mm} \mathrm{J}^{-1}$ & 10 & 10 & Estimate, Lassu and Seeger (2015) \\
\hline
\end{tabular}

\subsubsection{LISEM Calibration}

The LISEM calibration was done by adjusting the Green and Ampt infiltration parameters as they determine runoff and erosion amounts (Hessel et al., 2003b). Runoff was calibrated by adjusting $\mathrm{K}_{\text {sat }}$ and the wetting front suction $(\Psi)$ values, as $\mathrm{K}_{\text {sat }}$ influences the steady state runoff and $\Psi$ influences the starting time and slope of the hydrograph (Jetten 2017).

Sediment flow was adjusted using Manning's ( $n$ ) calibration as it regulates the flow velocity (Hessel et al., 2003a). Optimizing these parameters was done by comparing the simulated runoff and erosion peaks for each rainfall event with the measured peaks. Furthermore, the total runoff water and erosion sediment amounts were also compared. Goodness-of-fit was evaluated using the Nash-Sutcliff model efficiency factor (MEF) (Nash and Sutcliffe, 1970):

$\mathrm{MEF}=1-\frac{\sum_{\mathrm{t}=1}^{\mathrm{T}}\left(\mathrm{Q}_{\mathrm{obs}}^{\mathrm{t}}-\mathrm{Q}_{\mathrm{mod}}^{\mathrm{t}}\right)^{2}}{\sum_{\mathrm{t}=1}^{\mathrm{T}}\left(\mathrm{Q}_{\mathrm{obs}}^{\mathrm{t}}-\overline{\mathrm{Q}_{\mathrm{obs}}}\right)^{2}}$

Where $\mathrm{Q}_{\mathrm{obs}}$ is the observed discharge. $\mathrm{Q}^{\mathrm{t}}$ mod and $\overline{\mathrm{Q}_{\mathrm{obs}}}$ are the modelled and the mean observed discharges at time $t$, respectively. 


\subsubsection{PestPost model: theory and input requirements}

The LISEM model simulates sediment and water transport and can store the values for each time-step. The PestPost model was built to use the output of LISEM and predict the fate of chemicals (AgNPs, pesticides or others) in time by means of a simple mass balance approach. Besides the values of water and sediment transport (output of LISEM), PestPost requires the initial AgNP content values as input.

In PestPost, a simple direct relationship was assumed between the AgNP content and the transport of water and sediment. This relationship is described by only two parameters, which are the maximum AgNP concentration in runoff water $\left(C_{w}\right)$ and the maximum AgNP concentration attached to eroded soil particles $\left(C_{s}\right)$. These parameter values were estimated from the measured AgNP content in the runoff water and the sediments as well as the contents in each section of the flume at the end of the experiment. The program PestOpt has been developed for this aim. PestOpt uses the Controlled Random Search method to find the best fit between computed and observed values of contents (Price, 1977; Wesseling et al, 2008, Wesseling 2009). With these two parameters (and the known infiltration value), the AgNP content at the surface can be computed by a simple mass balance equation for each timestep considered.

AgNP content at the surface was calculated using Eq. 5.2:

$$
Y_{k}=\int_{y=y_{\min , k}}^{y_{\text {max }, k}} \int_{x=x \min }^{x=x(\max )} \Gamma d x d y=\sum_{j=1}^{N_{k, y}} \sum_{i=1}^{N_{x}} \Gamma_{i, j} \Delta x \Delta y
$$

Where $Y_{k}=$ AgNP content of segment $k(\mu g), \Gamma_{i, j}=$ AgNP content of discretized area $(i, j)(\mu g)$, $\mathrm{N}_{\mathrm{k}}, \mathrm{y}=$ Number of discrete steps in $\mathrm{k}^{\text {th }}$ segment in $\mathrm{y}$-direction $(-), \mathrm{N}_{\mathrm{x}}=$ Number of discrete steps in x-direction (-), $\Delta_{\mathrm{x}}=$ Compartment size in x-direction $(\mathrm{m}), \Delta_{\mathrm{y}}=$ Compartment size in $\mathrm{y}$ direction $(\mathrm{m})$

The output of PestPost consists of AgNP content after each simulation step, allowing calculate AgNP content changes in time. Furthermore, this output was stored in the NetCDF format, hence the files can be read by a number of standard programs that create 2dimensional charts and animations.

\subsubsection{Solute fluxes direction theory in PestPost}

Modelling AgNP content distribution on the soil surface requires knowledge of the transport direction of AgNPs over the soil surface from one cell to the next cell and so on. To calculate this, the slope of the whole soil flume and of the height difference between two adjacent cells should be known. Even though this can be derived from the DEM, LISEM cannot store 
the target cell of water which makes it impossible to derive the contents of AgNPs on the flume (soil) surface. In addition, ponding of water on the soil surface (as in Figure 5.3) is another problem since it can affect the slope of the surface water which influences the flow direction.

To overcome this problem, the slope between 2 adjacent cells was adjusted by considering the thickness of the ponding layer for each cell, which can be read from the LISEM output, for every timestep.
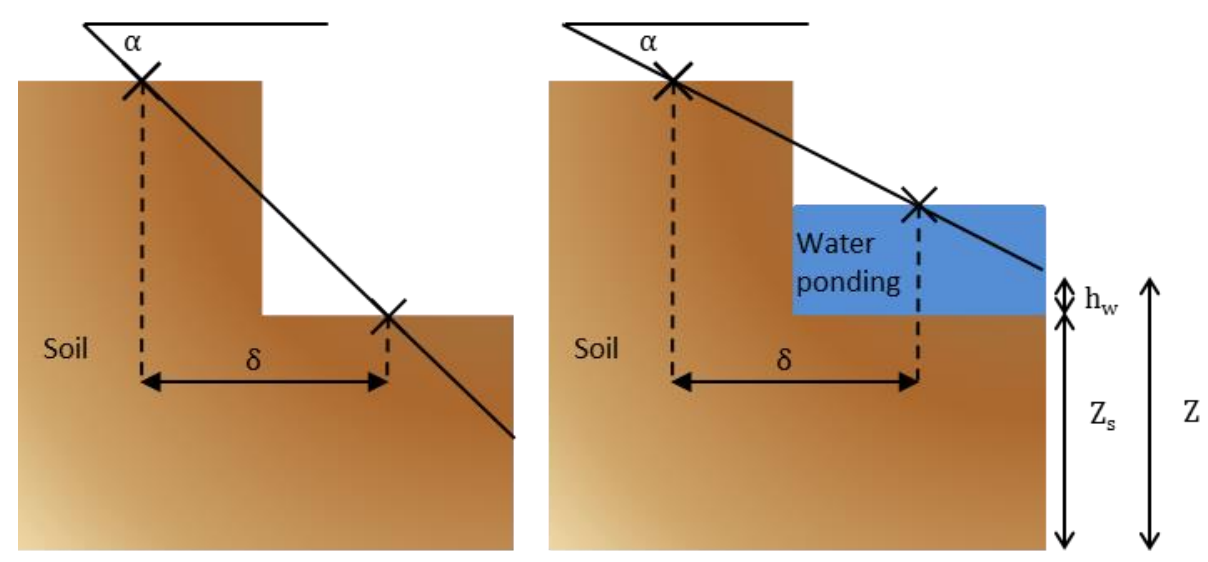

Figure 5.3 Non-ponding and ponding cases and their effect of soil slope. Where $z=z_{s}+h_{w}, z_{s}$ is the height of the soil surface and $h_{w}$ is the thickness of the ponding layer of water. $\alpha_{i}$ is the slope between the cells under consideration and its $i^{\text {th }}$ neighbour cell can be computed from $\alpha_{i}=\frac{z-z_{i}}{\delta_{i}}$ where $\delta_{i}$ is the distance between the centres of the two cells.

AgNP content in runoff water, eroded sediment and deposited sediment was calculated from the difference between inflow and outflow as a simple mass balance as shown in Eq. 5.3.

For AgNP content transport by water and sediments simulations, two parameters have been introduced: the maximum weight of AgNPs that can be transported by a volume of water $\left(C_{w}, \mu g \mathrm{~m}^{-3}\right)$ and a certain mass of soil (Cs, $\left.\mu \mathrm{g} \mathrm{kg}^{-1}\right)$ AgNP content ( $\left.\Gamma\right)(\mu \mathrm{g})$ in a cell (i) at time (j) that can be computed from the content at the cell at time $\mathrm{j}^{-1}$.

$\Gamma_{1}^{j+1}=\Gamma_{1}^{j}+\sum_{k=1}^{N_{i}} C_{w, k}^{i} v_{i, k}^{w}-\sum_{k=1}^{N_{o}} C_{w, l}^{j} v_{o, k}^{w}+\sum_{k=1}^{N_{i}} C_{s, k}^{i} v_{i, k}^{s}-\sum_{k=1}^{N_{o}} C_{s, l}^{j} v_{o, k}^{s}-C_{w, l}^{j} l_{l}$

Where $\Gamma_{1}^{\mathrm{j}}=$ AgNP content of compartment $\mathrm{i}$ at time $\mathrm{j}(\mu \mathrm{g}), \mathrm{N}_{\mathrm{i}}=$ Number of source compartments (-), $\mathrm{N}_{\mathrm{o}}=$ Number of sink compartments $(-), \mathrm{C}_{\mathrm{w}, \mathrm{k}}^{\mathrm{i}}=$ Concentration in water of compartment $\mathrm{k}$ at time $\mathrm{j}\left(\mu \mathrm{g} \cdot \mathrm{m}^{-3}\right), \mathrm{C}_{\mathrm{s}, \mathrm{k}}^{\mathrm{i}}=$ Concentration around solids of compartment $\mathrm{k}$ at 
time $j\left(\mu g \mathrm{~kg}^{-3}\right), v_{i, k}^{w}=$ Runoff from $k^{\text {th }}$ source compartment $\left(m^{3}\right), v_{o, k}^{w}=$ Runoff to $k^{\text {th }}$ sink compartment $\left(\mathrm{m}^{3}\right), v_{\mathrm{i}, \mathrm{k}}^{\mathrm{s}}=$ Solid transport from $\mathrm{k}^{\text {th }}$ source compartment $(\mathrm{kg}) \mathrm{v}_{\mathrm{o}, \mathrm{k}}^{\mathrm{s}}=$ Solid transport to $\mathrm{k}^{\text {th }}$ sink compartment $(\mathrm{kg}), \mathrm{I}=$ Volume of infiltrated water $\left(\mathrm{m}^{3}\right)$.

\subsubsection{PestPost calibration and performance evaluation}

The model was calibrated by finding the optimal values of the maximum AgNP concentration in runoff water and sediment $\left(C_{w}\right.$ and $\left.C_{s}\right)$, yielding results that were closest to the measured values. To compare the simulated PestPost AgNP concentrations with the concentrations as measured in the experiment, the Mean Distance of Points to Line (MDPL, $\triangle \mathrm{pl}$ ) was used as a criterion. The MDPL method was previously developed by (Wesseling et al., 2008). This value was computed by first scaling the axes to the interval $[0,1]$ and then computing the average distance between the (measured) points and the (simulated) line. For example, a value of $\Delta \mathrm{pl}=0.05$ means that the average distance of the points to the line is $1 / 20^{\text {th }}$ of the axes sizes. In general, this method is a better criterion for the goodness of fit than the root of squares of deviations (Wesseling 2009; Wesseling et al., 2008).

\subsection{Results and discussion}

\subsubsection{Modelling runoff and erosion with LISEM}

To calibrate and validate the LISEM model for the flume experiments, the relevant DEMS of both flumes were used as input layer for LISEM. Also the measured soil property data as well as details on the rain event characteristics were applied. Most importantly, the observed runoff and sediment losses during the entire experimental period were needed to calibrate the LISEM model and validate simulation results against collected measurements.

Results of LISEM calibration for both flumes are shortly summarized in Table 5.2. Optimal calibration results could be achieved by adapting and optimizing certain important soil properties. Properties re-valued during the calibration procedure were $\mathrm{K}_{\text {sat, }}$ Manning's $\mathrm{n}$ factor, and suction at the wetting front $\psi$. The calibration results achieved showed a reasonable to good model performance for both flumes and simulated runoff and sediment losses. MEF values ranged between 0.73 and 0.88 , see Table 5.2. 
Table 5.2: LISEM optimal calibration results for the S10 and S20 flume experiments.

\begin{tabular}{llllllll}
\hline & $\begin{array}{l}\text { Total water } \\
(\mathrm{mL})\end{array}$ & $\begin{array}{l}\text { Total sediment } \\
(\mathrm{g})\end{array}$ & $\mathrm{K}_{\text {sat_f }}$ & $\mathrm{N}_{-} \mathrm{f}$ & $\begin{array}{l}\Psi_{-} \text {a } \\
(\mathrm{cm})\end{array}$ & $\begin{array}{l}\text { MEF } \\
(\text { water })\end{array}$ & $\begin{array}{l}\text { MEF } \\
\text { (sediment) }\end{array}$ \\
\hline S10_Obs & 8326 & 66 & -- & -- & -- & -- & - \\
S10_Cal & 7426 & 73 & 0.24 & 0.37 & 74.8 & 0.84 & 0.88 \\
S20_Obs & 6471 & 213 & -- & -- & -- & -- & -- \\
S20_Cal & 7586 & 225 & 0.24 & 0.37 & 74.8 & 0.73 & 0.74 \\
\hline
\end{tabular}

Note: Obs = observed results, $\mathrm{Cal}=$ simulated results. $\mathrm{K}_{\text {sat_f }} \mathrm{f}$ and $\mathrm{N}_{-} \mathrm{f}$ are multiplication factors for original input, resulting in $\mathrm{K}_{\text {sat }}=37.2$ and $\mathrm{N}=0.028$ as used values in the model. $\Psi_{-} \mathrm{a}$, is the wetting front suction adjusted value.

With the calibrated LISEM model the full flume experiments have been simulated, as depicted in Figure 5.4. Here both hydrographs and sedigraphs are shown of observed and simulated runoff and sediment losses over time. For the S10 flume simulated runoff and sediment patterns are almost identical to observed data. For flume S20, simulation results are less identical as in \$210, showing both higher runoff and sediment losses than observed values.

\subsubsection{Simulation of AgNP transport using PestPost}

AgNP transport by runoff and erosion was modelled over time by the PestPost model, and by using the relevant LISEM output data for this purpose.

First, the $C_{w}$ and $C_{s}$ calibration values were derived using the procedure described in section 5.2.3.2. The PestPost calibration parameters are shown in Table 5.3, indicating different values for each flume. The parameter values are basically indicating that per $\mathrm{m}^{3}$ of runoff water $575 \mu \mathrm{g}$ AgNPs can be transported in flume S10, and $225 \mu \mathrm{g}$ in S20. Furthermore, for each $\mathrm{kg}$ of transported sediment $0.45 \mu \mathrm{g}$ AgNPs can be transported for the S10 flume, and $1.35 \mu \mathrm{g}$ for $\mathrm{S} 20$. 

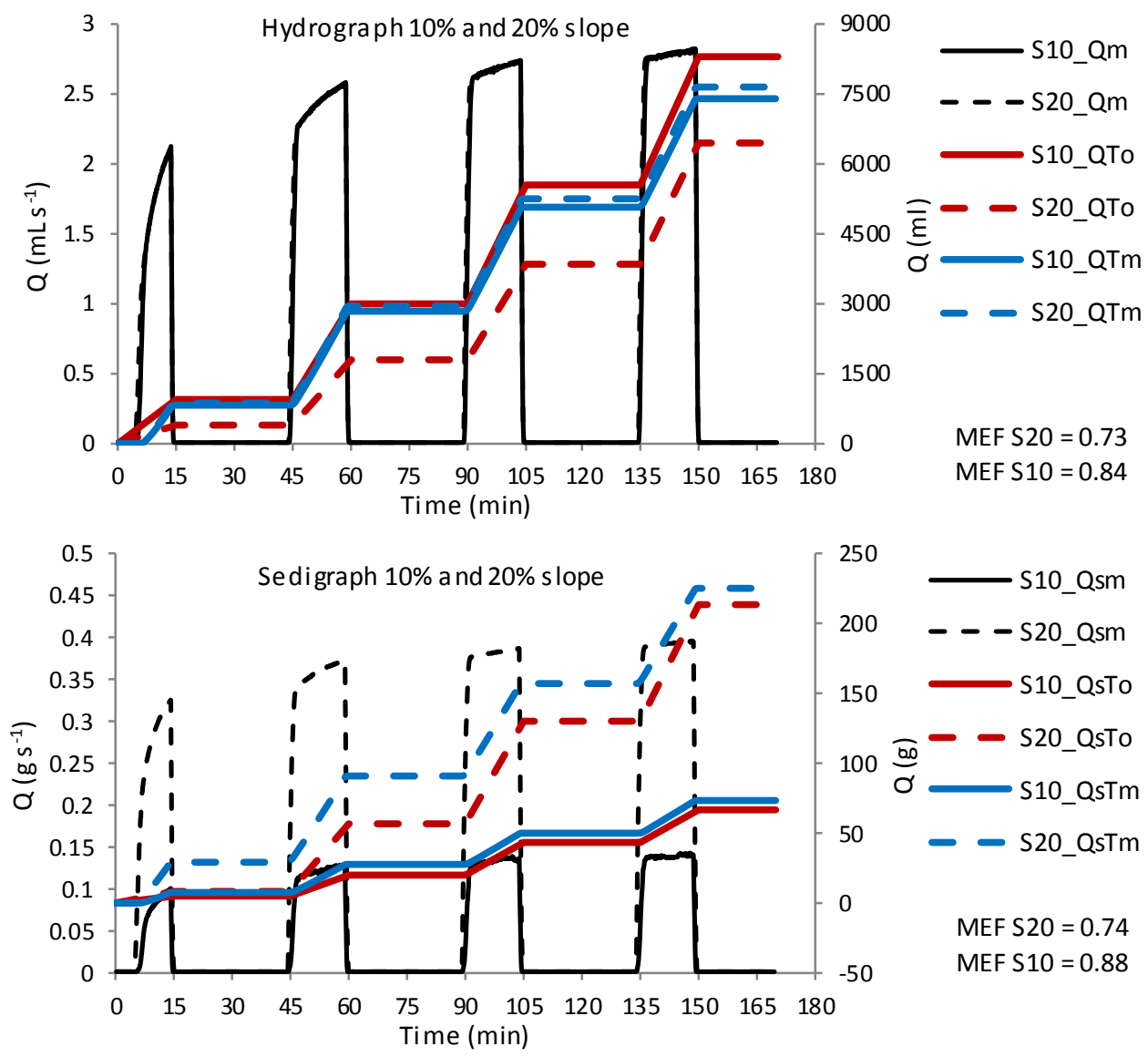

Figure 5.4: Simulated hydrographs and sedigraphs at the outlet of the S1O and S2O flumes. Qm is the modelled runoff $\left(\mathrm{ml} \mathrm{s}^{-1}\right)$ and Qsm the modelled sediment discharge $\left(\mathrm{g} \mathrm{s}^{-1}\right)$. QTo and QTm are respectively the observed and simulated cumulative runoff $(\mathrm{ml})$, while QsTo and QsTm are the observed and simulated cumulative sediment losses. MET stand for the Nash-Sutcliff coefficient.

\subsubsection{AgNP distribution on the flume surface}

PestPost showed results that reasonable approximated the experimental AgNP measurements per flume segment (Figure 5.5). Overall, flume S20 showed a better performance than S10. This was attributed to a reduced infiltration on the steeper slope (as shown in Table 5.3). AgNP transported from segment 1 to the downstream segments mainly took place with runoff water (Mahdi et al., 2017). In S10, more infiltration occurred, which reduced the AgNP amount transported (Figure 5.5). However, possible variation of rainfall rates across the flume could have affected the runoff rates also, affecting the amount of transported AgNPs. 
Table 5.3 Calibration parameters for PestPost.

\begin{tabular}{lll}
\hline Parameter & S10 & S20 \\
\hline$C_{w}\left(\mu \mathrm{g} \mathrm{m}^{-3}\right)$ & 575 & 225 \\
$C_{s}\left(\mu \mathrm{kg}^{-3}\right)$ & 0.45 & 1.35 \\
$\mathrm{I}(-)$ & 0.45 & 0.01 \\
\hline
\end{tabular}

$\mathrm{C}_{\mathrm{w}}$ is the maximum AgNP concentration that can be transported with runoff water, and $C_{s}$ is the maximum AgNP concentration that can be transported with erosion sediment, and $\mathrm{I}$ is the fraction of infiltrated water transporting AgNP.
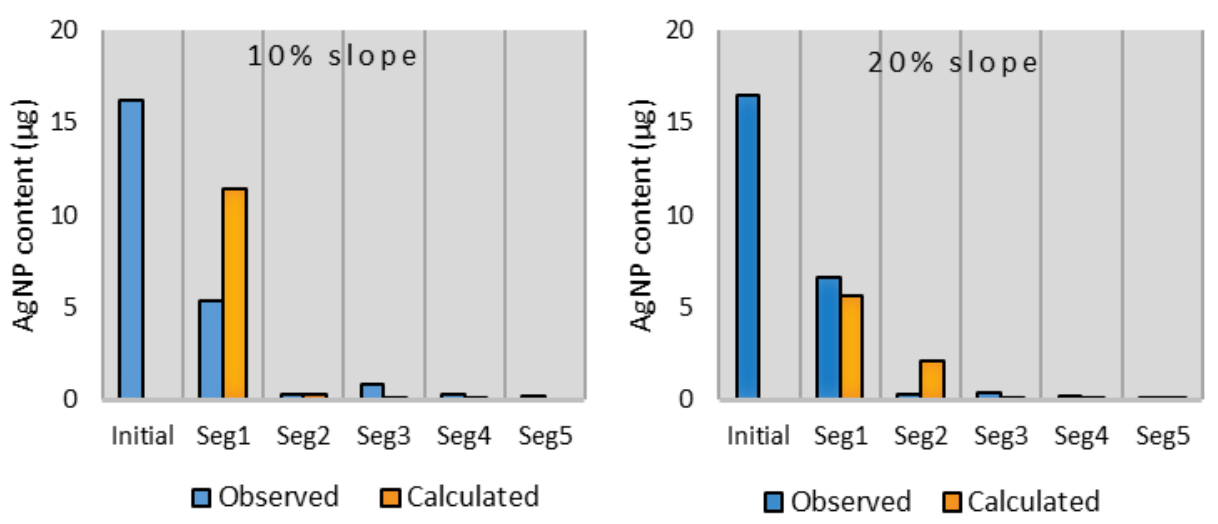

Figure 5.5 Calculated vs. observed AgNP content in different flume segments at the end of the experiment.

\subsubsection{AgNPs content in the runoff water}

The amounts of AgNPs in the runoff water and transported sediments at the outlet of the flume were calculated using the PestPost model also. The measured and calculated values are shown in Figure 5.6. PestPost calculations for AgNPs content in the runoff water at the outlet of the flume agreed better with observations than for transported sediment. $\Delta \mathrm{pl}$ for the runoff simulations for both flumes ( 110 and S20) did not exceed 0.01 which means a good fit between simulated and observed values. Results for the S20 flume are slightly better than for the S10 flume, as infiltration in S20 was less than in S10. 


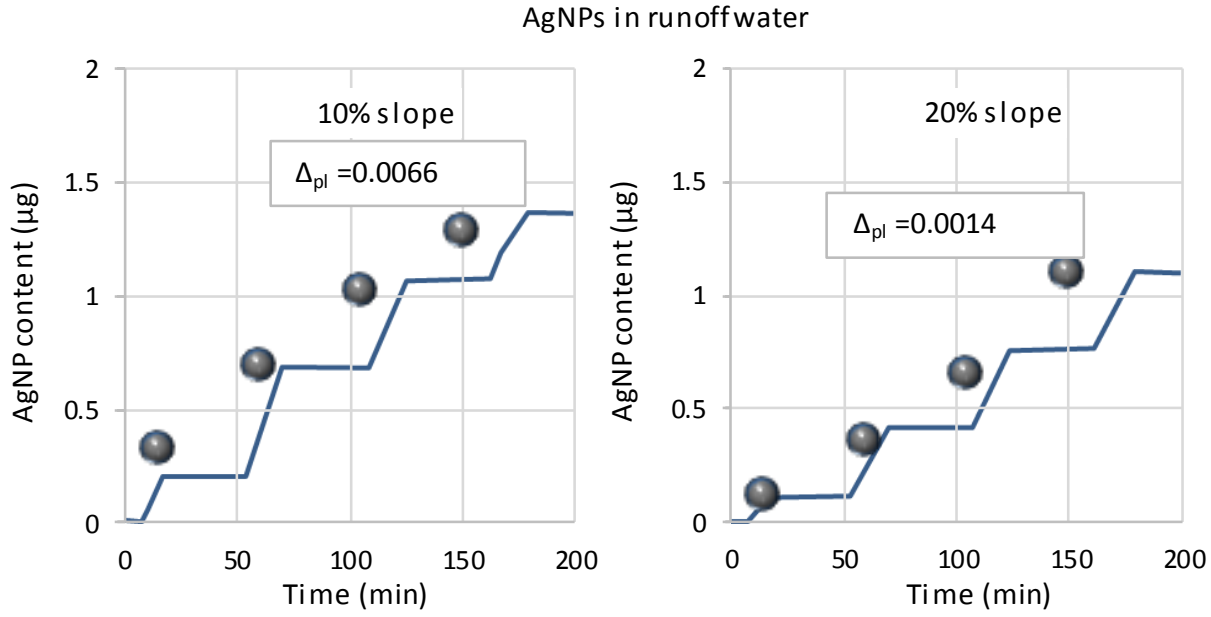

Figure 5.6 Measured (dots) and simulated (line) AgNPs content in runoff water at the outlet of the flume S10 (left) and S2O (right). $\Delta_{p l}$ is the Mean Distance of Points to line.

\subsubsection{AgNP content in the eroded sediments}

PestPost also calculated AgNP content in the eroded sediment transported by runoff water at the flume outlet. Simulated and observed values are shown in Figure 5.7 for both flumes.

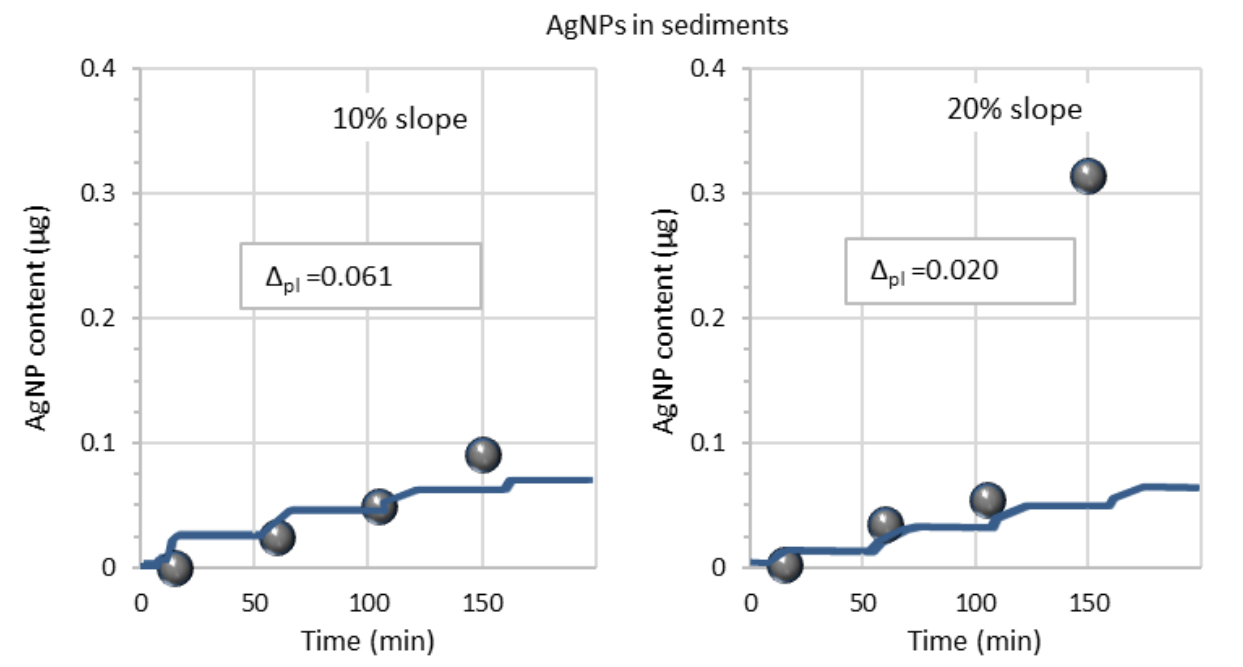

Figure 5.7 The measured (dots) and simulated (line) AgNP content in erosion sediments of the outlet of the flume $S 10$ (left) and S2O (right). $\Delta_{p l}$ is the Mean Distance of Points to line.

First, it can be concluded that AgNP transport by eroded sediment is a magnitude lower compared with the amounts transported by runoff water. Secondly, during the last rain 
event AgNP content in the eroded sediment increased distinctly, especially in flume S20. This may be related to higher amounts of discharged clay and silt fractions and OM in S2O than in S10 (Koiter et al., 2017). These compounds are adsorbing AgNPs most strongly, and are therefore dominant in sediment related AgNP transport processes (Mahdi et al., 2017). In addition, AgNPs transported with runoff water in S20 was slightly lower than observed in S10 (Figure 5.6), indicating that possibly more AgNPs migrated into the sediments and adsorbed to the fine soil fractions and OM in flume S20 than in S10. This might be the explanation for the distinct rise in AgNP content in the eroded sediment during the last rainfall event. If the experiment would have continued longer, it might be expected that transport of AgNPs by eroded sediment might become increasingly important. From that perspective, LISEM and PestPost should be further improved in order to simulate the transport of different soil fractions, including OM. This would provide a more accurate representation of the observed runoff and erosion transport mechanisms of AgNPs in the S10 and S20 flumes.

\subsection{Conclusions}

By combining the LISEM and PestPost models, it was possible to simulate AgNP transport by runoff and erosion processes across experimental flumes. Results indicate that AgNPs are primarily transported by runoff water, and the loss by particulate transport is a magnitude lower. However, in time AgNP adsorption might become more prominent, indicating that erosion induced transport of AgNPs might become increasingly important at the long-term. Furthermore, erosion induced transport of AgNPs is mainly related to displacement of specific soil fractions and OM, which should be accounted for in future runoff and erosion simulation models. Further model improvements and a targeted field experiment might provide additional insights in the transport mechanisms of AgNPs in soil systems. Lastly, the combination of the LISEM and the PestPost models can potentially be used for risk assessment purposes of AgNPs (and other nanomaterials) displacement in the soil-water domain. 


\section{Synthesis}




\subsection{Research findings and discussion}

The field of nanotechnology has evolved quickly over the past 15-20 years as newlyproduced nanomaterials (NMs) offer a wide range of possibilities (Hong et al., 2013; Tran and Le, 2013). World demand for NMs is expected to continue growing and the total future turn-over could reach US\$ 75.8 billion by 2022 (Businesswire 2015). Considering the increased production and popularity of NMs, it stands to reason that more and more nanoparticles will find their way into the environment. This is especially the case for silver nanoparticles (AgNPs) since these particles are used in a wide range of products and applications (Kaegi et al., 2010). Our knowledge and understanding of the distribution and fate of AgNPs in the environment is still limited and many issues need to be resolved (Anjum et al., 2013).

This thesis aims to broaden our knowledge of AgNPs by developing an analytical technique for the detection of AgNPs in soil, by studying the transport and fate of AgNPs in soil systems, and modelling AgNP behaviour. The research findings of the thesis are schematically summarised in Figure 6.1. The development of the analytical method in Chapter 2 allowed us to study the vertical and horizontal transport of AgNPs in soils as described in Chapters 3 and 4. In Chapter 5, AgNP transport over the soil surface was studied and simulated using two combined models.

\subsubsection{Developing a method to extract AgNPs from soils to measure concentration and particle size}

A range of different methods have been used to extract AgNPs from soil (see Chapter 2), however the EPA-method "3051" (EPA 1995) has been used most often. With this method, soil samples that contain AgNPs were digested with strong acids to determine the total concentration as ionic silver instead of AgNPs. As a result, information regarding the particulate size of $\mathrm{Ag}$ in these samples is thereby lost (Whitley et al., 2013). Furthermore, only high AgNP concentrations in soil (ppm range) can be assessed using this method. 


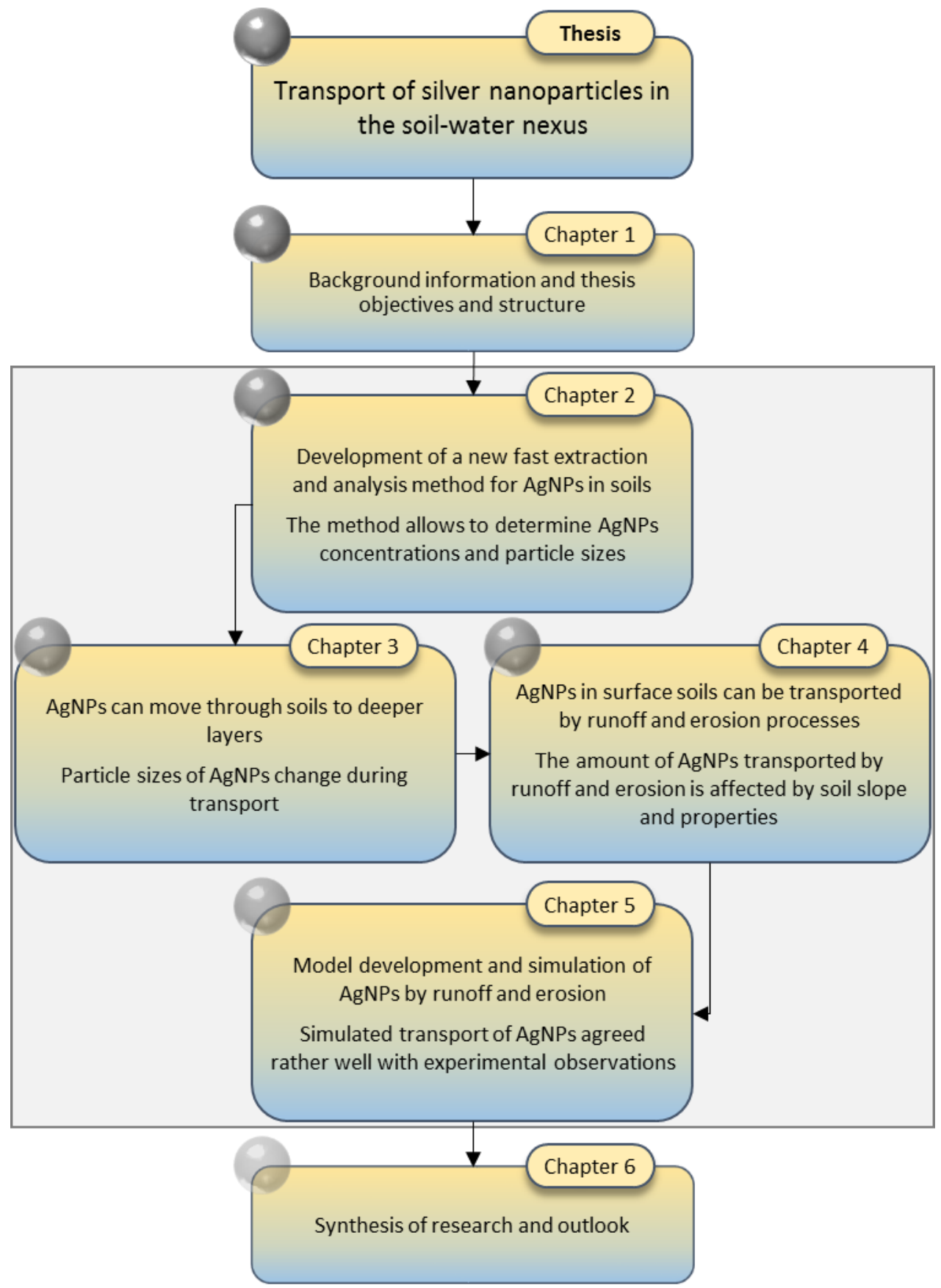

Figure 6.1 Schematic summary of the most important research findings presented in the synthesis. Method development for AgNP detection in soil (Chapter 2) allowed us to measure the vertical transport of AgNPs though soil profiles (Chapter 3) and over soil (Chapter 4). Transport of AgNPs over a soil surface was simulated with the combined LISEM and PestPost models (Chapter 5). 
In this study, we developed a method to detect both the concentration and size of AgNPs in low-level AgNP concentration scenarios in soil. The final method was chosen after testing 4 extraction methods using different approaches. In all of these approaches, 3 soil types (sand, loam and clay) were used to test the recovery rate of the spiked AgNPs in order to understand the effect of the different soil properties on the recovery process. The aqueous extraction combined with single-particle ICP-MS for detection and characterization of AgNPs appeared to provide the best results and highest rates. The lowest limit of AgNP concentration detection ( $\mathrm{LOD}_{\text {con }}$ ) using this method is $5 \mu \mathrm{g} \mathrm{kg}^{-1}$. This method can also be used to determine particle size distribution within the soil samples, which can help to determine the behaviour of AgNPs applied to different soil types.

Detection of AgNPs in soil is often difficult due to the complexity of the soil matrix. This complexity forces the applied AgNPs to undergo transformations once they are released into the soil which can significantly reduce their recovery (Brunetti et al., 2015). Therefore, there have been very few studies attempting to detect AgNPs in soil samples and even in the few cases where detection was undertaken, the methods used involved long processes due to the multiple analytical instruments required (Koopmans et al., 2015). Furthermore, the recovery rate of AgNPs from soil is often low. Coutris et al. (2012) reported a recovery rate of $21 \%$ two hours after spiking the soil and only $0.3 \%$ of the AgNPs were recovered after two days. Whiteley et al. (2013) also reported low recoveries for AgNPs extraction $(<10 \%)$ in his study.

We found that AgNP extraction recovery using the newly developed method ranged from $32 \%$ for sandy soil to $46 \%$ for clayey soil. The method was tested further to prove its repeatability (RSDr) and reproducibility (RSDR) in the analyses. The method showed high RSDr and RSDR which made the method useful and acceptable for a validation level of 50 $\mu \mathrm{g} \mathrm{kg}{ }^{-1}$ (initial concentration) since the calculated Horwitz ratios were within the acceptance range of $0.5-2$ (Horwitz and Albert, 2006).

The aqueous method we developed for extraction combined with the spICP-MS technique enabled the detection of low concentration AgNPs that exist in soil samples in a particle form but not in an ionic form (digestion). The extraction of AgNPs from soil were affected by soil organic matter and cation exchange capacity. Therefore, these should always be taken into account when assessing the transport of AgNPs through/over soil. Furthermore, soil particle-size distribution should also be considered since AgNPs showed a higher affinity for transport with smaller-sized soil particles. 


\subsubsection{Soil column experiment to determine vertical transport of AgNPs and related particle changes}

After developing a method to extract AgNPs from soil samples in Chapter 3, we applied this method in tracking the vertical transport patterns for AgNPs in soil columns and leachate. AgNP transport in soil columns has been examined in other studies also (Cornelis et al., 2013; Hoppe et al., 2015; Sagee et al., 2012). However, in most of these studies, AgNP concentration was applied to soil in higher concentrations than in real-life scenarios. Furthermore, as discussed in the previous section, the analysis of the AgNPs extracted from soil layers was mostly done by digesting the soil samples, which diminishes any possibility to examine any changes to AgNP size during transport within the soil. In addition to this, in most studies, AgNPs were normally applied to the soil using spraying techniques (such as in pesticides) which is not the case in real real-case scenarios as see indicated the study of Sagee et al. (2012).

In our study, low concentrations of AgNPs were applied to the soil and the application procedures mimicked realistic scenarios of AgNP application to soil (sludge application). AgNP transport was tested using 3 different soil types: loam soil with high $(3.4 \pm 0.46)$ organic matter (LSH), loam sand with low $(1.8 \pm 0.11$ ) organic matter $(\mathrm{LSH})$, and sand (without organic matter) to compare the impact of different soil characteristics on AgNP transport. The experiment was conducted using a series of soil columns. Each soil column was divided into 4 equal layers and each of these layers were subject to detection of AgNP concentration and particle size. Soil physical properties (texture) and chemical properties (cation exchange capacity (CEC), organic matter (OM), and ionic strength (IS)) were measured for each layer. Soil physical properties mainly affected the transported amount of AgNPs while the soil chemical properties affected the changes in AgNP size, as was also observed by Liang et al. (2013b).

In the sandy soil columns, transport of AgNPs was higher than in the loam soils. Main reason is that sandy soil contains less clay and silt than the loam soils, leading to increased mobility of AgNPs in the sandy soils, as also observed by El Badawy et al. (2013). CEC is also higher in the loamy soils, resulting in stronger binding of AgNPs than in sandy soils, as shown earlier by Bronick and Lal (2000) also. As a result, the amount of transported AgNPs was lowest in the LSH column, followed by LSL and thereafter Sand, see Figure 6.2. As a result, AgNP concentrations were highest in the different soil column layers as well as the collected leachate water (Figure 6.2). Liang et al. (2013a) and Tian et al. (2010) observed similar patterns. 


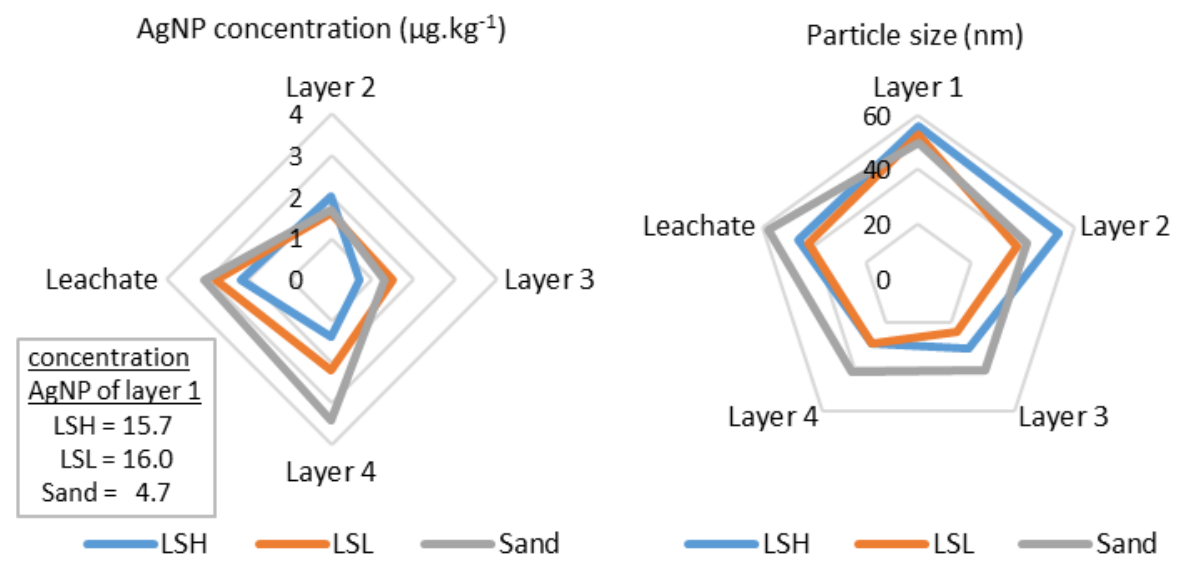

Figure 6.2 AgNP size and concentration after the column experiment. The depth for layer 1 is $0-4 \mathrm{~cm}$, layer 2 is 4-8 cm, layer 3 is $8-12 \mathrm{~cm}$ and layer 4 is $12-16 \mathrm{~cm}$. Soils used in the column experiment were loam soil with high organic matter (LSH), loam sand with low organic matter (LSH) and sand (no organic matter). AgNP size at the start of the column experiment was $60 \mathrm{~nm}$ and the initial AgNP concentration was

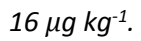

The AgNP particle size decreased significantly with time and depth in the LSH and LSL soil columns, see Figure 6.2. Reduction of AgNP size was less pronounced in the column packed with sand, due to lower organic matter content and CEC levels compared with the loamy soils. Higher organic matter content and CEC levels will increase AgNP adsorption and enhance AgNP dissolution also, as earlier stated by Coutris et al. (2012) and Liang et al. (2013a). Interestingly, the AgNP size in the effluent water of the sand column is almost identical to the size of originally applied AgNP in layer 1 of the columns, indicating a fast and almost non-reactive transport towards the bottom of the soil column. For the LSH and LSL columns this was not the case. Nevertheless, results indicate that AgNPs indeed can be transported towards the subsoil and possibly groundwater reservoirs.

\subsubsection{AgNP transport and distribution on the soil surface due to surface runoff}

Based on the results obtained from Chapter 3, we found that around $90 \%$ of the AgNPs applied to soil were retained in the first layer, even after multiple rain events. Therefor, AgNPs that remain in this surface layer could be subjected to runoff and erosion processes, potentially leading to off-site AgNP pollution. Such behaviour has also been found for multiple other compounds like herbicides (Ulén et al., 2014), pesticides (Candela et al., 2010) and heavy metals (He et al., 2004). 
In this study, AgNP transport by runoff and erosion processes during multiple rainfall events was analysed using an experimental flume setup. In this setup, runoff and erosion occurred as infiltration excess overland flow, which is common for most rainfall experiments (Dunkerley, 2008).

AgNP content was determined across the flume, namely in non-eroded soil (BS), replaced soil material on the flume surface (SS), and in discharge water (RW) and sediment collected of the flume (RS), as shown in Figure 6.3. Results indicate that AgNP displacement to the BS and RW compartments were more or less identical for both flumes. Largest differences between the S10 and S20 flumes were related to the SS and RS compartments, indicating clearly more sediment loss from the S20 flume than the S10 one.
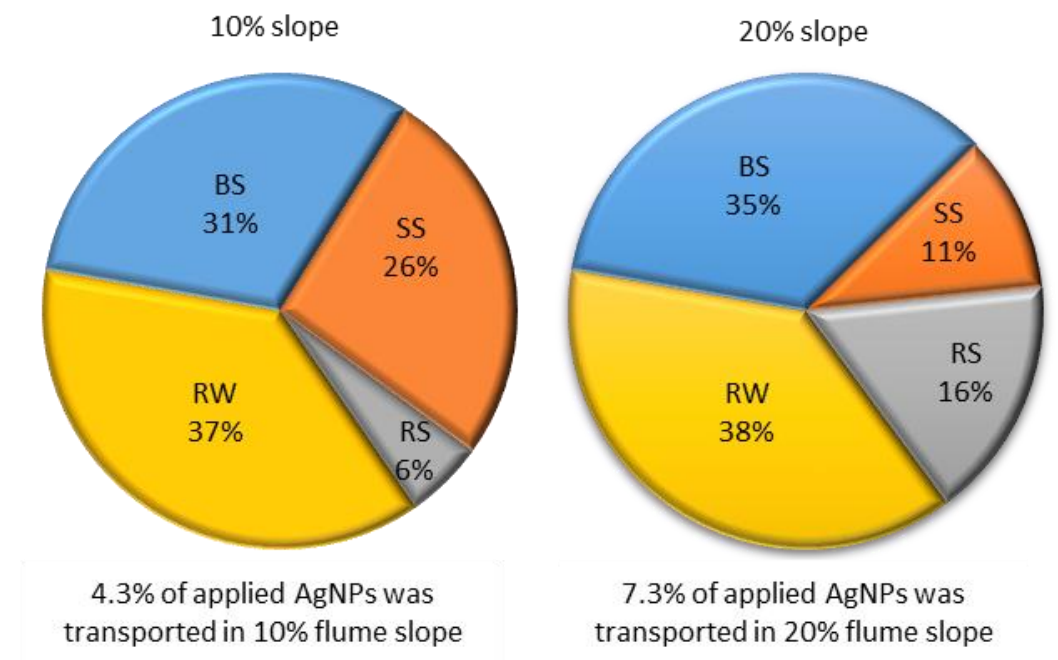

Figure 6.3 Amount of AgNPs detected in different compartments after the flume experiment in background soil (BS), flume sediment (SS), runoff water (RW) and runoff sediment (RS).

\subsubsection{Simulation of transport of AgNPs by runoff and erosion using LISEM and PestPost models}

The results presented in the previous section (6.1.3) showed the ability of AgNPs to be transported and redistributed by runoff and erosion processes. To simulate the transport of AgNPs over the soil surface, we combined 2 models: a hydrological soil erosion model (LISEM), used to simulate runoff and erosion processes (Jetten 2002) and a particletransport model (PestPost) used to simulate AgNP transport across soil surfaces. The two models were calibrated separately using measured data from the laboratory experiments. 
The LISEM simulated water and sediment losses from the flumes rather well, in particular for the water component. Furthermore simulated sediment losses were higher for the S20 flume due to faster and more concentrated flow paths than observed in the S10 flume.

The LISEM results were tested for their validity using the Nash-Sutcliffe efficiency (MEF) approach. High model efficiency (MEF) values for both sediment (MEF=0.81) and runoff (MEF=0.79) were achieved. According to Moriasi et al. (2007), a MEF value between 0.75 and 1.0 is regarded as a "very good performance" for a model simulation.

In PestPost, a simple mass balance solution was been combined with a direct-search optimization procedure in order to find the parameters that yielded the best approximation of the measured AgNP values in runoff and erosion. The applied criterion was the Mean Distance of Points to Line $\left(\Delta_{\mathrm{pl}}\right)$ criterion (Wesseling et al., 2008), where the measured values were considered as points and the simulated values as a line. Our results showed that the simulation of AgNP content transport with runoff water was more robust than that in the eroded sediment for both flumes ( $\Delta_{\mathrm{pl}}<1 \%$ for runoff, and $\Delta_{\mathrm{pl}}=6.1 \%$ and $20.3 \%$ for sediment in S10 and S20, respectively). This difference in results for sediment might be related to the increasing AgNP content in the sediment after each single rainfall event due to the increased AgNP adsorption on soil particles (as described in the previous section).

The current work is regarded as the first simulation study of nano-based material transport (AgNPs) via soil erosion and runoff. Therefor it is advancing the state of knowledge and contribute to better understanding of potential off-site impacts. Especially, the integrated dynamic and event-based modelling approach is adding value, and can support future studies in this domain in particular.

\subsection{Implications}

\subsubsection{Implication for the environment}

The fate and transport processes of AgNPs in soils are affected by AgNP characteristics (particle size, concentration) and soil physical-chemical properties. AgNP interaction with soil cations might result in decreasing AgNP size, which possibly influence toxicity levels of AgNPs for soil organisms and plants (Li et al., 2015; Tian et al., 2010). Soil organic matter can prevent AgNPs from moving though soil towards ground water systems (Sagee et al., 2012). Often, AgNP contents in soil are low and detection is rather difficult. For that purpose, a robust AgNP extraction method from soils is required. 
The in this study newly developed extraction method, using state-of-the-art technologies, facilitated rapid detection of AgNP in soils, including providing information about particle sizes. This means that flow and transport processes of AgNP across soil-water compartments can be studied more accurately, providing insights in compound behaviour and on- and off-site impacts. The combined LISEM and PestPost models offer the possibility to execute scenario analysis for more detailed future projections, and related risk assessments.

\subsubsection{Implication for society and regulation}

AgNPs (and other NPs) are often described as emerging pollutants (Geissen et al., 2015). Although AgNPs have greatly improved our daily-life through a range of products and applications, they may also pose an impact on the environment as a result of pollution and related societal and health aspects (National Research, 2005, Stander and Theodore, 2011).

Therefore, more process knowledge is required to better understand flow and transport of AgNPs across environmental domains. Furthermore, it might be needed to derive critical thresholds levels in order to protect the environment. So far, from a regulatory point of view, additional efforts are required to ensure protection of soil life, plants, organisms and people. In addition, remediation strategies to clean up sites with AgNP contamination levels deserve attention also. Minimizing hazard risks is essential and expected in society.

\subsection{Limitation of the study and recommendations for future research}

During this study, some challenges were uncovered that should be addressed in the future such as:

- More research is needed to develop a method that can increase the limit of detection for ions released from AgNPs and attached to soil particles due to dissolution.

- Combining lateral and downward transport processes (surface runoff and leaching) in an overarching empirical and modelling approach would benefit better understanding of AgNP behaviour in soil systems.

- Ecotoxicological risk assessments are required to determine effects of AgNPs on soil organisms, aquatic life and plants/crops.

- More detailed studies on the behaviour and dynamics of other nano materials in the environment deserve the required attention. 


\section{Literature cited}

Ahamed M., Al Salhi M.S., Siddiqui M.K.J. 2010. Silver nanoparticle applications and human health. Clinica Chimica Acta 411:1841-1848.

Allen H.J., Impellitteri C.A., Macke D.A., Heckman J.L., Poynton H.C., Lazorchak J.M., Govindaswamy S., Roose D.L., Nadagouda M.N. 2010. Effects from filtration, capping agents, and presence/absence of food on the toxicity of silver nanoparticles to Daphnia magna. Environmental Toxicology and Chemistry 29:2742-2750.

Anjum N.A., Gill S.S., Duarte A.C., Pereira E., Ahmad I. 2013. Silver nanoparticles in soil-plant systems. Journal of Nanoparticle Research 15:1-26.

Aqion, 2016 Electrical Conductivity (EC). Retrieved from Http://www.aqion.de/.

ASTM 2000. Standard test methods for moisture, ash, and organic matter of peat and other organic soils. American Society of Testing and Materials. doi 10:D2974.

Auffan M., Rose J., Bottero J-Y., Lowry G.V., Jolivet J-P., Wiesner M.R. 2009. Towards a definition of inorganic nanoparticles from an environmental, health and safety perspective. Nature Nanotechnology 4:634.

Baartman J.E.M., Jetten V.G., Ritsema C.J., Vente J. 2012. Exploring effects of rainfall intensity and duration on soil erosion at the catchment scale using openLISEM: Prado catchment, SE Spain. Hydrological Processes 26:1034-1049.

Baartman J.E.M., Temme A.J.A.M., Veldkamp T., Jetten V.G. and Schoorl J.M. 2013. Exploring the role of rainfall variability and extreme events in long-term landscape development. Catena 109:25-38.

Batley G.E., Kirby J.K. and McLaughlin M.J. 2012. Fate and risks of nanomaterials in Aquatic and Terrestrial Environments. Accounts of Chemical Research 46:854-862.

Benelmekki M., 2015. Designing hybrid nanoparticles: Morgan \& Claypool Publishers.

Benn T.M., Westerhoff P. 2008. Nanoparticle silver released into water from commercially available sock fabrics. Environmental Science and Technology 42:4133-4139.

Bergeson L.L. 2010. Nanosilver pesticide products: what does the future hold? Environmental Quality Management 19:73-82.

Blaser S.A., Scheringer M., MacLeod M., Hungerbühler K. 2008. Estimation of cumulative aquatic exposure and risk due to silver: contribution of nano-functionalized plastics and textiles. Science of the Total Environment 390:396-409.

Blokker A.C.M. 2014. Assessing soil erosion resulting from laboratory rainfall simulation using close-range photogrammetry. Master thesis, Wageningen University and Research. 
Bolea E., Jimenez-Lamana J., Laborda F., Castillo J.R. 2011. Size characterization and quantification of silver nanoparticles by asymmetric flow field-flow fractionation coupled with inductively coupled plasma mass spectrometry. Analytical and Bioanalytical Chemistry 401:2723-2732.

Bout B., Jetten V.G. 2018. The validity of flow approximations when simulating catchmentintegrated flash floods. Journal of Hydrology 556:674-688.

Brar S.K., Verma M., Tyagi R.D., Surampalli R.Y. 2010. Engineered nanoparticles in wastewater and wastewater sludge - Evidence and impacts. Waste Management 30:504-520.

Bronick C.J., Lal R. 2005. Soil structure and management: a review. Geoderma 124: 3-22.

Brunetti G., Donner E., Laera G., Sekine R., Scheckel K.G., Khaksar M., Vasilev K., De Mastro G., Lombi E. 2015. Fate of zinc and silver engineered nanoparticles in sewerage networks. Water Research 77:72-84.

Businesswire 2015. Global nanotechnology market outlook 2022. Reportlinker https://www.reportlinker.com.

Bystrzejewska-Piotrowska G., Golimowski J., Urban P.L. 2009. Nanoparticles: their potential toxicity, waste and environmental management. Waste Management 29:2587-2595.

Cammeraat L.H., Imeson A.C. 1998. Deriving indicators of soil degradation from soil aggregation studies in southeastern Spain and southern France. Geomorphology 23:307-321.

Candela L., Caballero J., Ronen D. 2010. Glyphosate transport through weathered granite soils under irrigated and non-irrigated conditions, Barcelona, Spain. Science of the Total Environment 408:2509-2516.

Cascio C., Geiss O., Franchini F., Ojea-Jimenez I., Rossi F., Gilliland D., Calzolai L. 2015. Detection, quantification and derivation of number size distribution of silver nanoparticles in antimicrobial consumer products. Journal of Analytical Atomic Spectrometry 30:1255-1265.

Chen X., Schluesener H.J., 2008. Nanosilver: A nanoproduct in medical application. Toxicology Letters 176:1-12.

Cornelis G., DooletteMadeleine Thomas C., McLaughlin M.J., Kirby J.K., Beak D.G., Chittleborough D. 2012. Retention and dissolution of engineered silver nanoparticles in natural soils. Soil Science Society of America Journal 76:891-902.

Cornelis G., Pang L., Doolette C., Kirby J.K., McLaughlin M.J. 2013. Transport of silver nanoparticles in saturated columns of natural soils. Science of the Total Environment 463:120-130.

Cortie M.B., Van der Lingen E. 2002. Catalytic gold nano-particles. Institute of Materials Engineering Australasia Ltd.

Coutris C., Joner E.J., Oughton D.H. 2012. Aging and soil organic matter content affect the fate of silver nanoparticles in soil. Science of the Total Environment 420:327-333. 
Creed J.T., Magnuson M.L., Pfaff J.D., Brockhoff C. 1996. Determination of bromate in drinking waters by ion chromatography with inductively coupled plasma mass spectrometric detection. Journal of Chromatography A 753:261-267.

Dai W., Kheireddin B., Gao H., Liang H. 2016. Roles of nanoparticles in oil lubrication. 2016. Tribology International 102:88-98.

Dakal T.C., Kumar A., Majumdar R.S., Yadav V. 2016. Mechanistic basis of antimicrobial actions of silver nanoparticles. Frontiers in Microbiology 7:1831.

Dale A.L., Casman E.A., Lowry G.V., Lead J.R., Viparelli E., Baalousha M. 2015. Modeling nanomaterial environmental fate in aquatic systems. Environmental Science \& Technology 49:2587-2593.

De Roo A.P.J., Offermans R.J.E. 1995. LISEM: A physically-based hydrological and soil erosion model for basin-scale water and sediment management. IAHS Publications-Series of Proceedings and Reports-Intern Assoc Hydrological Sciences 231:399-408.

De Roo A.P.J., Wesseling C.G., Cremers N., Offermans R.J.E., Ritsema C.J., Van Oostindie K. 1994. LISEM: a new physically-based hydrological and soil erosion model in a GISenvironment, theory and implementation. IAHS Publications-Series of Proceedings and Reports-Intern Assoc. Hydrological Sciences 224:439-448.

De Roo A.P.J., Wesseling C.G., Ritsema C.J. 1996. LISEM: A single-event physically based hydrological and soil erosion model for drainage basins. I: theory, input and output. Hydrological Processes 10:1107-1117.

Devia G.K., Ganasri B.P., Dwarakish G.S. 2015. A review on hydrological models. Aquatic Procedia 4:1001-1007.

Dimkpa, C.O., McLean J.E., Martineau N., Britt D.W., Haverkamp R., Anderson A.J. 2013. Silver nanoparticles disrupt wheat (Triticum aestivum L.) growth in a sand matrix. Environmental Science \& Technology 47:1082-1090.

Domingos R.F., Baalousha M.A., Ju-Nam Y., Reid M.M., Tufenkji N., Lead J.R., Leppard G.G., Wilkinson K.J. 2009. Characterizing manufactured nanoparticles in the environment: multimethod determination of particle sizes. Environmental Science \& Technology 43:7277-7284.

Dunkerley D. 2008. Rain event properties in nature and in rainfall simulation experiments: a comparative review with recommendations for increasingly systematic study and reporting. Hydrological Processes 22:4415-4435.

Durán N., Marcato P.D., Alves O.L., De Souza G.I.H., Esposito E. 2005. Mechanistic aspects of biosynthesis of silver nanoparticles by several Fusarium oxysporum strains. J Nanobiotechnol 3:1-7.

EC 2011. Commission Recommendation of 18 October 2011 on the definition of nanomaterial (2011/696/EU). 
EC 2017. Assessing the environmental safety of manufactured nanomaterials. In-depth Report 14 produced for the European Commission, DG Environment by the Science Communication Unit, UWE, Bristol. European Commission.

Echegoyen Y. 2015. Nano-developments for food packaging and labeling applications. Nanotechnologies in Food and Agriculture 141-166.

El Badawy A.M., Aly Hassan A., Scheckel K.G., Suidan, M.T., Tolaymat T.M. 2013. Key factors controlling the transport of silver nanoparticles in porous media. Environmental Science \& Technology 47:4039-4045.

Englert B. C. 2007. Nanomaterials and the environment: uses, methods and measurement. Journal of Environmental Monitoring 9:1154-1161.

EPA 1995: Microwave assisted acid digestion of sediments, sludges, soils, and oils. Test methods for evaluating solid waste: A3051.

Fabrega J., Luoma S.N., Tyler C.R., Galloway T.S., Lead J.R. 2011. Silver nanoparticles: behaviour and effects in the aquatic environment. Environment International 37:517531.

Farkas J., Christian P., Urrea J.A.G., Roos N., Hassellöv M., Tollefsen K.E., Thomas K.V. 2010. Effects of silver and gold nanoparticles on rainbow trout (Oncorhynchus mykiss) hepatocytes. Aquatic Toxicology 96:44-52.

Feynman R.P. 1960. There's plenty of room at the bottom. Engineering and Science 23:2236.

Franze B., Engelhard C. 2014. Fast separation, characterization, and speciation of gold and silver nanoparticles and their ionic counterparts with micellar electrokinetic chromatography coupled to ICP-MS. Analytical chemistry 86:5713-5720.

Gaillet S., Rouanet J-M 2015. Silver nanoparticles: Their potential toxic effects after oral exposure and underlying mechanisms - A review. Food and Chemical Toxicology 77:5863.

Geissen V., Mol H., Klumpp E., Umlauf G., Nadal M., van der Ploeg M., Van der Zee S.E., Ritsema C.J. 2015. Emerging pollutants in the environment: A challenge for water resource management. International Soil and Water Conservation Research 3:57-65.

Gliga A.R., Skoglund S., Wallinder I.O., Fadeel B., Karlsson H.L. 2014. Size-dependent cytotoxicity of silver nanoparticles in human lung cells: the role of cellular uptake, agglomeration and $\mathrm{Ag}$ release. Particle and Fibre Toxicology 11:11.

Goldman L., Coussens C. 2005. Implications of nanotechnology for environmental health research; National Academies Press: Washington DC.

Gottschalk F., Nowack B. 2011. The release of engineered nanomaterials to the environment. Journal of Environmental Monitoring 13:1145-1155.

Gottschalk F., Sonderer T., Scholz R.W., Nowack B. 2009. Modeled environmental concentrations of engineered nanomaterials (TiO2, $\mathrm{ZnO}, \mathrm{Ag}, \mathrm{CNT}$, fullerenes) for different regions. Environmental Science and Technology 43:9216-9222. 
Gottschalk F., Sun T., Nowack B. 2013. Environmental concentrations of engineered nanomaterials: review of modeling and analytical studies. Environmental Pollution 181:287-300.

Govers G. 1992. Relationship between discharge, velocity and flow area for rills eroding loose, non-layered materials. Earth Surface Processes and Landforms 17:515-528.

Griffitt, R.J., Brown-Peterson N.J., Savin D. A., C.S. Manning I. Boube R.A. Ryan, Brouwer M. 2012. Effects of chronic nanoparticulate silver exposure to adult and juvenile sheepshead minnows (Cyprinodon variegatus). Environmental Toxicology and Chemistry 31:160-167.

Handy R.D., van den Brink N., Chappell M., Mühling M., Behra R., Dušinská M., Simpson P., Ahtiainen J., Jha A.N., Seiter J. 2012. Practical considerations for conducting ecotoxicity test methods with manufactured nanomaterials: what have we learnt so far? Ecotoxicology 21:933-972.

Hänsch M., Emmerling C. 2010. Effects of silver nanoparticles on the microbiota and enzyme activity in soil. Journal of Plant Nutrition and Soil Science 173:554-558.

He Z.L., Zhang M.K., Calvert D.V., Stoffella P.J., Yang X.E., Yu S. 2004. Transport of heavy metals in surface runoff from vegetable and citrus fields. Soil Science Society of America Journal 68:1662-1669.

Helmlinger J., Sengstock C., Groß-Heitfeld C., Mayer C., Schildhauer T.A., Köller M., Epple M. 2016. Silver nanoparticles with different size and shape: equal cytotoxicity, but different antibacterial effects. RSC Advances 6:18490-18501.

Hessel R., Jetten V., Guanghui Z. 2003a. Estimating Manning's n for steep slopes. Catena 54:77-91.

Hessel R., Jetten V., Liu B., Zhang Y., Stolte J. 2003b. Calibration of the LISEM model for a small Loess Plateau catchment. Catena 54:235-254.

Ho C.M., Wong C.K., Yau S.K.W., Lok C.N., Che C. M. 2011. Oxidative dissolution of silver nanoparticles by dioxygen: a kinetic and mechanistic study. Chemistry-an Asian Journal 6:2506-11.

Holder A.L., Vejerano E.P., Zhou X., Marr L.C. 2013. Nanomaterial disposal by incineration. Environmental Science: Processes and Impacts 15:1652-1664.

Hong J., Peralta-Videa J.R., Gardea-Torresdey J.L. 2013. Nanomaterials in agricultural production: benefits and possible threats? Sustainable nanotechnology and the environment: advances and achievements. ACS Publications pp. 73-90.

Hoppe M., Mikutta R., Utermann J., Duijnisveld W., Kaufhold S., Stange C.F., Guggenberger G. 2015. For remobilization of sterically stabilized silver nanoparticles from farmland soils determined by column leaching. European Journal of Soil Science 66:898-909.

Horwitz W. 2002. AOAC guidelines for single laboratory validation of chemical methods for dietary supplements and botanicals. AOAC International: Gaithersburg MD, USA. 
Horwitz W., Albert R. 2006. The Horwitz ratio (HorRat): a useful index of method performance with respect to precision. Journal of AOAC International 89:1095-1109.

Hou J., Zhang M., Wang P., Wang C., Miao L., Xu Y., You G., Lv B., Yang Y., Liu Z. 2017. Transport, retention, and long-term release behavior of polymer-coated silver nanoparticles in saturated quartz sand: The impact of natural organic matters and electrolyte. Environmental Pollution 229:49-59.

ISO 1994. Soil quality-Determination of effective cation exchange capacity and base saturation level using Barium Chloride Solution. ISO 11260.

ISO 2010. Nanotechnologies vocabulary, part 1: Core terms. International Organization for Standardization.

Jetten V. 2002. LISEM: Limburg Soil Erosion Model. Utrecht University. Utrecht, the Netherlands.

Jetten V. 2017. LISEM Limburg Soil Erosion Model v 3.9 x. Documentation and User Manual. Kaegi R., Sinnet B., Zuleeg S., Hagendorfer H., Mueller E., Vonbank R., Boller M., Burkhardt M. 2010. Release of silver nanoparticles from outdoor facades. Environmental Pollution 158:2900-2905.

Kah M., Hofmann T. 2014. Nanopesticide research: current trends and future priorities. Environment international 63:224-235.

Kaiser J.P., Diener L., Wick P. 2013. Nanoparticles in paints: A new strategy to protect façades and surfaces? 429. IOP Publishing pp. 012036.

Kim T.H., Kim M., Park H.S., Shin U.S., Gong M.S., Kim H.W. 2012. Size-dependent cellular toxicity of silver nanoparticles. Journal of Biomedical Materials Research Part A 100:1033-1043.

Klaine S.J., Koelmans A.A., Horne N., Carley S., Handy R.D., Kapustka L., Nowack B., von der K. 2012. Paradigms to assess the environmental impact of manufactured nanomaterials. Environmental Toxicology and Chemistry 31:3-14.

Klitzke S., Metreveli G., Peters A., Schaumann G.E., Lang F. 2015. The fate of silver nanoparticles in soil solution - Sorption of solutes and aggregation. Science of the Total Environment 535:54-60.

Koiter A.J., Owens P.N., Petticrew E.L., Lobb D.A. 2017. The role of soil surface properties on the particle size and carbon selectivity of interrill erosion in agricultural landscapes. Catena 153: 194-206.

Koopmans G.F., Hiemstra T., Regelink I.C., Molleman B., Comans R.N.J. 2015. Asymmetric flow field-flow fractionation of manufactured silver nanoparticles spiked into soil solution. Journal of Chromatography A 1392:100-109.

Kraas M., Schlich K., Knopf B., Wege F., Kägi R., Terytze K., Hund-Rinke K. 2017. Long-term effects of sulfidized silver nanoparticles in sewage sludge on soil microflora. Environmental Toxicology and Chemistry. 
Kumar N., Palmer G.R., Shah V., Walker V.K. 2014. The effect of silver nanoparticles on seasonal change in arctic tundra bacterial and fungal assemblages. PloS ONE 9:e99953.

Kumahor S.K., Hron P., Metreveli G., Schaumann G.E., Klitzke S., Lang F., Vogel H-J. 2016. Transport of soil-aged silver nanoparticles in unsaturated sand. Journal of Contaminant Hydrology 195:31-39.

Kwak J.I., An Y-J. 2015. Ecotoxicological effects of nanomaterials on earthworms: a review. Human and Ecological Risk Assessment 21:1566-1575.

Laborda F., Bolea E., Jiménez-Lamana J. 2013. Single particle inductively coupled plasma mass spectrometry: a powerful tool for nanoanalysis. Analytical Chemistry 86: $2270-$ 2278.

Lapied E., Moudilou E., Exbrayat J-M, Oughton D.H. Joner E.J. 2010. Silver nanoparticle exposure causes apoptotic response in the earthworm Lumbricus terrestris (Oligochaeta). Nanomedicine 5:975-984.

Lassu T., Seeger M. 2012. Set-up and calibration of an indoor nozzle-type rainfall simulator for soil erosion studies. EGU General Assembly Conference 14 pp. 9966.

Lassu T., Seeger M., Peters P., Keesstra S.D. 2015. The Wageningen rainfall simulator: Setup and calibration of an indoor nozzle-type rainfall simulator for soil erosion studies. Land Degradation \& Development 26:604-612.

Li L., Wu H., Peijnenburg W.J.G.M., van Gestel C.A.M. 2015. Both released silver ions and particulate $\mathrm{Ag}$ contribute to the toxicity of AgNPs to earthworm Eisenia fetida. Nanotoxicology 9:792-801.

Liang Y., Bradford S.A., Simunek J., Heggen M., Vereecken H., Klumpp E. 2013a. Retention and remobilization of stabilized silver nanoparticles in an undisturbed loamy sand soil. Environmental Science and Technology 47:12229-12237.

Liang Y., Bradford S.A., Simunek J., Vereecken H., Klumpp E. 2013b. Sensitivity of the transport and retention of stabilized silver nanoparticles to physicochemical factors. Water Research 47:2572-82.

Lin S., Huang R., Cheng Y., Liu J., Lau B.L.T., Wiesner M.R. 2013. Silver nanoparticle-alginate composite beads for point-of-use drinking water disinfection. Water Research 47:39593965.

Linsinger T.P.J., Peters R., Weigel S. 2014. International interlaboratory study for sizing and quantification of Ag nanoparticles in food simulants by single-particle ICPMS. Analytical and bioanalytical chemistry 406:3835-3843.

Liu J., Jiang G. 2015. Silver nanoparticles in the environment. Springer.

Liu J., Sonshine D.A., Shervani S., Hurt R.H. 2010. Controlled release of biologically active silver from nanosilver surfaces. ACS nano 4:6903-6913.

Lombi E., Donner E., Scheckel K.G., Sekine R., Lorenz C., Von Goetz N., Nowack B. 2014. Silver speciation and release in commercial antimicrobial textiles as influenced by washing. Chemosphere 111:352-358. 
Lombi E., Donner E., Taheri S., Tavakkoli E., Jämting Å.K., McClure S., Naidu R., Miller B.W., Scheckel K.G., Vasilev K. 2013. Transformation of four silver/silver chloride nanoparticles during anaerobic treatment of wastewater and post-processing of sewage sludge. Environmental Pollution 176:193-7.

López-Serrano A., Olivas R.M., Landaluze J.S., Cámara C. 2014. Nanoparticles: a global vision. Characterization, separation, and quantification methods. Potential environmental and health impact. Analytical Methods 6:38-56.

Lorenz C., Hagendorfer H., von Goetz N., Kaegi R., Gehrig R., Ulrich A., Scheringer M., Hungerbühler K. 2011. Nanosized aerosols from consumer sprays: experimental analysis and exposure modeling for four commercial products. Journal of Nanoparticle Research 13:3377-3391.

Lowry G.V., Hotze E.M., Bernhardt E.S., Dionysiou D.D., Pedersen J.A., Wiesner M.R., Xing B. 2i010. Environmental occurrences, behavior, fate, and ecological effects of nanomaterials: an introduction to the special series. Journal of Environmental Quality 39:1867-1874.

Luoma S.N. 2008. Silver nanotechnologies and the environment. The Project on Emerging Nanotechnologies, Report 15.

Mahdi K.N.M., Commelin M., Peters R.J.B., Baartman J.E.M., Ritsema C.J., Geissen V. 2017. Transport of silver nanoparticles by runoff and erosion - A flume experiment. Science of the Total Environment 601-602:1418-1426.

Mahdi K.N.M., Peters R.J.B., Klumpp E., Bohme S., van der Ploeg M., Ritsema C.J., Geissen V. 2016. Silver nanoparticles in soil: Aqueous extraction combined with single-particle ICP-MS for detection and characterization. Environmental Nanotechnology, Monitoring \& Management 7:24-33.

Malysheva A., Ivask A., Hager C., Brunetti G., Marzouk E.R., Lombi E., Voelcker N.H. 2016. Sorption of silver nanoparticles to laboratory plastic during (eco) toxicological testing. Nanotoxicology 10:385-390.

Mattarozzi M., Suman M., Cascio C., Calestani D., Weigel S., Undas A., Peters R. 2017. Analytical approaches for the characterization and quantification of nanoparticles in food and beverages. Analytical and Bioanalytical Chemistry 409:63-80.

McKenzie N., Coughlan K., Cresswell H. 2002. Soil physical measurement and interpretation for land evaluation. Csiro Publishing.

Moriasi D.N., Arnold J.G., Van Liew M.W., Bingner R.L., Harmel R.D., Veith T.L. 2007. Model evaluation guidelines for systematic quantification of accuracy in watershed simulations. Transactions of the ASABE 50:885-900.

Mueller N.C., Nowack B. 2008. Exposure modeling of engineered nanoparticles in the environment. Environmental Science \& Technology 42:4447-53.

Musee N. 2011. Nanowastes and the environment: Potential new waste management paradigm. Environment International 37:112-128. 
Nanodatabase 2017. The Nanodatabase is developed by the DTU Environment. Technical University of Denmark (DTU).

Nash J.E., Sutcliffe J.V. 1970. River flow forecasting through conceptual models part I-A discussion of principles. Journal of Hydrology 10:282-290.

National Research C. 2005. Implications of nanotechnology for environmental health research. The National Academies Press.

Navratilova J., Praetorius A., Gondikas A., Fabienke W., von der Kammer F., Hofmann T. 2015. Detection of engineered copper nanoparticles in soil using single particle ICP-MS. International Journal of Environmental Research and Public Health 12:15756-15768.

Nazari A., Riahi S., Riahi S., Shamekhi S.F., Khademno A. 2010. Improvement the mechanical properties of the cementitious composite by using TiO2 nanoparticles. Journal of American Science 6:98-101.

Nowack B., Bucheli T.D. 2007. Occurrence, behavior and effects of nanoparticles in the environment. Environmental Pollution 150:5-22.

Nowack B., Krug H.F., Height M. 2011. 120 years of nanosilver history: implications for policy makers. ACS Publications.

OCED 2014. Ecotoxicology and environmental fate of manufactured nanomaterials: test guidelines. (ENV/JM/MONO(2014)1).

Pal S., Tak Y.K., Song J.M. 2007. Does the antibacterial activity of silver nanoparticles depend on the shape of the nanoparticle? A study of the gram-negative bacterium Escherichia coli. Applied and Environmental Microbiology 73:1712-1720.

Pallavi, Mehta C.M., Srivastava R., Arora S., Sharma A.K. 2016. Impact assessment of silver nanoparticles on plant growth and soil bacterial diversity. Biotech 6:254.

Pan B., Xing B. 2012. Applications and implications of manufactured nanoparticles in soils: a review. European Journal of Soil Science 63:437-456.

Peijnenburg W., Praetorius A., Scott-Fordsmand J., Cornelis G. 2016. Fate assessment of engineered nanoparticles in solids dominated media - Current insights and the way forward. Environmental Pollution 218:1365-1369.

Peters R.J.B., Bouwmeester H., Gottardo S., Amenta V., Arena M., Brandhoff P., Marvin H.J.P., Mech A., Moniz, F-B, Pesudo L-Q. 2016. Nanomaterials for products and application in agriculture, feed and food. Trends in Food Science \& Technology 54:155164.

Peters R.J.B., Herrera-Rivera Z., Undas A., van der Lee M., Marvin H., Bouwmeester H., der Lee M., Weigel S. 2015. Single particle ICP-MS combined with a data evaluation tool as a routine technique for the analysis of nanoparticles in complex matrices. Journal of Analytical Atomic Spectrometry 30:1274-1285.

Peters R.J.B., Rivera Z.H., van Bemmel G., Marvin H.J.P., Weigel S., Bouwmeester H. 2014. Development and validation of single particle ICP-MS for sizing and quantitative 
determination of nano-silver in chicken meat. Analytical and Bioanalytical Chemistry 406:3875-3885.

Peters R.J.B., van Bemmel G., Milani N.B.L., den Hertog G.C.T., Undas A.K., van der Lee M., Bouwmeester H. 2018. Detection of nanoparticles in Dutch surface waters. Science of the Total Environment 621:210-218.

Prasad R., Kumar V., Prasad K.S. 2014. Nanotechnology in sustainable agriculture: present concerns and future aspects. African Journal of Biotechnology 13:705-713.

Price W.L. 1977. A controlled random search procedure for global optimisation. The Computer Journal 20: 367-370.

Rai M., Yadav A., Gade A. 2009. Silver nanoparticles as a new generation of antimicrobials. Biotechnology Advances 27:76-83.

Ramaswami A., Milford J.B., Small M.J. 2005. Integrated environmental modeling: pollutant transport, fate, and risk in the environment. Wiley.

Regalado C.M., Ritter A., Alvarez-Benedi J., Munoz-Carpena R. 2005. Simplified method to estimate the Green-Ampt wetting front suction and soil sorptivity with the PhilipDunne falling-head permeameter. Vadose Zone Journal 4:291-299.

Reidy B., Haase A., Luch A., Dawson K.A., Lynch I. 2013. Mechanisms of silver nanoparticle release, transformation and toxicity: a critical review of current knowledge and recommendations for future studies and applications. Materials 6:2295-2350.

Research and Markets 2015. Global Nanotechnology Market Outlook 2022.

Rui M., Ma C., Tang X., Yang J., Jiang F., Pan Y., Xiang Z., Hao Y., Rui Y-k, Cao, W. 2017. Phytotoxicity of silver nanoparticles to peanut (Arachis hypogaea L.): physiological responses and food safety. ACS Sustainable Chem. Eng., 5: 6557-6567.

Sagee O., Dror I., Berkowitz B. 2012. Transport of silver nanoparticles (AgNPs) in soil. Chemosphere 88:670-675.

SCENIHR 2006. Scientific Committee on Emerging and Newly Identified Health Risks (SCENIHR modified Opinion (after public consultation) on the appropriateness of existing methodologies to assess the potential risks associated with engineered and adventitious products of nanotechnologies. European Commission Health \& Consumer Protection Directorate-General 002/05.

SCENIHR 2007. The existing and proposed definitions relating to products of nanotechnologies. European Commission.

Schlich K., Hoppe M., Kraas M., Fries E., Hund-Rinke K. 2017. Ecotoxicity and fate of a silver nanomaterial in an outdoor lysimeter study. Ecotoxicology: 1-14.

Schlich K., Klawonn T., Terytze K., Hund-Rinke K. 2013a. Effects of silver nanoparticles and silver nitrate in the earthworm reproduction test. Environmental Toxicology and Chemistry 32:181-188.

Schlich K., Klawonn T., Terytze K., Hund-Rinke K. 2013b. Hazard assessment of a silver nanoparticle in soil applied via sewage sludge. Environmental Sciences Europe 25:17. 
Schwertfeger D.M., Velicogna J.R., Jesmer A.H., Saatcioglu S., McShane H., Scroggins R.P., Princz J.I. 2017. Extracting metallic nanoparticles from soils for quantitative analysis: method development using engineered silver nanoparticles and SP-ICP-MS. Analytical Chemistry 89:2505-2513.

Shoults-Wilson W.A., Reinsch B.C., Tsyusko O.V., Bertsch P.M., Lowry G.V., Unrine J.M. 2011a. Effect of silver nanoparticle surface coating on bioaccumulation and reproductive toxicity in earthworms (Eisenia fetida). Nanotoxicology 5:432-444.

Shoults-Wilson W.A., Reinsch B.C., Tsyusko O.V., Bertsch P.M., Lowry G.V., Unrine J.M. 2011b. Role of particle size and soil type in toxicity of silver nanoparticles to earthworms. Soil Science Society of America Journal 75:365-377.

Silva T., Pokhrel L.R., Dubey B., Tolaymat T.M., Maier K.J., Liu X. 2014. Particle size, surface charge and concentration dependent ecotoxicity of three organo-coated silver nanoparticles: Comparison between general linear model-predicted and observed toxicity. Science of the Total Environment 468:968-976.

Simonin M., Richaume A. 2015. Impact of engineered nanoparticles on the activity, abundance, and diversity of soil microbial communities: a review. Environmental Science and Pollution Research: 1-14.

SNWG 2017. Silver Nanotechnology Working Group. Accessed Nov. 3, 2017, from https://nanotech.lawbc.com/.

Sotiriou G.A., Meyer A., Knijnenburg J.T.N., Panke S., Pratsinis S.E. 2012. Quantifying the origin of released $\mathrm{Ag}^{+}$ions from nanosilver. Langmuir 28:15929-15936.

Stander L., Theodore L. 2011. Environmental implications of nanotechnology-an update. International Journal of Environmental Research and Public Health 8:470-479.

Stegemeier J.P., Schwab .F, Colman B.P., Webb S.M., Newville M., Lanzirotti A., Winkler. C., Wiesner, M.R., Lowry G.V. 2015. Speciation matters: Bioavailability of silver and silver sulfide nanoparticles to alfalfa (Medicago sativa). Environmental Science \& Technology 49:8451-8460.

Sumner M.E., Miller W.P. 1996. Cation exchange capacity and exchange coefficients. Methods of Soil Analysis Part 3. Chemical Methods: 1201-1229.

The Project of Emerging Nanotechnologies 2015. An inventory of nanotechnology-based consumer products. http://www.nanotechproject.org/search/?q=silver\&x=0\&y=0.

Thomsen L.M., Baartman J.E.M., Barneveld R.J., Starkloff T., Stolte J. 2015. Soil surface roughness: comparing old and new measuring methods and application in a soil erosion model. Soil 1:399-410.

Thuesombat P., Hannongbua S., Akasit S., Chadchawan S. 2014. Effect of silver nanoparticles on rice (Oryza sativa L. Cv. KDML 105) seed germination and seedling growth. Ecotoxicology and Environmental Safety 104:302-309.

Tian Y., Gao B., Silvera-Batista C., Ziegler K.J. 2010. Transport of engineered nanoparticles in saturated porous media. Journal of Nanoparticle Research 12:2371-2380. 
Tolaymat T.M., El Badawy A.M., Genaidy A., Scheckel K.G., Luxton T.P., Suidan M. 2010. An evidence-based environmental perspective of manufactured silver nanoparticle in syntheses and applications: A systematic review and critical appraisal of peer-reviewed scientific papers. Science of the Total Environment 408:999-1006.

Tran Q.H., Le A-T. 2013. Silver nanoparticles: synthesis, properties, toxicology, applications and perspectives. Advances in Natural Sciences: Nanoscience and Nanotechnology 4:033001.

Tsyusko, O.V., Hardas S.S., Shoults-Wilson W. A., Starnes C.P., Joice G., Butterfield D.A., Unrine J.M. 2012. Short-term molecular-level effects of silver nanoparticle exposure on the earthworm, Eisenia fetida. Environmental Pollution 171:249-255.

Ulén B.M., Larsbo M., Kreuger J.K., Svanbäck A. 2014. Spatial variation in herbicide leaching from a marine clay soil via subsurface drains. Pest Management Science 70:405-414.

UTwente. 2018. openLISEM: a spatial model for runoff, floods and erosion. Retrieved from https://blog.utwente.nl/lisem/download/.Van.

Vance M.E., Kuiken T., Vejerano E.P., McGinnis S.P., Hochella Jr M.F, Rejeski D., Hull M.S. 2015. Nanotechnology in the real world: Redeveloping the nanomaterial consumer products inventory. Beilstein Journal of Nanotechnology 6:1769.

Velicogna J.R., Ritchie E.E., Scroggins R.P., Princz J.I. 2016. A comparison of the effects of silver nanoparticles and silver nitrate on a suite of soil dwelling organisms in two field soils. Nanotoxicology 10:1144-1151.

Von der Kammer F., Ferguson P.L., Holden P.A., Masion A., Rogers K.R., Klaine S.J., Koelmans A.A., Horne N., Unrine J. M. 2012. Analysis of engineered nanomaterials in complex matrices (environment and biota): general considerations and conceptual case studies. Environmental Toxicology and Chemistry 31:32-49.

Walser T., Schwabe F., Thöni L., Hellweg S. 2013. Nanosilver emissions to the atmosphere: a new challenge? EDP Sciences.

Wang P., Menzies N.W., Dennis P.G., Guo J., Forstner C., Sekine R., Lombi E., Kappen P., Bertsch P.M., Kopittke P.M. 2016. Silver nanoparticles entering soils via the wastewater-sludge-soil pathway pose low risk to plants but elevated $\mathrm{Cl}$ concentrations increase Ag bioavailability. Environmental Science \& Technology 50:8274-8281.

Weinberg H., Galyean A., Leopold M. 2011. Evaluating engineered nanoparticles in natural waters. TrAC Trends in Analytical Chemistry 30:72-83.

Werkenthin M., Kluge B., Wessolek G. 2014. Metals in European roadside soils and soil solution - A review. Environmental Pollution 189:98-110.

Wesseling J.G. 2009. Soil physical data and modeling soil moisture flow. Alterra Scientific Contributions 29. Alterra, Wageningen-UR, the Netherlands.

Wesseling J.G., Ritsema C.J., Stolte J., Oostindie K., Dekker L.W. 2008. Describing the soil physical characteristics of soil samples with cubical splines. Transport in Porous Media 71:289-309. 
Whiteley C.M., Dalla Valle M., Jones K.C., Sweetman A.J. 2013. Challenges in assessing release, exposure and fate of silver nanoparticles within the UK environment. Environmental Science: Processes \& Impacts 15:2050-2058.

Whitley A.R., Levard C., Oostveen E., Bertsch P.M., Matocha C.J., von der Kammer F. and Unrine J.M. 2013. Behavior of Ag nanoparticles in soil: effects of particle surface coating, aging and sewage sludge amendment. Environmental Pollution 182:141-149.

Wiechmann B., Dienemann C., Kabbe C., Brandt S., Vogel I., Roskoch A. 2012. Klärschlammentsorgung in der Bundesrepublik Deutschland. Umweltbundesamt, Bonn.

Yang X., Van Der Zee S.E., Gai L., Wesseling J.G., Ritsema C.J., Geissen V. 2016. Integration of transport concepts for risk assessment of pesticide erosion. Science of the Total Environment 551:563-570.

Yang X., Wang F., Bento C.P.M., Xue S., Gai L., van Dam R., Mol H., Ritsema C.J., Geissen V. 2015. Short-term transport of glyphosate with erosion in Chinese loess soil-a flume experiment. Science of the Total Environment 512:406-414.

Yang Y., Bi X., Westerhoff P., Hristovski K., McLain J.E. 2014. Engineered nanomaterials impact biological carbon conversion in soils. Environmental Engineering Science 31:381-392.

Yin Y., Yu S., Shen M., Liu J., Jiang G. 2015a. Fate and transport of silver nanoparticles in the environment. Silver Nanoparticles in the Environment. Springer: 73-108.

Yin Y., Yu S., Yang X., Liu J., Jiang G. 2015b. Source and pathway of silver nanoparticles to the environment. Silver Nanoparticles in the Environment. Springer: 43-72.

Yu S., Li L., Zhou Q., Liu J., Jiang G. 2015a. Environmental bioeffects and safety assessment of silver nanoparticles. Silver Nanoparticles in the Environment. Springer: 139-152.

Yu S., Zhou X., Liu J. 2015b. Separation and determination of silver nanoparticles. Silver Nanoparticles in the Environment. Springer: 9-42.

Yu S., Yin Y., Liu J. 2013. Silver nanoparticles in the environment. Environmental Science: Processes \& Impacts 15:78-92.

Zhang H., Oyanedel-Craver V. 2011. Evaluation of the disinfectant performance of silver nanoparticles in different water chemistry conditions. Journal of Environmental Engineering 138:58-66.

Zhang H., Smith J.A., Oyanedel-Craver V. 2012. The effect of natural water conditions on the anti-bacterial performance and stability of silver nanoparticles capped with different polymers. Water Research 46:691-9.

Zhang W., Yao Y., Sullivan N., Chen Y. 2011. Modeling the primary size effects of citratecoated silver nanoparticles on their ion release kinetics. Environmental Science \& Technology 45:4422-4428.

Zhou Q., Liu W., Long Y., Sun C., Jiang G. 2015. Toxicological effects and mechanisms of silver nanoparticles. Silver Nanoparticles in the Environment. Springer: 109-138. 


\section{English summary}

Silver nanoparticles (AgNP) are considered new, promising, high-tech materials that can be used for many applications. Due to their unique properties, nanomaterials (NMs) are important in a wide range of scientific, industrial and medicinal applications. According to the "Project on Emerging Nanotechnologies" inventory, AgNPs are used in more than 400 commercial products including plastics, textiles, and kitchen appliances as well as health care and medical products. The unique properties of AgNPs (and other NMs), such as their high surface/volume ratio, make NMs more reactive than their bulky counterparts and may pose potential risks to the environment as a result.

AgNPs can enter the soil from different pathways. Their available concentration in soil is expected to be low which makes their detection beyond the ability of many current measuring techniques. Moreover, extracting AgNPs from soil samples is a troublesome process due to the difficulties posed by the soil matrix and the high adsorption affinity between soil particles and AgNPs. Once applied to soil, AgNP size is reduced due to the dissolution/transformation processes which occur as a response to the soil physical/chemical properties. The possible risks and impacts of AgNPs on soils and plants have been confirmed by many studies. However, knowledge about the transport mechanisms of AgNPs through soil and over soil surfaces as a result of leaching, runoff and erosion is still limited. These soil processes can facilitate AgNP migration to deeper soil layers and downhill areas and to ground and surface water systems. This thesis presents results for AgNP detection in soil as well as measurements and modelling results of its fate and transport.

Chapter 1 of this thesis is a general introduction on nanomaterials and includes the main objectives and structure of this PhD study.

Chapter 2 describes the development and validation of an extraction method for AgNP quantification and particle size determination in soil samples. The developed method is simple and fast thus reducing analysing time and costs. AgNPs recoveries were calculated by comparing AgNP concentration measured in the soil samples to the initial (spiked) AgNPs concentration. Two AgNP-spiking suspensions were prepared with concentrations of 0.5 and $5\left(\mathrm{mg} \mathrm{l}^{-1}\right)$ using commercially obtained 60 and $100 \mathrm{~nm}$ stock suspensions. $100 \mu \mathrm{l}$ of the AgNP-spiked suspensions was added and mixed with 1 gram of the soil samples and then 
vortexed for $10 \mathrm{~min}$. The samples were then left to equilibrate for 24 hours in the dark at room temperature. The initial AgNP concentration in soil was measured at $50 \mu \mathrm{gg}^{-1}$ for low concentration samples and $500 \mu \mathrm{gg}^{-1}$ for high concentration samples. The extraction method was developed in multiple steps but the final method consisted of pre-wetting the soil sample, exposing it to sonication and then extracting from the aqueous solution. Prewetting was done with the aim of re-suspending the adsorbed AgNPs, which facilitated their extraction. All of the samples were analysed using the principle of single particle inductively coupled plasma mass spectrometry (spICP-MS). Validation of the method showed that the recovery rate of AgNPs was $44 \%$ for sandy soil and $42 \%$ for clayey soil. Although this recovery rate is relatively low, the repeatability and reproducibility values for the concentrations were $1.2 \%$, which is within the limits of the Horwitz ratio (0.5-2). This makes the method suitable for its purpose and effective in environmental, toxicological and pollution studies since the method limit of detection for concentrations ( $\operatorname{LOD}_{c}$ ) is $5 \mu \mathrm{g} \mathrm{kg}^{-1}$ soil.

In Chapter 3, presents the results of AgNP transport. AgNP transport through the soil profile was monitored using a series of polyethylene (PE) hydraulic soil columns with a diameter of $12 \mathrm{~cm}$ and a depth of $25.5 \mathrm{~cm}$. Three soil types were used: loam soil with high organic matter (3.4 \pm 0.46$)(\mathrm{LSH})$, loam sand with low organic matter $(1.8 \pm 0.11)(\mathrm{LSH})$ and sand (zero organic matter). Soils were put into soil columns to a depth equal to $\pm 16 \mathrm{~cm}$ in 4 equal layers. The bottom of each column was filled with a $2 \mathrm{~cm}$ layer of fine gravel $(2-4 \mathrm{~mm})$ to work as a filter and the columns were sealed on the bottom with a thin nylon mesh with apertures $(<1 \mathrm{~mm})$. The column was filled with 3 soil layers without AgNPs. A top layer that contained AgNPs was then added. The moisture content in all of the soil layers was maintained at the approximate level at the start of the experiment. The results showed that in the LSH columns, $6.7 \%$ of the AgNPs applied to the top soil layer (layer 1 ) was transported to the 3 other soil layers in the soil column, 3.4\% was leached with effluent water and the rest (89.9\%) stayed in the top soil layer. In the LSL columns, $8.9 \%$ of the AgNPs applied to the top layer was transported to the 3 other soil layers and $4.3 \%$ was leached with effluent, leaving $86.8 \%$ in the top layer. In the sandy soil columns, $24.6 \%$ of the amount applied was transported to the 3 other soil layers and $13.9 \%$ was detected in the effluent. AgNP size decreased during transport through soil layers due to the soil cation exchange capacity (CEC). The decrease in AgNP size increased as the AgNPs moved deeper though soil column layers. Thus, the size of the AgNPs in layer 1 was > in layer 2, and so on. In addition to that, AgNP size in the columns packed with LSL and LSH decreased more than that in the columns packed with sand because of the limited value of CEC. There was less of a reduction in AgNP size in the effluent water for all soil columns as compared to AgNPs that were retained in the soil layers. Similar to what was seen in the soil, the effluent from the sand columns had the least amount of reduction in their particle size. This work highlights the ability to track the concentrations and particle sizes of low concentration applied AgNPs as they leach 
through soil into groundwater, which increases our knowledge of the patterns of AgNPs during their transport in soil.

In Chapter 4, the results of the study focusing on AgNP transport will be discussed. AgNP transport via runoff and erosion processes were analysed using 2 different soil flumes slopes ( $10 \%$ and $20 \%$ ). Each soil flume had the same dimensions $100 \times 50 \times 30 \mathrm{~cm}$ (length $\mathrm{x}$ width $\mathrm{x}$ depth). These flumes were divided into 5 segments of $20 \mathrm{~cm}$ each and a bucket was placed at the flume outlet to collect runoff water (RW) and sediment (RS). Rainfall application was constant $\left(60 \mathrm{~mm} \mathrm{~h}^{-1}\right)$ during the whole experiment. AgNPs mixed with soil were applied to the top (first) flume segment with the target (initial) concentration of AgNPs in the soil at $50 \mu \mathrm{g} \mathrm{kg}^{-1}$. Due to runoff and erosion processes which occurred after applying the rain, two main soil clusters with different characteristics appeared on the flume surface and were categorized as background soil (BS) and surface sedimentation (SS). Therefore, the AgNPs were measured in these different soil clusters on flume as well as in the eroded sediments and runoff water. BS samples contained a higher amount of silt while SS samples had a higher sand content. Organic matter (OM) and cation exchange capacity (CEC) in the BS samples were about three times higher than those measured in the SS samples, while the $\mathrm{pH}$ was found to be similar for both. Thus, AgNP content was higher in the BS than in the SS. The measured AgNP content in the BS samples in the S20 experiments were higher than in the S10 experiments however, the SS distribution area on the soil flume surface in S10 (measured by picture analysis) was larger than in S20. This could raise concerns for AgNPs pollution on the soil surface where the slope is less steep. The amounts of RW collected were comparable for the $10 \%$ and $20 \%$ slopes, while the amounts of RS collected after each event were higher for the S20 than for the S10. With each subsequent rain event, the AgNP content increased in the RS samples and decreased in the RW samples. Overall, the total AgNP content measured was higher in S20 than in S10 since 7.3\% of the total applied AgNPs was transported in the S20 flume, while only $4.3 \%$ was transported in the S10 flume. This study also confirmed that the highest amount of AgNPs was transported with RW, which enhances our understanding of the potential river water pollution by AgNPs due to the runoff process.

In Chapter 5, a hydrological soil erosion model (LISEM) was combined with a recently developed particle-transport model (PestPost) in order to simulate the transport of AgNPs caused by runoff and erosion processes. AgNPs were mixed with soil and applied to the upper part of the soil as described in the previous chapter (Chapter 4). The models were calibrated separately using the results of the flume experiment conducted in the laboratory. The aim of this study was to simulate AgNP transport over the soil surface with runoff water and sediment samples for each time-step during runoff and erosion processes. This was achieved using the output of the LISEM of runoff and erosion that migrated in the PestPost 
model and using this as data base for measuring AgNP transport over soil surface. The calibration of the LISEM showed high model efficiency (MEF) for both sediment $=0.81$ and runoff $=0.79$. For the PestPost model, a simple optimisation procedure was used to find the simulated results that were closest to the measured ones. The results of the AgNP simulation in runoff water were better than those in the eroded sediment for both flumes ( $\Delta_{\mathrm{pl}}$ for runoff $<0.01$ and for sediment $=0.06$ in S10 and 0.02 in S20). It was shown that the processes affecting the transport of AgNPs on the soil surface, mainly runoff and erosion due to rainwater, can be predicted using the combination of the LISEM and PestPost model.

Overall, the outcome of this study shows the possibilities of AgNP detection and transport in the soil, which will increase the knowledge and awareness of AgNPs in our daily-life applications. 


\section{Nederlandse samenvatting}

Zilver nanodeeltjes (AgNP) worden beschouwd als nieuwe, veelbelovende, high-tech materialen die in veel toepassingen kunnen worden gebruikt. Vanwege hun unieke eigenschappen zijn nanomaterialen (NM's) belangrijk in een breed scala van wetenschappelijke, industriële en medicinale toepassingen. Volgens het "Project on Emerging Nanotechnologies" worden AgNP's toegepast in meer dan 400 commerciële producten waaronder kunststoffen, textiel en keukenapparatuur, evenals verzorging en medische producten. De unieke eigenschappen van AgNP's (en NM's in het algemeen) zijn een gevolg van de hoge oppervlakte/volume verhouding en maken NM's reactiever dan hun dagelijkse, niet-nano, vormen. Als gevolg daarvan kunnen deze NM's echter ook potentiële risico's voor het milieu opleveren.

AgNP's kunnen via verschillende routes in de bodem terecht komen. De verwachting is dat de gehaltes van AgNP's in de bodem laag zijn, zelfs zo laag dat het met de huidige analytische technieken een probleem is de aanwezigheid van deze deeltjes aan te tonen. Daarbij is de extractie van AgNP's uit bodemmonsters problematisch vanwege de adsorptie van AgNP's aan bodemdeeltjes. Eenmaal geadsorbeerd aan bodemdeeltjes lossen de AgNPs langzaam op afhankelijk van de fysisch-chemische eigenschappen van de bodem. De kennis over de transportmechanismen van AgNP's door de bodem en over de bodemoppervlakten als gevolg van percolatie, afstroming en erosie is echter beperkt. Bodemprocessen kunnen de migratie van AgNP's naar diepere grondlagen en naar grond- en oppervlaktewatersystemen vergemakkelijken. Dit proefschrift presenteert resultaten van een nieuwe methode voor de detectie van AgNP's in de bodem, evenals metingen van stromingsprocessen en modellering van het transport van AgNP's door en over de bodem.

Hoofdstuk 1 van dit proefschrift is een inleiding over NM's, en in het bijzonder AgNP's en beschrijft de belangrijkste doelstellingen en structuur van het proefschrift.

Hoofdstuk 2 beschrijft de ontwikkeling en validatie van een analysemethode voor detectie, karakterisering en kwantificering van AgNP's in bodemmonsters. De ontwikkelde methode is eenvoudig en snel waardoor een redelijk aantal monsters in beperkte tijd geanalyseerd kan worden. De uiteindelijke methode bestaat uit het voorbevochtigen van een bodemmonster waarna een ultrasone extractie met water wordt uitgevoerd. De voorbevochtiging werd uitgevoerd met het doel om geadsorbeerde AgNP's opnieuw te 
mobiliseren en zo hun extractie te vergemakkelijken. De waterige monsterextracten werden geanalyseerd met inductief gekoppeld plasma massaspectrometrie in de zogenaamde single-particle mode (spICP-MS). Een uitgebreide validatie van de methode toonde aan dat circa $44 \%$ van de toegediende AgNP's aan zandgronden werden teruggevonden, en in klei $42 \%$. Hoewel dit relatief lage percentages zijn, waren de herhaalbaarheids- en reproduceerbaarheidsafwijkingen volgens verwachting en bedroeg de detectiegrens van de methode $5 \mu \mathrm{g} \mathrm{kg}^{-1}$. Dit maakt de methode uiteindelijk toch geschikt voor zijn doel, namelijk het detecteren van AgNP's in bodemmonsters.

Hoofdstuk 3 beschrijft de resultaten van het transport van AgNP's in de bodem. Dit transport werd bestudeerd in met grond gepakte polyethyleen (PE) hydraulische bodemkolommen met een diameter van $12 \mathrm{~cm}$ en een diepte van $25,5 \mathrm{~cm}$. Er werden drie bodemsoorten gebruikt: leemgrond met een hoog organisch stof gehalte (LSH), met een laag organisch stof gehalte (LSL) en zand zonder organisch stof (SAND). De grond werd in 4 gelijke lagen in de bodemkolommen gepakt met een totale diepte van $16 \mathrm{~cm}$. De bodem van elke kolom werd afgesloten met een laag fijn grind van $2 \mathrm{~cm}$ en tenslotte met nylon gaas. De kolom werd vervolgens gevuld met 3 bodemlagen van ieder $4 \mathrm{~cm}$ zonder additie van AgNP's. Tenslotte werd de bovenste bodemlaag aangebracht waar AgNP's doorheen waren gemengd. Het vochtgehalte in alle grondlagen werd aan het begin van het experiment op een gelijk en representatief niveau gehouden waarna de percolatieproeven werden uitgevoerd. De resultaten toonden aan dat in de $\mathrm{LSH}$-kolommen 6,7\% van de toegevoegde AgNP's werden getransporteerd naar diepere bodemlagen in de kolom terwijl $3,4 \%$ uit de kolom werden uitgespoeld. Circa 90\% van de toegevoegde AgNP's bleef in de bovenste bodemlaag en werden niet getransporteerd. In de LSL-kolommen werd 8,9\% van de aan de toplaag toegevoegde AgNP's getransporteerd naar diepere bodemlagen, en 4,3\% werd onder aan de kolom uitgespoeld. Circa 87\% van de toegevoegde AgNP's bleef in de toplaag zitten. In de SAND-kolommen werd ca. $25 \%$ van de geaddeerde AgNP's getransporteerd naar diepere bodemlagen en werd ca. $14 \%$ in het effluent water teruggevonden. Uit de metingen bleek verder dat de diameter van de AgNP deeltjes tijdens het transport door grondlagen af nam. Deze afname nam toe naarmate de AgNP's verder werden getransporteerd. Ook bleek dat de afname van de diameter van de AgNP deeltjes in de kolommen gepakt met LSL en LSH meer af nam dan in de SAND-kolommen. Tenslotte was de afname van de diameter van de AgNP deeltjes in het effluentwater kleiner dan die van AgNP deeltjes die in de diepere grondlagen werden teruggevonden. Dit duidt op snel transport van een deel van de AgNP's door de kolom. Deze studie laat zien dat we met de ontwikkelde analysetechniek in staat zijn het transport van AgNP's door de bodem, en de invloed daarvan op de deeltjesgrootte van AgNP's te volgen. 
Hoofdstuk 4 beschrijft de resultaten van een studie gericht op het transport van AgNP's over de bodem door oppervlakkige afstroming en erosie. Het onderzoek is uitgevoerd met 2 met grond gevulde afstroomgoten onder hellingen van $10 \%$ en $20 \%$. De afstroomgoten hadden afmetingen van $100 \times 50 \times 30 \mathrm{~cm}$ (lengte $\mathrm{x}$ breedte $\mathrm{x}$ diepte). De goten werden verdeeld in 5 segmenten van ieder $20 \mathrm{~cm}$. Bij de gootuitlaat werd een emmer geplaatst om afstromend water (RW) en sediment (RS) te verzamelen. Aarde gemengd met AgNP's werd aangebracht op het bovenste (eerste) gootsegment met een initiële concentratie van $50 \mu \mathrm{g} \mathrm{kg}^{-1}$. Regenval werd gesimuleerd en was constant $\left(60 \mathrm{~mm} \mathrm{~h}^{-1}\right)$ gedurende het gehele experiment. Als gevolg van afstromings- en erosieprocessen die optreden tijdens het beregenen ontstonden er twee belangrijke bodemclusters met verschillende kenmerken, namelijk oorspronkelijk niet getransporteerd materiaal (BS) en wel getransporteerde grond (SS). AgNP gehaltes werden vervolgens gemeten in de verschillende bodemclusters in de goot en in het onder aan de goot uitgespoelde water (RW) en sediment (RS). Uit de resultaten bleek dat het AgNP-gehalte hoger was in de BS dan in de SS monsters. Ook bleek dat het gemeten AgNP-gehalte in de BS-monsters in de experimenten met een helling van $20 \%$ hoger was dan in die van de experimenten met een helling van $10 \%$ terwijl het SSverspreidingsgebied op het bodemgootoppervlak in de experimenten met een helling van $10 \%$ groter was dan in de experimenten met een helling van $20 \%$. De hoeveelheden afgestroomd water (RW) waren vergelijkbaar voor de hellingspercentages van $10 \%$ en $20 \%$ terwijl de hoeveelheden afgestroomd sediment (RS) hoger waren voor de goot met hellingspercentage van $20 \%$ dan voor die van $10 \%$. Bij toenemende regen gebeurtenissen nam het AgNP-gehalte in de RS-monsters toe terwijl het daalde in de RW-monsters. Uit de totaal gemeten gehaltes AgNP's bleek dat in het experiment met een $20 \%$ hellingspercentage $7,3 \%$ van de aan de bovenste laag toegevoegde AgNP's waren getransporteerd. In de bodemgoot met een hellingspercentage van $10 \%$ was dat $4,3 \%$. Uit de resultaten bleek dat het grootste gehalte AgNP's werd getransporteerd door het afstromend water, RW, wat mogelijk kan leiden tot afspoeling van AgNP's naar rivierwater.

In hoofdstuk 5 wordt een hydrologisch bodemerosiemodel (LISEM) gecombineerd met een recent ontwikkeld deeltjestransportmodel (PestPost) om het transport van AgNP's in afvoer- en erosieprocessen te simuleren. Aan het begin van het experiment werden AgNP's gemengd met grond en aangebracht op het bovenste deel van de bodemgoot zoals beschreven in hoofdstuk 4. De modellen werden afzonderlijk gekalibreerd met behulp van de resultaten van het gootexperiment dat in het laboratorium werd uitgevoerd. Het doel van deze studie was om het AgNP-transport over het bodemoppervlak te simuleren en te vergelijken met de observaties uit de stroomgoot experimenten. Dit werd bereikt door de uitvoer van het LISEM model te gebruiken als invoer voor het PestPost-model om zodoende het transport van de AgNP's in de goot experimenten te simuleren. De kalibratie van de LISEM liet een hoog modelrendement (MEF) zien voor zowel afstromend water (0.79) als 
het afstromend sediment $(0,81)$. Voor het PestPost-model werd een optimalisatieprocedure gebruikt om de gesimuleerde resultaten te vinden die het dichtst bij de gemeten resultaten lagen. De resultaten van de AgNP-simulatie in afstromend water waren voor beide goten beter dan die in het geërodeerde sediment $\left(\Delta_{\mathrm{pl}}\right.$ voor afstromend water $<0,01$ en voor sediment 0,06 en 0,02 in experimenten met een hellingspercentage van respectievelijk $10 \%$ en $20 \%$ ). Uit de resultaten bleek dat de processen die het transport van AgNP's op het bodemoppervlak beïnvloeden kunnen worden gesimuleerd met behulp van een combinatie van het LISEM- en PestPost-model.

Over het geheel tonen de uitkomsten van het onderzoek aan dat het mogelijk is AgNP's in bodem te detecteren en het AgNP-transport in en over de bodem te volgen en zelfs te voorspellen. Hierdoor neemt onze kennis over de verspreiding en het lot van AgNP's in het milieu toe. 


\section{Acknowledgements}

Moving to a foreign country with your family in order to start a PhD study is like going with them on a boat trip to middle of an ocean. It is indeed an adventure and it feels amazing to finally reach the shore, which is the PhD defence. This success would not have happened without lots of support and encouragement from many people who surrounded me, without them, this doctoral study would not have been possible.

First, I would also like to acknowledge the higher committee for education development in Iraq (HCED) for the financial support for this research and their commitments to continue the funding despite the ongoing war in Iraq. Many thanks go to the people from Wageningen University and research for their unlimited support.

I feel so grateful for my wife Anwar Abutorab. She was so patient and supportive every moment of the last 5 years. She never complained when I had to work late at WUR or during the weekend. She took on the responsibility of taking care of everything related to our children and our home so that I could focus on my research.

Also, it is impossible to express my gratitude to my promoters Prof. Dr Violette Geissen and Prof. Dr Coen J. Ritsema. Violette helped me from the first day that I arrived in Wageningen not only with my research but also with other things like finding a school or a playgroup for my children or finding a job for my wife. Violette is a brilliant lady who provides inspiration and energy to all of her students. I will never forget the times that we shared a meal and laughed together at her house or at my house or even at work. When I felt tired or frustrated or had any kind of problem with my study or with my family, Violette was the first person I would talk to. I would rush into her office without an appointment and she would always have a solution to my problem. My other promotor, Coen, is an extraordinary scientist. I admire his way of thinking about and dealing with science, as well as the way he coaches people. Although he is a very busy Professor, Coen finds the time to step in and help find a solution to critical problems. I would also like to express my thanks to my co-promotor $\mathrm{Dr}$ Ruud J.B. Peters for his guidance and support during my study, especially while doing my lab work in RIKILT. His contribution to my research was vital and I learned a lot from him. Thank you to Dr Jantiene E.M Baartman, Dr Jan Wesseling Dr Martine van de Ploeg, and Prof. Dr Victor Jetten, for their significant contributions to this research. 
I would like to thank the technicians of the SLM group Hennie Gertsen, Piet Peters and Harm Gooren for their effective contribution in preparing the materials for this study and helping to carry out the experiments. I am also very grateful for the valuable contribution and the guidance of Greet van Bemmel, Sandra Munniks and many other people in RIKILT. Thanks to Klaas Oostindie for his help in preparing my final thesis booklet. Special thanks to the lovely secretaries Marnella van der Tol, Esther van den Brug and formerly (Annelies van de Bunte) for smoothly handling all of the administrative issues throughout my study. Thanks also to the financial department (Geert Belgers and Siawash Tajdini). Many thanks to Demie Moore for helping me to improve my English as well as my Dutch. Thanks to Robin Palmer for her fast and efficient English revising of my thesis. Special thanks to Petra Cornelissen and Jacqueline de Graaff from Expat Centre in Wageningen University and Research for arranging visas and helping me with residency issues.

I want to thank the staff of the SLM group: prof.Dr.ir Sjoerd van der Zee, Dr.ir. Jos Van Dam, Dr. Jerry Marqoulis, Dr.ir. Aad Kessler, Dr.ir. Michel Riksen, Dr. Esperanza Huerta Lwanga, Dr.ir. Klaas Metselaar and Didi Stoltenborg.

I also want to thank my friends and colleagues at Wageningen University and Research: Dr. Xiaomei, Dr. Mohammadreza, Vera, Lington, Pavan, Chakaphon, Fabio, Carlo, Miao, Celia, Renée, Yueling, Ricardo, Corjan, Coleen, Meindert, Nicolas, Mirzokhid, Mousumi, Govinda, Yan, Belyse, Walle, Raoul, Meskerem, Daniël and the others. We had a lot of great moments together during lunchtimes, parties, and outings.

My sincere thanks to Dr. Ahmed A. Mohammed, the head of Environmental Engineering Department at Baghdad University (Iraq) for his assistance and support. Thanks to my friend Dr. Ammar A. Ali (former PhD student at WUR) who hosted my family and I in his house during our first days here in the Netherlands, which is when our friendship started. Thanks also to my friends Dr. Mustafa Al-Furaiji and Dr. Haider Al-Jashamy from Twente University. Thanks to my friends in the Netherlands, Muhanned, Daniel and Ali for their assistance. Many thanks to my friends in Iraq, eng. Khalid Ali, eng. Mohammedfadhil, eng. Farie, Ali Jabbar, Khalil and all of my other colleagues and friends in Karbala Municipality who supported and encouraged me.

I also want to deliver my gratitude to the many Dutch people who surrounded my family and me and gave us unlimited support including, but not limited to, Marian van Bruggen, Marlies den Boer, Sanne van Mourik, Margit van der Meulen, Carlo Melger and Astrid Gerritsen. I'm also very grateful to all of the teachers in "de Wegwijzer" school, the staff of 's Heerenloo and the municipalities of Wageningen and Ede for giving support to my children and my wife during our residency in these two lovely cities. 
I sincerely thank my parents in Iraq. During all of these years of study, they supported me and called me almost every day to encourage me to keep going. My mother's illness was the worst period of my study. Even though she was sick, she never stopped passionately supporting me which helped drive me to continue my research. Since the moment I began my bachelors study, my father encouraged me to continue my study and complete a PhD. Thanks to my brother Ahmed and my sisters Amani, Israa, Zahraa, and Abrar for all their support and assistance and for taking care of our parents when I couldn't be there. Thanks also to my brother-in-law Eng. Mohammed (Abu Ridha) for his support. I also want to thank the family of my wife for their support.

To all of you, thank you.

Karrar Najah Mahdi

Wageningen 


\section{Aknowledgments of finacial support}

The research conducted in this thesis was financially supported by the Higher Committee for Education Development in Iraq (HCED). 


\section{About the author}

Karrar Najah Mahdi was born on August 1, 1983 in Al-Muthanna province in Iraq. He obtained his bachelor's degree (BSc.) in civil engineering from the University of Baghdad (2005). In 2009, he received his master's degree (MSc.) in environmental engineering from the same university.

In 2007, Karrar started working for the Ministry of Municipalities and General Works in Iraq in the municipality of Karbala province. Since then, he has participated in many projects and headed several departments that deal with environmental works in Karbala city.

In 2012, he applied for a scholarship to continue his PhD study abroad though the "Education Initiative" which was funded by the Iraqi government under the Higher Committee for Education Development in Iraq (HCED). In 2013, Karrar was granted a scholarship by the HCED and started his PhD study in Wageningen University and Research in the Netherlands. During his PhD study, he participated in developing methods, conducting experiments and using simulation models with the aim to measure and simulate the transport of silver nanoparticles in the soil-water environment (water-soil).

Karrar has presented his study outcomes at several international conferences and meetings, including the 2016 Intervention Against Pollution (IAP) conference in Lleida (Spain), 2016 NanoCity in Amsterdam (Netherlands), and the 2017 European Geoscience Union General Assembly in Vienna (Austria).

Karrar is married and has 2 children: Mohammed who is 7 years old and Abbas who is 6 .

Email: karrarnmahdi@gmail.com, engkarrar@ymail.com 


\section{Scientific Publications}

- Mahdi K.N.M., Peters R.J.B., Klumpp E., Bohme S., van der Ploeg M., Ritsema C.J., Geissen V. 2016. Silver nanoparticles in soil: Aqueous extraction combined with single-particle ICP-MS for detection and characterization. Environmental Nanotechnology, Monitoring \& Management 7:24-33.

- Mahdi K.N.M., Commelin M., Peters R.J.B., Baartman J.E.M., Ritsema C.J., Geissen V. 2017. Transport of silver nanoparticles by runoff and erosion - A flume experiment. Science of the Total Environment 601-602:1418-1426.

\section{Oral and poster presentations}

- Mahdi K.N.M., Peters R.J.B., Klumpp E., Bohme S., van der Ploeg M., Ritsema C.J., Geissen V. Silver nanoparticles in soil: aqueous extraction combined with single-particle icpms for detection and characterization. IAP conference, 4-7 September 2016, Lleida, Spain. (Oral presentation)

- Mahdi K.N.M., Peters R.J.B., Klumpp E., Bohme S., van der Ploeg M., Ritsema C.J., Geissen V. Single particle ICP-MS method as a detection technique for AgNPs in natural soils. Hazard Risk and Sustainability in the Soil Environment symposium, 14 October 2015, Wageningen, The Netherlands. (Poster)

- Mahdi K.N.M., Commelin M., Peters R.J.B., Baartman J.E.M., Ritsema C.J., Geissen V. Transport mechanisms of Silver Nanoparticles by runoff - A Flume Experiment. European Geoscience Union, 24 April 2017, Vienna, Austria. (Poster)

- Mahdi K.N.M., Peters R.J.B., van der Ploeg M., Ritsema C.J., Geissen V. Tracking the transport of silver nanoparticles in the soil-a saturated column experiment. Symposium Soil contamination: Scope, advances and challenges, 01 September 2017, Wageningen, The Netherlands. (Poster)

- Mahdi K.N.M., Commelin M., Baartman J.E.M., Peters R.J.B., Jetten V., Geissen V., Ritsema C.J. and Wesseling J.G. Simulation of silver nanoparticles co-transport with runoff water and erosion processes using LISEM and PestPost models. Global symposium on soil pollution, FAO HQ, Rome, Italy, 2-4 may 2018. (Poster). 


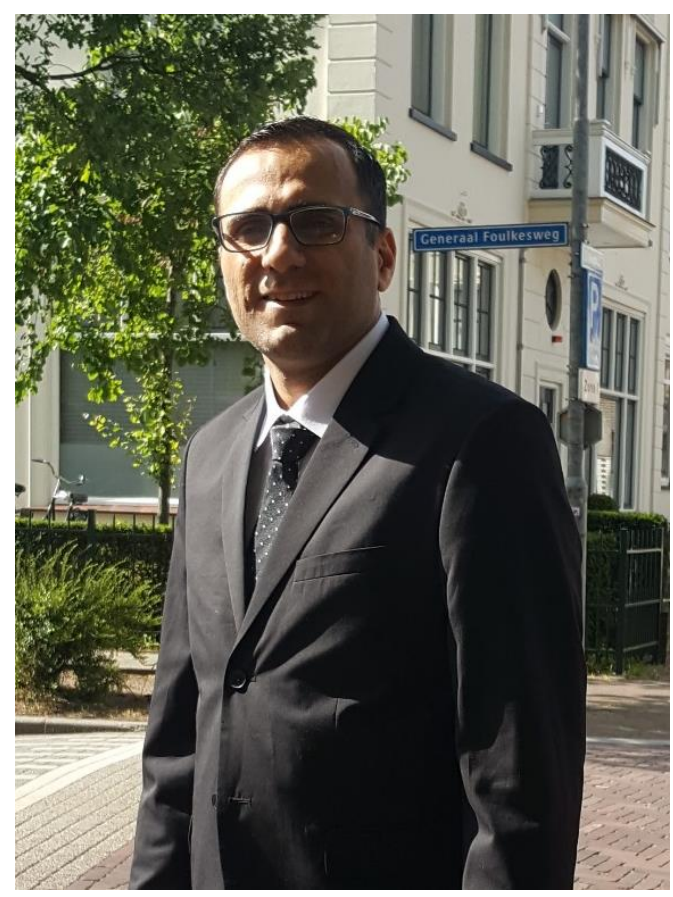




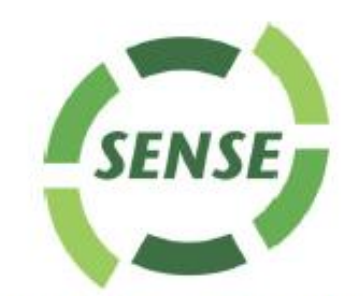

Netherlands Research School for the

Socio-Economic and Natural Sciences of the Environment

\section{I P L O M A}

For specialised PhD training

The Netherlands Research School for the Socio-Economic and Natural Sciences of the Environment

(SENSE) declares that

\section{Karrar Najah Mahdi}

born on 01 August 1983 in Al-Muthanna, Iraq

has successfully fulfilled all requirements of the Educational Programme of SENSE.

Wageningen, 5 July 2018
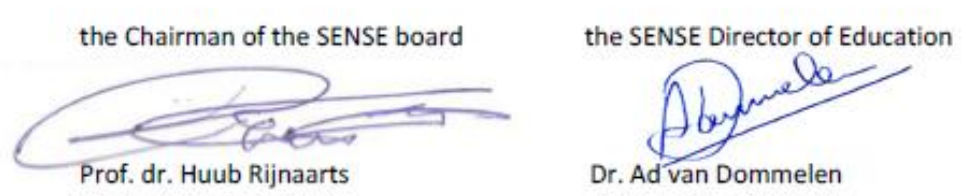

The SENSE Research School has been accredited by the Royal Netherlands Academy of Arts and Sciences (KNAW)

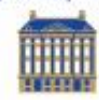




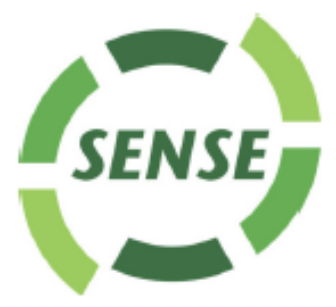

The SENSE Research School declares that Mr Karrar Najah Mahdi has successfully fulfilled all requirements of the Educational PhD Programme of SENSE with a work load of $39.4 \mathrm{EC}$, including the following activities:

\section{SENSE PhD Courses}

- Human induced Land Degradation (2013)

- Basic Statistics (2013)

- Environmental research in context (2014)

- Research in context activity: 'Co-organizing SENSE-WIMEK Symposium on Hazard, Risk and Sustainability in the Soil Environment, Wageningen, 14 October 2015'

- Introduction to R for Statistical Analysis (2015)

\section{Other PhD and Advanced MSc Courses}

- Summer course English for IELTS, Wageningen University (2013)

- Efficient Writing Strategies, Wageningen In'to Languages (2014)

- Techniques for Writing and Presenting a Scientific Paper, Wageningen University (2015)

- Nanotechnology and the Environment, Denmark Technical University (2015)

\section{External training at a foreign research institute}

- Training on ICP-MS machine and experimental work with nanoparticles, RIKILT, the Netherlands (2014)

- spICP-MS: data analysis, RIKILT, the Netherlands (2017)

\section{Oral Presentation}

- Silver nanoparticles in soil: aqueous extraction combined with single-particle icpms for detection and characterization. IAP conference, 4-7 September 2016, Lleida, Spain

\section{Poster Presentations}

- Single particle ICP-MS method as a detection technique for AgNPs in natural soils. Hazard Risk and Sustainability in the Soil Environment symposium, 14 October 2015, Wageningen, The Netherlands

- Transport mechanisms of Silver Nanoparticles by runoff - A Flume Experiment. European Geoscience Union, 24 April 2017, Vienna, Austria

- Tracking the transport of silver nanoparticles in the soil-a saturated column experiment. Symposium Soil contamination: Scope, advances and challenges, 01 September 2017, Wageningen, The Netherlands

SENSE Coordinator PhD Education

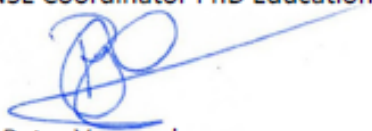

Dr. Peter Vermeulen 